$\therefore \rightarrow$

Atomics International Division

Rockwell International

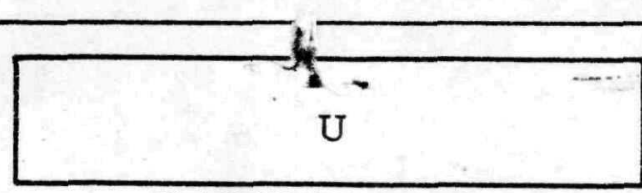

CLASSIFICATION LEVEL

(S, COR U)

COVER SHEET

DOCUMENT TITLE

Technical Manual, SNAP 10A

SNAP Prelaunch Test Facility Operations, Building 6527

Vandenberg Air Force Base
AUTHOR

THIS IS AN INTERNAL WORKING

DOCUMENT AND MAY BE

EXPANDED, MODIFIED, OR

WITHDRAWN AT ANY TIME.

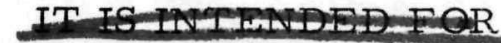

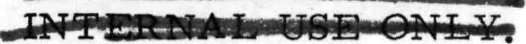

CLASSIFICATION TYPE

(RD OR DI)

IHIS-REPORT WAY NOT BE PUBLTSHED WITHOUT THE APPROVALOF-THE-PATENT BRANCH, AEC.

This report was prepared as an account of work sponsored by the United States Government. Neither the United States nor the United States Atomic Energy Commission, nor any of their employees nor any of their contractors, subcontractors, or their employees, makes any warranty, express or implied, or assumes any legal liability or responsibility for the accuracy, completeness or usefulness of any information, apparatus, product or process disclosed, or represents that its use would not infringe privately owned rights. 


\section{DISCLAIMER}

This report was prepared as an account of work sponsored by an agency of the United States Government. Neither the United States Government nor any agency Thereof, nor any of their employees, makes any warranty, express or implied, or assumes any legal liability or responsibility for the accuracy, completeness, or usefulness of any information, apparatus, product, or process disclosed, or represents that its use would not infringe privately owned rights. Reference herein to any specific commercial product, process, or service by trade name, trademark, manufacturer, or otherwise does not necessarily constitute or imply its endorsement, recommendation, or favoring by the United States Government or any agency thereof. The views and opinions of authors expressed herein do not necessarily state or reflect those of the United States Government or any agency thereof. 


\section{DISCLAIMER}

Portions of this document may be illegible in electronic image products. Images are produced from the best available original document. 
TECHNICAL MANUAL

SNAP $10 A$

SNAP PRELAUNCH TEST FACILITY OPERATIONS

BUILDING 6527

VANDENBERG AIR FORCE BASE

\section{ATOMICS INTERNATIONAL}
A DIVISION OF NORTH AMERICAN AVIATION, INC.
P.O. BOX 309
CANOGA PARK, CALIFORNIA

DECEMBER 30, 1964 


\section{NAA-SR-MEMO-9353}

TECHNICAL MANUAL

OPERATIONS AND MAINTENANCE

SNAP 10A PRELAUNCH TEST FACILITY

BUILDING 6527

VANDENBERG AIR FORCE BASE

FACILITY ADMINISTRATION, OPERATION AND MAINTENANCE ATOMICS INTERNATIONAL

PUBLISHED UNDER AUTHORITY OF

THE ATOMIC ENERGY COMMISSION CONTRACT AT(11-1)-GEN-8 
NAA-SR-MEMO-9353

\section{CONTENTS}

Page

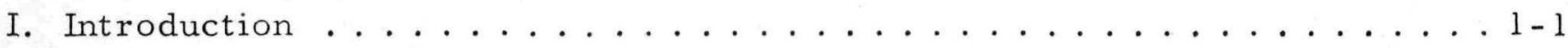

II. Facility Utilization. ......................... 2-

2-4. SPTF Operations Summary ..................... 1

2-9. Aerospace Ground Support Equipment . . . . . . . . . . . . 2-4

III. Site and Facility Description ..................... . . 1

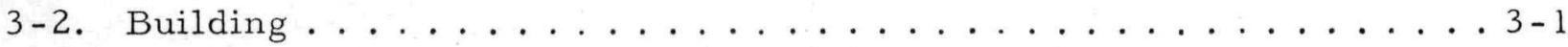

$3-21$. Service Systems. . . . . . . . . . . . . . 3-7

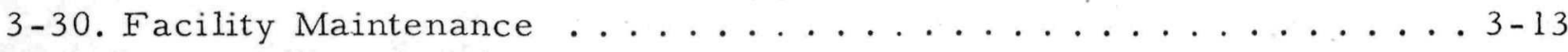

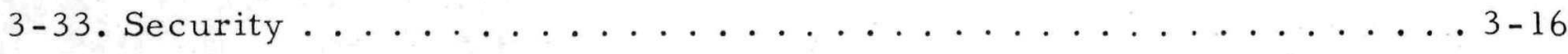

IV. Administrative Requirements . . . . . . . . . . . . . . 4-1

$4-2$. Field Unit Organization . . . . . . . . . . . . . 4-1

$4-5$. Operating Philosophy ................... . . . .

4-7. Job Description and Responsibilities ............. . . . . . . . . . . . . .

4-35. Documentation and Reporting Requirements . . . . . . . . . . 4-7

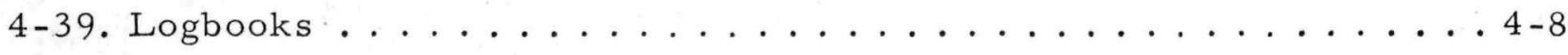

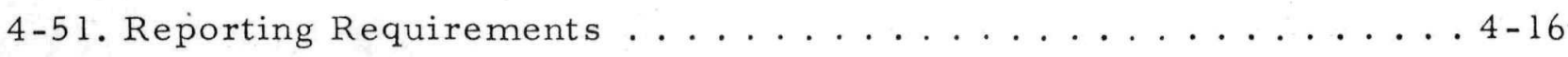

4-66. Procedure/Design Change Notice ... . . . . . . . . 4-19

4-74. SPTF Operating Rules. . . . . . . . . . . . . . . 4-25

$4-85$. Industrial Security . . . . . . . . . . . . . . 4-27

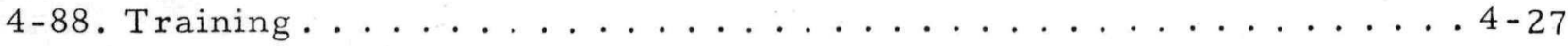

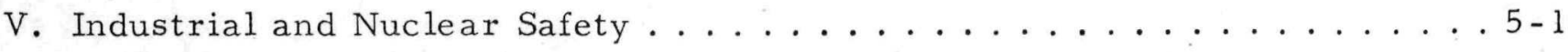

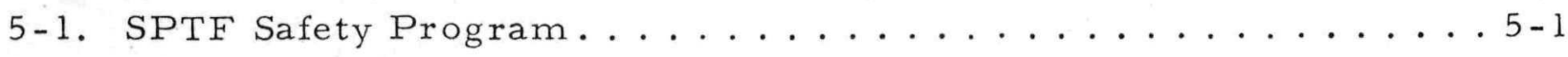

5 -14. Industrial Health and Safety ................ 5-5

5-18. Safety Precautions and Practices ................. 5-7

5 -74. Designation of Regulated Areas. . . . . . . . . . . 5-14

5-85. Emergency Evacuation . . . . . . . . . . . . . 5-17

5-94. Emergency Procedures ... . . . . . . . . . . . 5-19

VI. Aerospace Ground Equipment (AGE) . . . . . . . . . . . . 6- 6-

6-2. Electrical System Test Set, TSM-IIA. . . . . . . . . 6-1

6 -7. Mechanical AGE. . . . . . . . . . . . . . . 6-4 
Page

Appendices

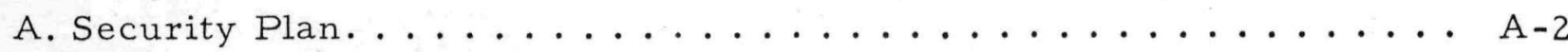

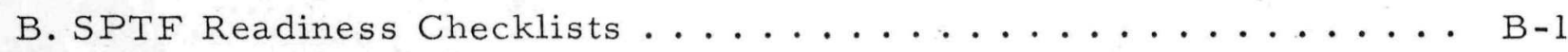

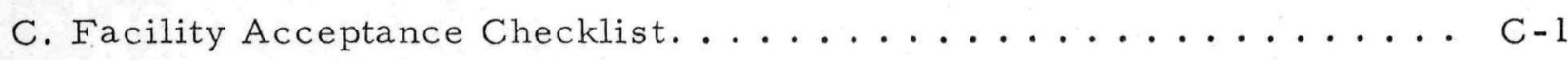

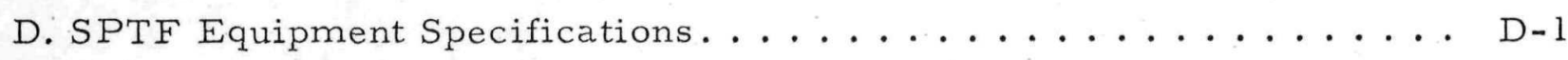

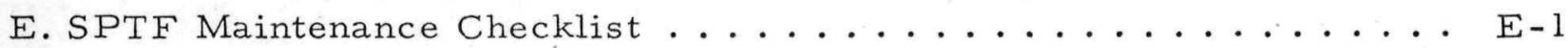

\section{TABLES}

3-1. SPTF Heating and Ventilating System Specifications . . . . . . . . 3-9

3-2. SPTF Fire Extinguishing Equipment ................ . . . 11

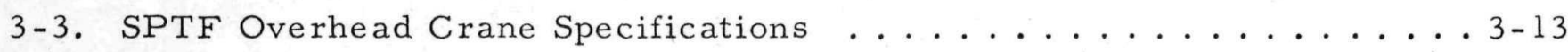

3-4. SPTF Building and Equipment Maintenance Schedule . . . . . . . . 3-15

5-1. Potential Hazards - NPU Operations . . . . . . . . . . . . . . 5-1

$5-2$. NPU Mechanical Safeguards..................... 5-2

5-3. Personnel Protection, Beryllium Hazards .............. . 5-5

5-4. Health and Safety Responsibilities and Activities at SPTF . . . . . . . 5-6

5-5. Fire - Building Occupied.................... 5-20

5-6. Fire Directly Involving Power System . . . . . . . . . . . . . . 5-22

5-7. Fire Not Directly Involving Power System .............. . 5-23

5-8. Radiation Alarm - Building Occupied . . . . . . . . . . . . . . . . 5-24

5-9. Radiation Alarm - Building Unoccupied .............. 5-25

6-1. Summary of Aerospace Ground Equipment ................ . 6-2

\section{FIGURES}

1-1. Flow Chart Illustrating NPU Prelaunch Operations From

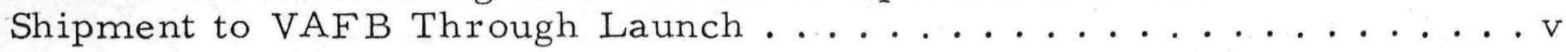

2-1. NPU System Shipping Containers.................. 2-2

2-2. Flow Diagram of Prelaunch Operations at the SPTF.......... 2-3

3-1. SNAP Prelaunch Test Facility, VAFB Building 6527.......... . 3-2

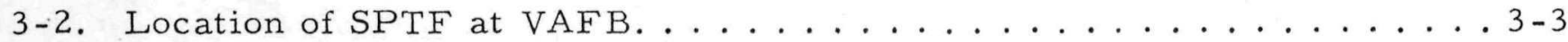

3-3. Elevation Views, Building 6527 (SPTF), VAFB . . . . . . . . 3-4

4. SPTF Floor Plan .......................... 3-5 


\section{FIGURES}

Page

3-5. SPTF Protective Systems and Safety Equipment Location Diagram. . . . $3-10$

3-6. Radiation Detector Located in High Bay . . . . . . . . . . . 3-14

4-1. SNAP 10A Prelaunch Operations Field Unit Organization . . . . . . 4-2

4-2. Chart Illustrating NPU Verification Logbook Input and Usage . . . . . . 4-9

4 -3. Sample of NPU Verification Log Page . . . . . . . . . . . . . 4-11

4-4. AI Form Used for Prelaunch Operations Facility,

AGE, and Instrument Logbooks. . . . . . . . . . . . . . 4-13

$4-5$. AI Visitor's Register Form . . . . . . . . . . . . . . . . 4-14

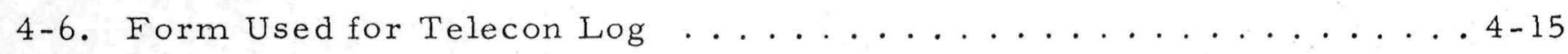

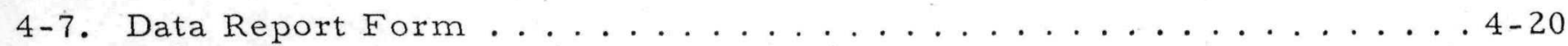

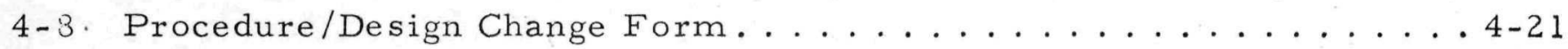

4-9. Addendum Page for Procedure/Design Change Form . . . . . . . . . 4-22

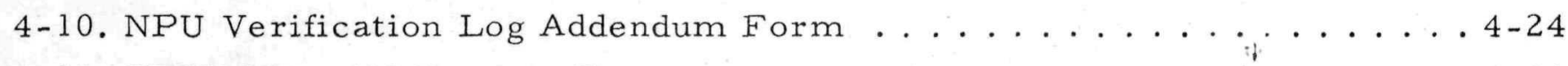

4-11. SPTF Material Request Form ... . . . . . . . . . . . 4-26

4-12. Inventory Control Form Used at the SPTF . . . . . . . . . 4-26

5-1. SNAP 10A Reflector Safety Devices.................. 5-3

$5-2$. Radiation Area Symbols ..................... 5-16

5-3. SPTF Evacuation Route and Emergency As sembly Area . . . . . . . 5-18

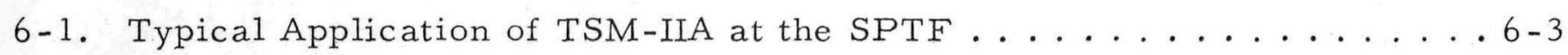

6-2. Typical AGE Mechanical Equipment Used in

NPU Prelaunch Operations. . . . . . . . . . . . . . . . 6-5 


\section{BLDG 19}

ACC. TEST FAC.

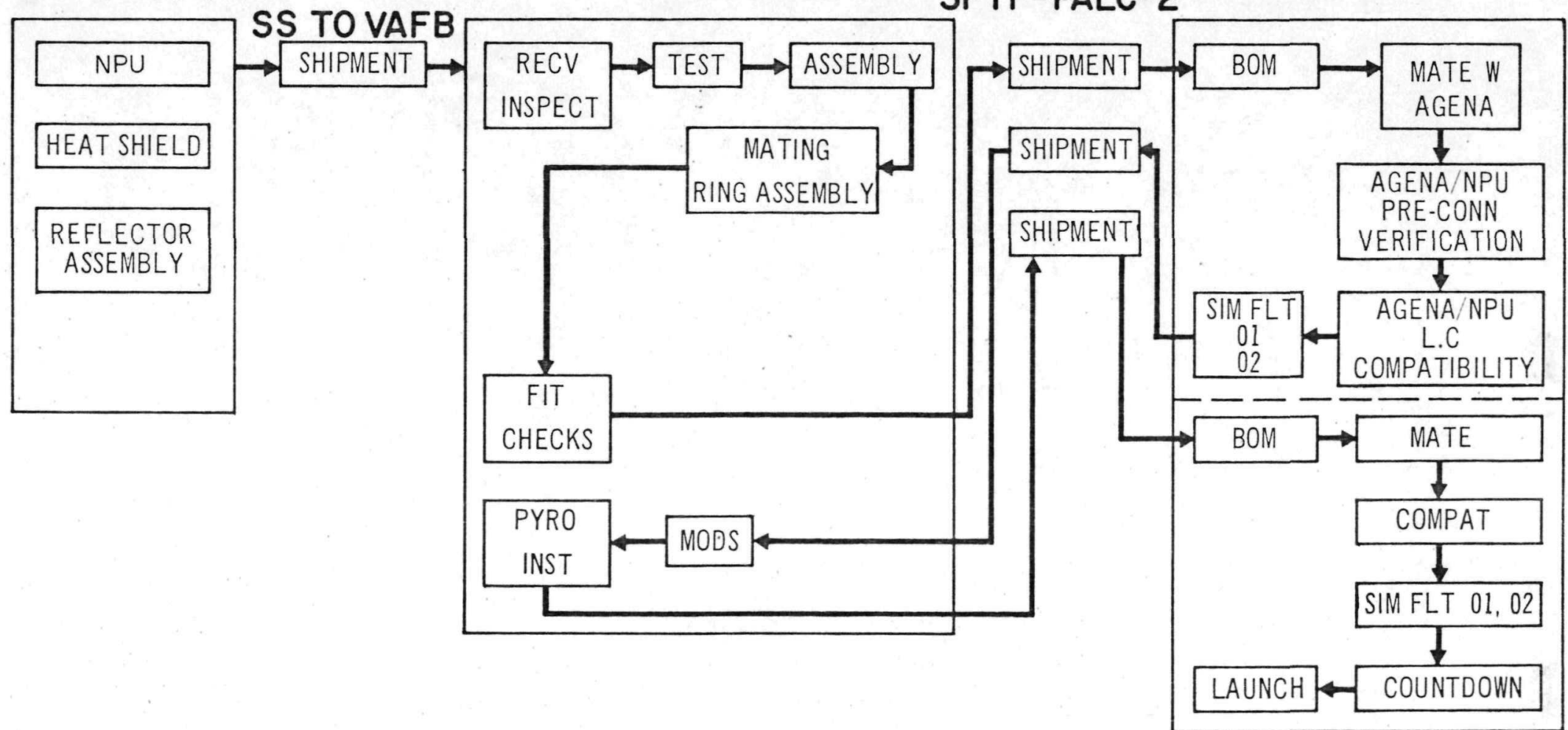

Figure 1-1. Flow Chart Illustrating NPU Prelaunch Operations From Shipment to VAFB Through Launch 


\title{
SECTION I
}

\author{
INTRODUCTION
}

1-1. This manual describes the SNAP Prelaunch Test Facility (SPTF) and the procedures utilized in support of the SNAP $10 A$ prelaunch testing program at Vandenberg Air Force Base (VAFB). The facility is identified as Building 6527 at VAFB, but for purpose of identification in this and companion manuals, it is referred to as the SPTF. The SPTF serves as a base of operations for Atomics International personnel assigned to the SNAPSHOT nuclear power unit (NPU) prelaunch testing program conducted at VAFB. The facility is utilized for receiving storage and non-nuclear testing of the SNAP IOA power systems prior to shipment to the launch complex at the Point Arguello Launch Complex No. 2 (PALC-2). NPU prelaunch operations carried out at VAFV are shown in the Figure 1-1 flow diagram.

1-2. The SPTF Operations Manual provides information relative to administration of the AI-VAFB field operations prelaunch testing program and the SPTF. Facility utilization, construction, staffing and related operating procedures are covered in detail. Administrative procedures describe the interim phase beginning with receipt of the NPU components at the facility through preparation for delivery to the launch complex. NPU prelaunch operations conducted at the facility are described in NAASR-MEMO-9352, NPU Prelaunch Operations-SPTF. A hazards analysis and discussion of the maximum credible accident is to be found in NAA-SR-MEMO-8685, "SNAP Prelaunch Test Facility Safeguards Report," (Atomics International, 1964). 


\section{SECTION II}

\section{FACILITY UTILIZATION}

2-1. The SNAP Prelaunch Test Facility (SPTF) is staffed and equipped by AI for prelaunch preparation of the nuclear power unit (NPU) at VAFB. SPTF operations include all activities related to the NPU following receipt of the NPU system at the facility, to delivery to the launch complex. The facility and as sociated equipment provides the support capability necessary to prepare and establish the NPU for flight readiness. The facility also provides the capability for minor repairs and interim storage of the NPU system.

2-2. Shipment of the SNAP 10 A Systems to the SPTF follows satisfactory completion of acceptance tests at the Atomics International Santa Susana facility (Building 019). Systems test, heat transfer medium loading, nuclear fuel loading, nuclear criticality tests and final reactivity adjustments have been completed prior to shipment to the SPTF. The testing and assembly operations performed at the SPTF prepare the SNAP power units for subsequent mating to the Atlas-Agena vehicle, and launch.

2-3. The SNAP $10 \mathrm{~A}$ system is received at the SPTF as three major subassemblies which are packaged separately in specially designed shipping containers (Figure 2-1). Operations performed in the SPTF include receiving inspection, system checkout, test, reassembly, and final flight readiness testing of the NPU, all of which are performed according to preestablished check sheets. A flow sequence of the final reassembly and test operations performed at the SPTF is shown in Figure 2-2. Only nonnuclear checkout and functional tests are conducted in the SPTF.

\section{2-4. SPTF OPERATIONS SUMMARY.}

2-5. The NPU subassemblies are retained in the shipping containers and placed in the storage area of the SPTF until required for checkout and system assembly. Following the inspection, testing, and reassembly phases, the assembled NPU is placed in its shipping container and moved to the storage area. At the proper time, the NPU is transported, in the shipping container, to the launch complex for further assembly checkouts atop the Agena vehicle. The operations conducted in the SPTF 

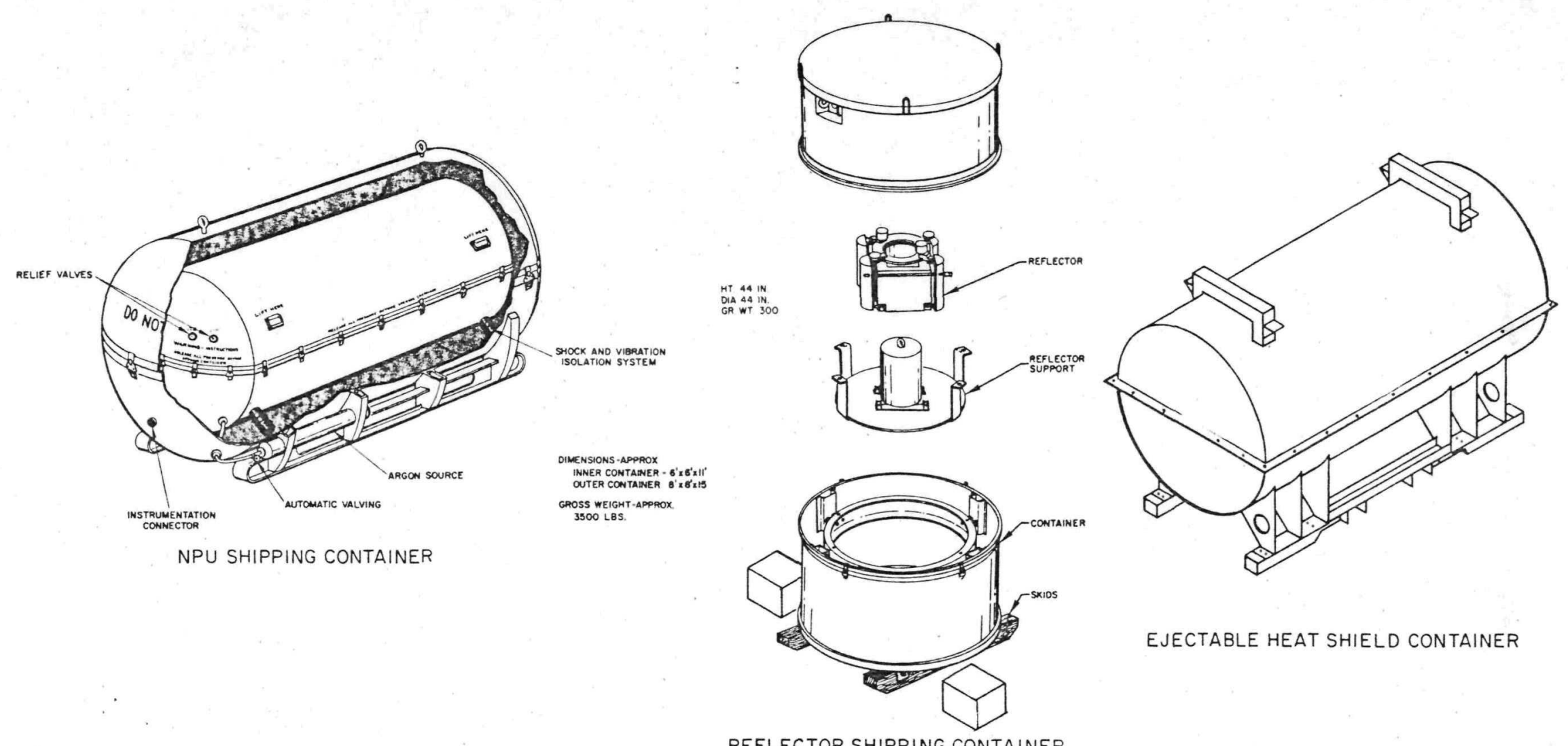

NPU SHIPPING CONTAINER 

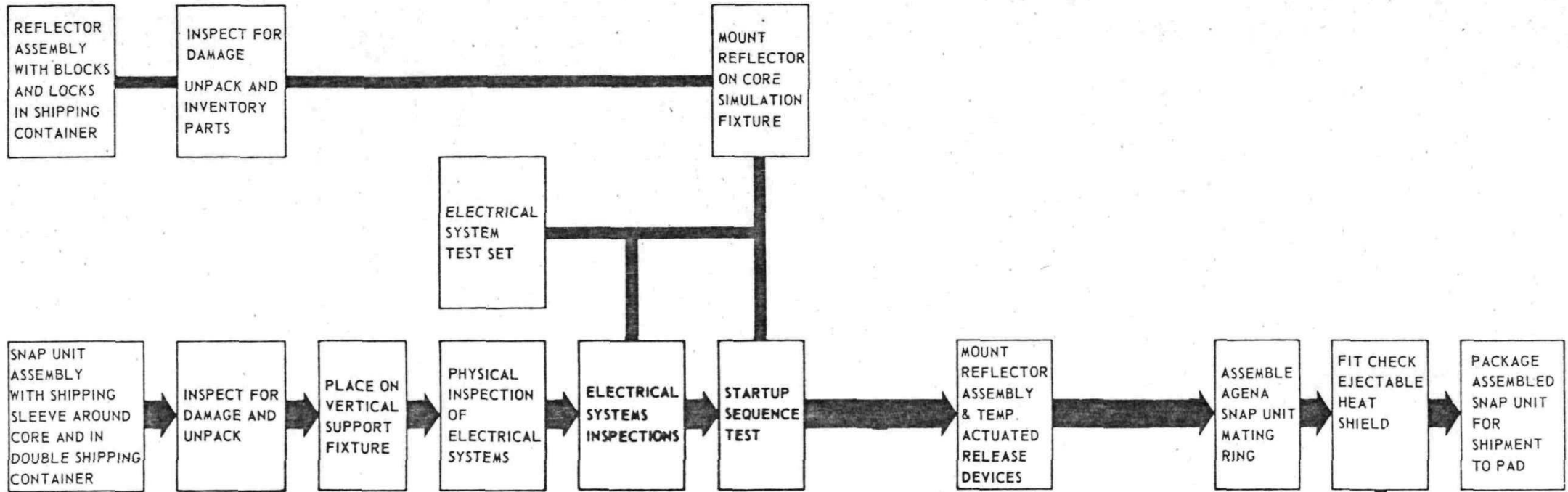

SELOUEMCE

DEVICES

TO PAD

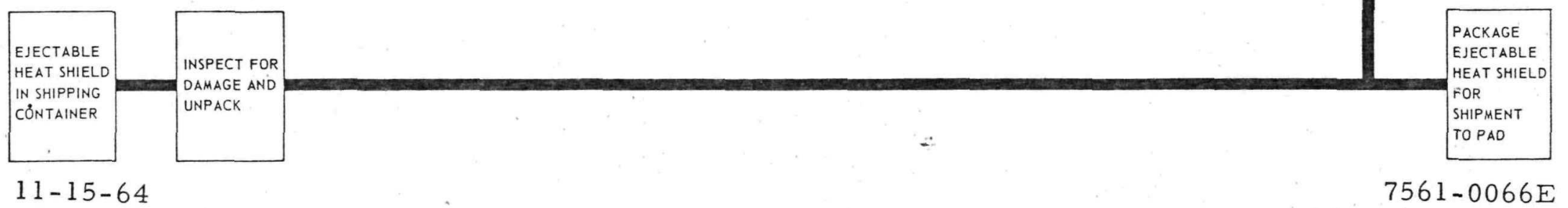

Figure 2-2. Flow Diagram of Prelaunch Operations Performed At The SPTF 
are summarized in the following paragraphs, and are covered in detail by Standard perating Procedures in NAA-SR-MEMO-9352, NPU Prelaunch Operations - SPTF. 2-6. RECEIVING INSPECTION. All SNAP IOA systems received at the SPTF undergo a visual inspection and instrumentation check to evaluate the possibility of in-transit damage. No preassembly tests or operations are performed on the systems unless all parts are certified to be in proper condition for use by the Test Conductor or his designee.

2-7. QUALITY ASSURANCE TESTING. This phase of NPU prelaunch operations includes a series of electrical reference and functional tests which are conducted to assure system integrity prior to reassembly operations.

2-8. After quality assurance testing, the reflector control assembly is installed, the Agena mating ring is attached to the NPU, and the ejectable heat shields are fit-checked. These operations prepare the NPU for subsequent shipment to PALC-2. The NPU is stored in the SPTF until scheduled for transfer to the launch complex.

\section{2-9. AEROSPACE GROUND SUPPORT EQUIPMENT (AGE).}

2-10. A complete set of handling equipment is available at the SPTF for the inspection, checking, and reassembly operations performed at the facility. This equipment is also used for subsequent operations at the launch pad. A general description of the ground support equipment available at the SPTF is given in Section VI of this manual.

2-11. Detailed descriptions, operation, and maintenance of AGE equipment is given in the AGE Manuals, NAA-SR-MEMO-9356, AGE Operation and Maintenance, Mechanical (Vol. I) and AGE Operation and Maintenance, Electrical (Vol. II). 


\section{SECTION III}

\section{SITE AND FACILITY DESCRIPTION}

3-1. The SNAP Prelaunch Test Facility building (Figure 3-1) is located at Vandenberg Air Force Base in Western Santa Barbara County of Southern California. VAFB lies approximately 140 miles northwest of Los Angeles and 55 miles westnorthwest of Santa Barbara. Details covering the topographical, meteorological, and other site conditions, and the population density of the surrounding area, are given in the SPTF Safeguards Report, NAA-SR-MEMO-8685.

\section{3-2. BUILDING.}

3-3. The SPTF building site is situated approximately 300 yards off 13th Street, one-half mile south of New Mexico Street, in the south end of Vandenberg AFB. Location of the facility in relation to other buildings on the base is shown in Figure 3-2.

3-4. The SPTF building is $60 \mathrm{ft}$ wide by $87 \mathrm{ft}$ long with main entrances on the long side of the building facing to the northeast. The building is divided into two basic areas, the low bay and the high bay. Offices for the administrative staff and technical support personnel are provided in the low bay area. This area also includes the rest rooms, machine shop, instrument maintenance laboratory, and auxiliary equipment rooms. The high bay area is utilized for operations which include final NPU assembly, inspection, test and storage. Building elevation is shown in Figure 3-3 and a floor plan of the building in Figure 3-4.

3-5. CONSTRUCTION. Standard design and field practices have been followed in construction of the building. Exterior walls are metal siding over steel framing; the roof is steel decking with builtup roofing. The floor is a concrete slab with the elevation set to assure drainage away from the building. Partitioning walls between the various areas are conventional stud construction paneled with fire retardant gypsum wallboard.

3-6. Special features include positive air pressure ventilation systems, door seals, and air filters to minimize dust infiltration into the building. Dust-free air conditioning is provided for the instrument laboratory. A radiation alarm system, heat actuated fire alarm system, NaK fire protection equipment, and a 5 -ton overhead crane are located in the high bay. 


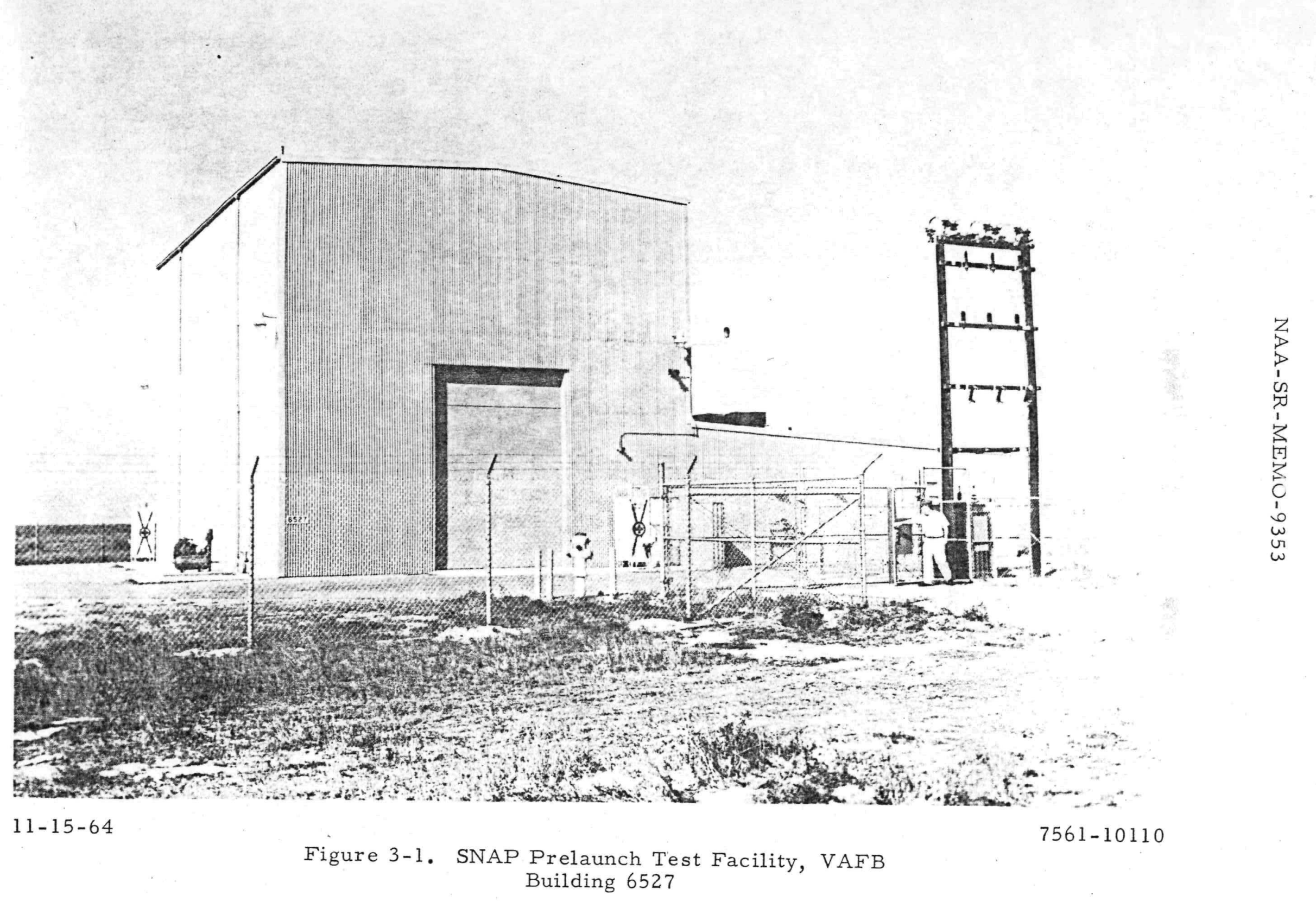




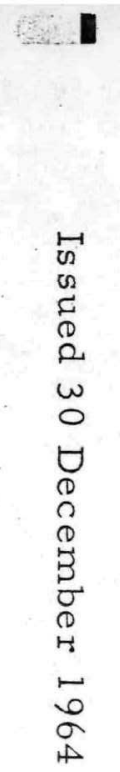

0

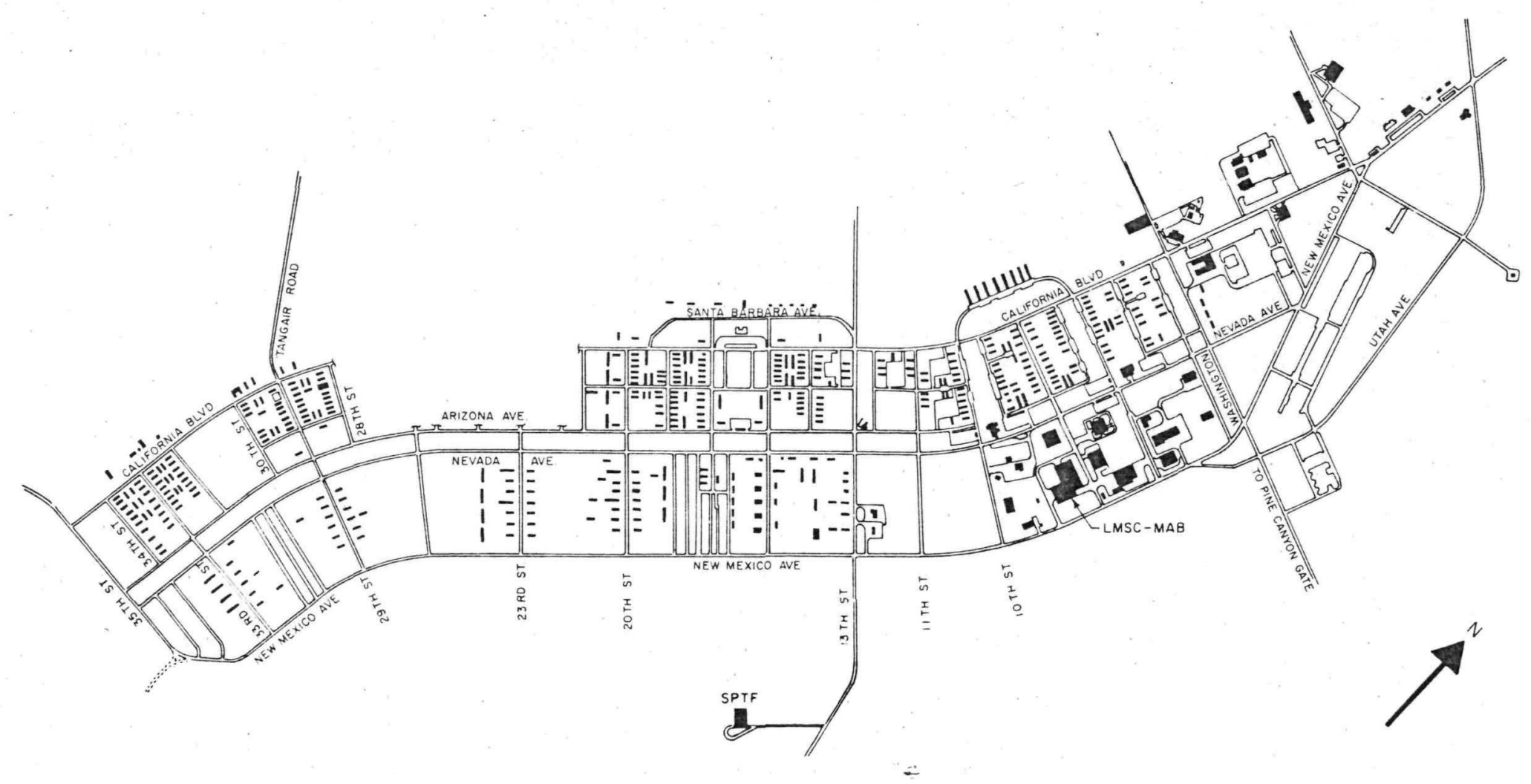

2
3
1
1
0
1
3
21
3
0
0
1
0
$w$
$w$
$w$

$11-15-64$

7561-10111

Figure 3-2. Location of SPTF at VAFB 


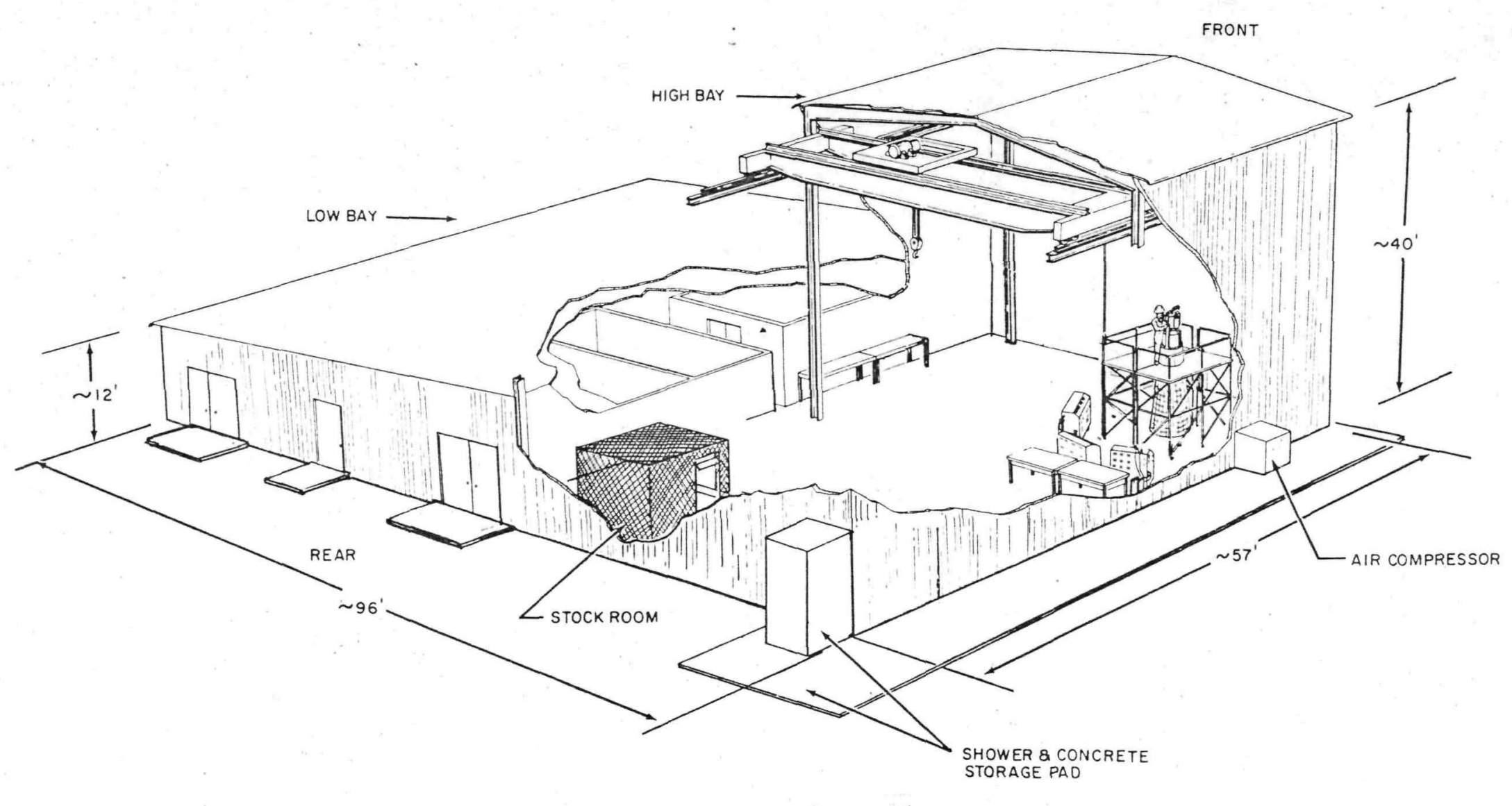

Figure 3-3. Elevation Views, Building 6527 (SPTF), VAFB

7561-10112 


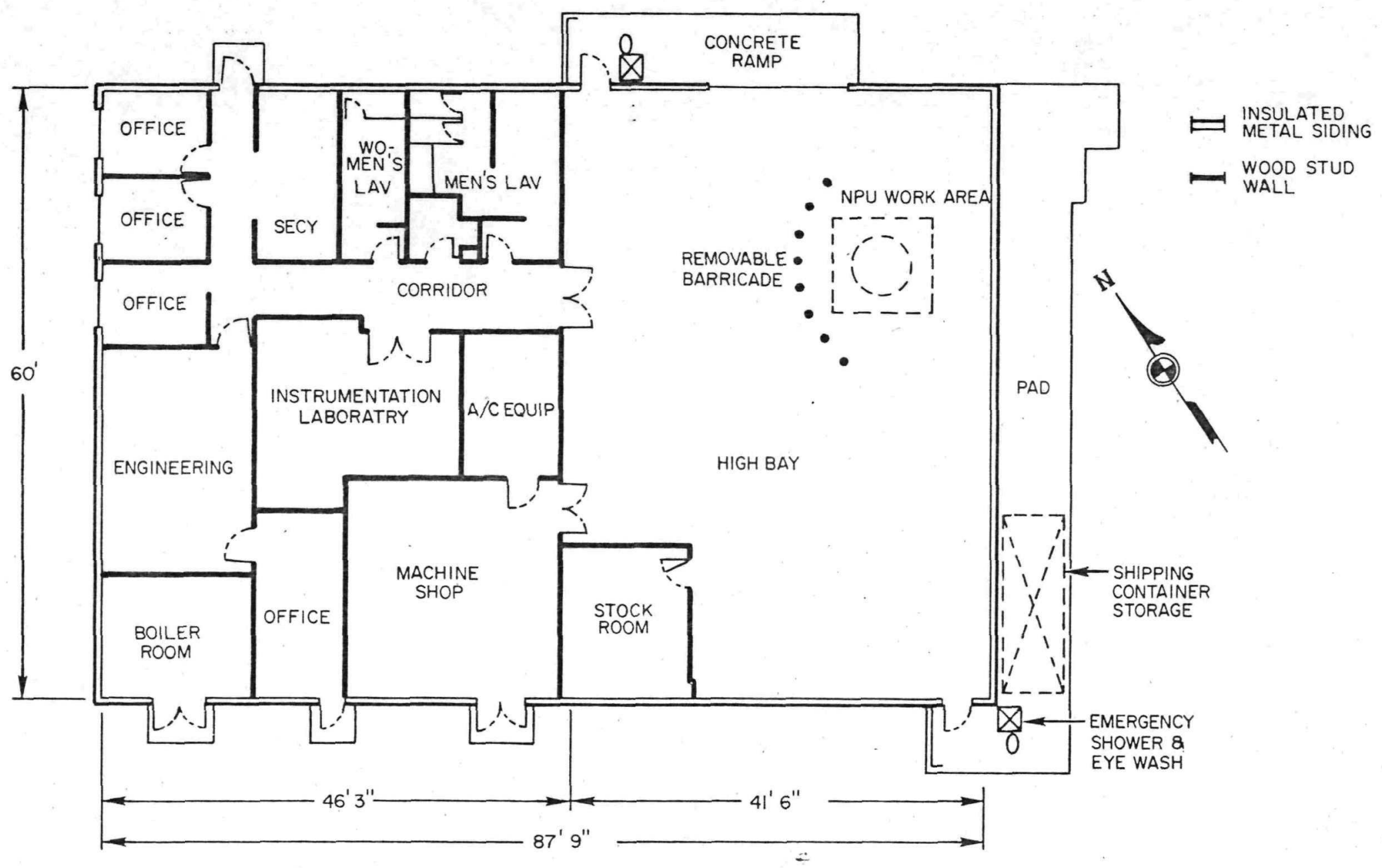


3-7. High Bay Area.

-8. The high bay is a 41 by $60 \mathrm{ft}$ open area containing the space and equipment necessary for performing the prelaunch assembly and testing operations on the NPU. The space is utilized for receiving and shipping, shipping container storage, final reassembly and test, inspection and parts storage. Approximately $90 \%$ of the usable floor area is serviced by a 5-ton capacity overhead traveling crane.

3-9. Equipmentaccess to the high bay area is made through one 14 by $20 \mathrm{ft}$ vertical lift sliding steel door at the nor theast side of the high bay. This doorway is large enough to permit entry of ground transport equipment carrying the NPU nose cone in a vertical position. (The door is kept locked when the NPU is in the building.) The door, which is hand operated by means of a geared hoist, is weather-sealed to minimize dust infiltration.

3-10. Two hollow metal personnel doors are provided at the northeast and southwest sides of the high bay for emergency exits to the outside (Figure 3-4). Emergency showers and eye wash basins are provided at these exits. There are no windows in the high bay area.

3-11. The concrete slab floor is designed to support 16,000 lb wheel loads, and is sealed for protection and cleanliness. Pipe sleeves are inserted in the floor for placement of removable stanchions which are used to protect the NPU from accidental collisions by mobile equipment. The stanchions are located at sufficient distance from the NPU to allow an operator to stop a vehicle before colliding with the NPU support fixture in the event of a collision with the stanchions.

3-12. Covered floor trenches are provided in the receiving and checkout area of the high bay to enclose power and testwiring. These 1 by $1 \mathrm{ft}$ trenches are covered with removable steel plates capable of supporting 16,000 1b wheel loads. Cover plate ends are designed to prevent objects from falling into the trench. The trenches are provided with a drain.

3-13. Temporary partitions are used to provide a parts storage area in the west corner of the high bay. Small parts, tools, and supplies are stored in this area which serves as a stock room. Access to the area is through a Dutch-type door, the bottom half of which serves as a counter and provides a means for controlling access to the area. 
3-14. Low Bay Area.

3-15. The low bay is 46 by $60 \mathrm{ft}$, partitioned to provide space for the facility support functions (Figure 3-4). These consist of the instrumentation laboratory, machine shop, office space, locker and rest rooms, boiler equipment room, and fan equipment room.

3-16. Four exterior doors provide access to the low bay area. Access to the boiler room and to the machine shop is provided by double hollow metal doors which are normally locked. Single metal doors are used for the main entrance and the office area on the opposite side of the building. Access to the high bay area is through either of two double doors (fire-rated); one set opens from the machine shop and the other from the main corridor.

3-17. Instrumentation Laboratory. The instrumentation calibration and maintenance laboratory is a room approximately 15 by $20 \mathrm{ft}$ in which spare instrumentation and calibration equipment is stored and maintained. Work benches are provided for routine maintenance and repair of instrumentation components. The room is equipped with an independent air conditioning and heating system, complete with intake dust filters and controls for automatic operation.

3-18. Machine Shop. The machine shop is a room approximately 21 by $22 \mathrm{ft}$ adjoining and having access to the high bay through a set of double doors. The shop is equipped to provide the capability for facility maintenance, AGE maintenance, and minor repair operations.

3-19. Office Area. Three 8 by $10 \mathrm{ft}$ offices, one 9 by $19 \mathrm{ft}$ engineering office, one 15 by $25 \mathrm{ft}$ engineering office, and a 12 by $22 \mathrm{ft}$ reception and clerical area are provided with desks and cabinets for supervisory, engineering, technical, and clerical personnel.

3-20. Low Bay Facilities Rooms. The 12 by $15 \mathrm{ft}$ boiler equipment room located at the northwest end of the low bay is furnished with conventional forced hot water gas burning heating equipment. The 9 by $14 \mathrm{ft}$ fan equipment room adjacent to the high bay area houses the equipment which provides forced air ventilation for the high bay. A men's locker room and a ladies rest room are located off the corridor leading to the high bay area.

3-21. SERVICE SYSTEMS.

3-22. The SPTF is equipped with the conventional service systems commonly installed in support facilities of this type to provide proper working conditions. In addition, the building is equipped with a radiation alarm.

Issued 30 December 1964 
3-23. HEA TING, VENTILATING, AND AIR CONDITIONING. The building is supplied th three separate heating and ventilating systems to serve the office, high bay, and machine shop area. The Instrumentation Calibration and Maintenance Room is served independently by a mechanical heat pump type air conditioning unit mounted on the roof. Both the high bay and low bay heating requirements are supplied by a single gas burning forced hot water boiler which is provided with three hot water circulating pumps, one for each of the three systems. Filtered air is circulated throughout the building by three ventilating fans. The air is heated by heating coils at the fan inlet and is moved through a system of ductwork to the area supply registers. Heating and ventilating system specifications are listed in Table 3-1. Air pressure in the low bay is maintained at a higher pressure than the high bay, whereas the high bay is maintained at a slightly positive pressure with respect to the outside atmosphere to assure clean filtered air to the area to minimize the infiltration of dust. All ventilation ducts which pass through partition walls contain fire dampers equipped with fusible link-type controls and access doors. In the event of an accident involving toxic material release, the entire ventilation sy.stem will be shut off manually by the Engineering Supervisor or his designee, using the Emergency Shutdown switch located just inside the main entrance to the low bay area, in order to assist in the containment of toxic materials in the high bay. To isolate the high bay, a spring loaded back pressure relief damper is provided in the ceiling of the high bay and a back pressure damper is installed in the return duct of the high bay. After an emergency which necessitates actuation of the dampers, the dampers must be reset manually prior to reuse of the building.

3-24. FIRE PROTECTION SYSTEMS AND EQUIPMENT. The SPTF fire detection and control systems consist of heat actuated detectors, signal sounding appliances (warning horns), manual fire alarm boxes, and portable extinguishers. SPTF protective systems and equipment locations are shown in Figure 3-5. Water sprinkler systems are not used for fire protection due to the presence of NaK in the NPU system. Signs reading USE NO WATER FOR FIRES are posted throughout the high bay area. These steps are taken to prevent the possibility of NaK contact with water and a resultant NaK water reaction. The types of fire extinguishing equipment used in the facility and their recommended use are listed in Table 3-2. Fire protection in the high bay area is provided by heat actuated detectors which operate the warning horns, and by use of portable $\mathrm{CO}_{2}$ extinguishers for electrical fires and MET-L-X extinguishers for NaK fires or fires involving uranium conium hydride fuel. The low bay area is supplied with heat actuated 


\begin{tabular}{|c|c|c|c|c|}
\hline & System and Component & $\begin{array}{c}\text { Area } \\
\text { Served }\end{array}$ & $\begin{array}{l}\text { System } \\
\text { Capacity }\end{array}$ & $\begin{array}{c}\text { Air Changes } \\
\text { per hr. }\end{array}$ \\
\hline A. & $\begin{array}{l}\text { Heating System } \\
\text { Boiler, gas fired } \\
\text { Pump and heat exchanger } \\
\text { Pump and heat exchanger } \\
\text { Pump and heat exchanger }\end{array}$ & $\begin{array}{l}\qquad \text { SPTF } \\
\text { Low Bay* } \\
\text { Machine shop } \\
\text { High Bay }\end{array}$ & $\begin{array}{l}24,000 \mathrm{Btu} \\
\text { out/hr }\end{array}$ & $\begin{array}{l}- \\
- \\
- \\
-\end{array}$ \\
\hline B. & $\begin{array}{l}\text { Ventilating System } \\
\text { Fan No. } 1 \\
\text { Fan No. } 2 \\
\text { Fan No. } 3\end{array}$ & $\begin{array}{l}\text { Low Bay } \\
\text { Machine shop } \\
\text { High Bay }\end{array}$ & $\begin{array}{l}1900 \mathrm{cfm} \\
1900 \mathrm{cfm} \\
6100 \mathrm{cfm}\end{array}$ & $\begin{array}{l}15 \\
15 \\
10 * *\end{array}$ \\
\hline C. & Air Conditioning & Instrument shop & & \\
\hline
\end{tabular}

*Includes occupied areas of low bay, but excludes machine shop. ***Based on a $15 \mathrm{ft}$ height.

Table 3-1. SPTF Heating and Ventilating System Specifications 
1
$x$
1
$x$
1
$x$
1
1
$x$
1
$x$
1 $x-x-x-x-x-x-1$

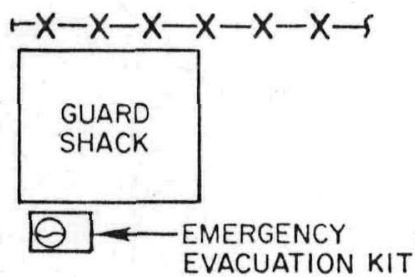

\section{EMERGENCY}

SHUTDOWN

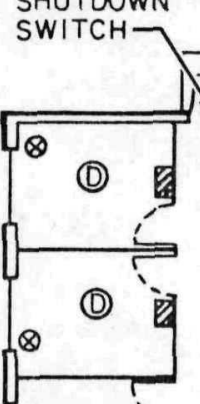

Si

INTERCOM MASTER

\section{(1)}

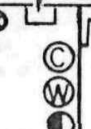

(C)

(a)

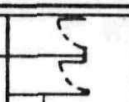

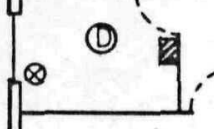
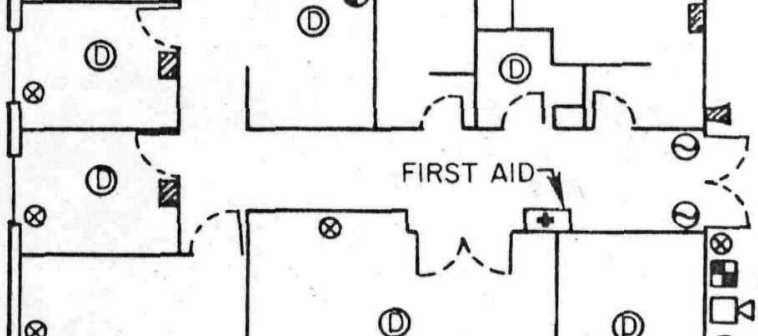

$\otimes$<smiles>C1CCCC1</smiles><smiles>C1CCCC1</smiles>

(D)

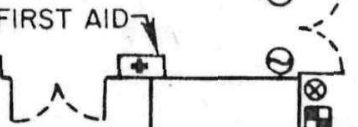

(D)

(D)

$\otimes$

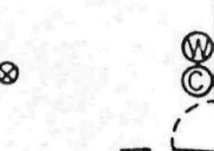

C

(c)

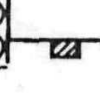

$m$

(D)

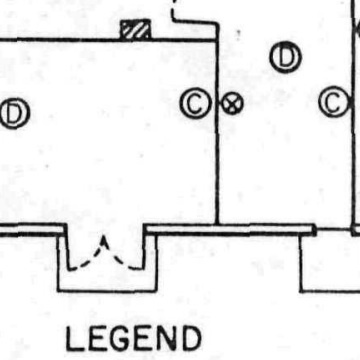

LEGEND

(D) HEAT ACTUATED ALARM

(C) PORTABLE $\mathrm{CO}_{2}$ EXTINGUISHER

- LIQUid metal FIRE EXTINGUISHER

MET-L-X-30

portable calcium carbonate

(11) PORTABLE WATER

$\Theta$ BREATHING APPARATUS

D DRY CHEMICAL

G LIQUID METAL FIRE EXTINGUISHER

MET-L-X-150

INTERCOM SPEAKER-8

INTERCOM SPEAKER-2

- TELEPHONE (TENTATIVE)

SHOP AIR OUTLETS

$$
11-15-64
$$

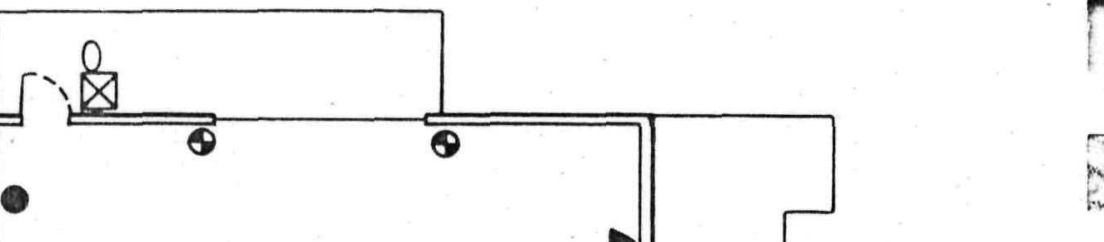

(D)

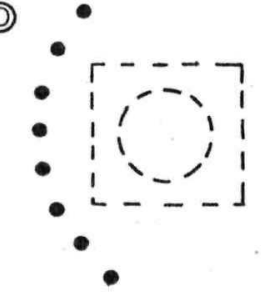

(D)

Figure 3-5. SPTF Protective Systems and Safety Equipment 


\begin{tabular}{|c|c|c|c|c|}
\hline $\begin{array}{c}\text { Fire Extinguisher } \\
\text { Type }\end{array}$ & Size & $\underset{(e a)}{\text { Quantity }}$ & $\begin{array}{l}\text { Location } \\
\text { (General) }\end{array}$ & Recommended Use \\
\hline $\begin{array}{l}\text { Water, portable } \\
\text { pump cans }\end{array}$ & $2-1 / 2$ gal $\mid$ & 3 & $\begin{array}{l}\text { Low bay area } \\
\text { only }\end{array}$ & $\begin{array}{l}\text { Nonelectric fires involving } \\
\text { standard combustible } \\
\text { materials }\end{array}$ \\
\hline $\begin{array}{c}\mathrm{CO}_{2} \text { portable high } \\
\text { pressure bottles }\end{array}$ & $15 \mathrm{lb}$ & 8 & $\begin{array}{l}\text { Low bay office } \\
\text { and shop areas } \\
\text { and high bay }\end{array}$ & $\begin{array}{l}\text { All fires including elec- } \\
\text { trical fires but excluding } \\
\text { NaK fires. }\end{array}$ \\
\hline Dry chemical type & $20 \mathrm{lb}$ & 3 & $\begin{array}{l}\text { Low bay entry } \\
\text { Instrument shop } \\
\text { Machine shop }\end{array}$ & Oil and grease fires \\
\hline $\begin{array}{l}\text { Drycalciumcar- } \\
\text { bonate, portable }\end{array}$ & $50 \mathrm{lb}$ & 3 & High bay area & USE FOR \\
\hline $\begin{array}{l}\text { MET-L-X liquid } \\
\text { metalextin- } \\
\text { guishers }\end{array}$ & $\begin{array}{l}30 \mathrm{lb} \\
150 \mathrm{lb}\end{array}$ & $\begin{array}{l}2 \\
2\end{array}$ & High bay area & $\begin{array}{l}\text { NaK } \\
\text { FIRES }\end{array}$ \\
\hline
\end{tabular}

Table 3-2. SPTF Fire Extinguishing Equipment 
fire detectors, which operate the alarm horns in the facility. The fire detector and rm system is equipped with an emergency (battery) power supply which is automatically switched into the detector circuit in the event of a facility power outage. Portable $\mathrm{CO}_{2}$ extinguishers and portable water pump cans are provided in each room to control a fire. The combination rate-of-rise and fixed temperature heat sensing fire detectors monitor the entire building by activating the fire alarm horns in the facility. A warninghorn is alsolocated on the outside eastwall of the high bay. Manual fire-alarm boxes are located near the exits of the high bay and sound the fire warning horns when activated. In addition to the fire extinguishing equipment shown in Table $3-2$, the following safety equipment is provided in the facility for use in combating fires:

a. Three sets of self contained breathing apparatus.

b. Respirators.

c. Protective clothing.

3-25. The VAFB fire department has the capability for fighting fires involving pyrophoric materials. The special fire-fighting problems associated with operation of the facility have been made known to the VAFB Department. Actuation of the fire alarm system requires immediate notification of the Base Fire Department, as operating personnel are not allowed to turn off any fire protection system.

3-26. RADIATION ALARM。A radiation alarm system is installed in the building to provide a means for monitoring radiation levels. This system consists of a scintillation-type gamma radiation detector located in the high bay, a siren in the low bay area and a siren and rotating red beacon on the facility roof. These sirens and the rotating beacon are activated in the event radiation levels in the high bay exceed preset limits of $20 \mathrm{mr} / \mathrm{hr}$ at the detector. An emergency battery power supply is included as part of the radiation alarm system so the monitoring capability continues in the event of loss of facility electrical power. An audible alarm and red light on the detector provide alarm capabilities in this event (Figure 3-6).

3-27. ELECTRICAL. Commercial electrical power service is installed in the building. Local substations transform the power to the following services: $480 \mathrm{v}$, $208 \mathrm{v}$, and $120 \mathrm{v}, 3$-phase supply for general service and lighting requirements. A $120 \mathrm{v}$ ac regulated voltage supply is provided for the instrumentation laboratory. A $28 \mathrm{v} \mathrm{dc}$ voltage supply is provided in the high bay and instrumentation laboratory. 
A separate power supply connecting before the $480 \mathrm{v}$ station circuit breaker is provided to power the fire alarm system. This provides alarm capability even though facility circuits are deactivated. Battery powered Exide lights are available, and operate automatically, in the event facility power is lost.

3-28. A master switch located just inside the main entrance to the low bay is provided to shutdown the ventilation system in the event of an emergency.

3-29. EQUIPMENT HANDLING. Material handling equipment provided with the facility consists of an overhead traveling crane. Crane specifications are listed in Table 3-3. The special aerospace ground equipment to be used in the facility for handling the NPU components is described in Section 6 of this manual.

\begin{tabular}{|l|l|}
\hline \multicolumn{1}{|c|}{ Item } & \multicolumn{1}{c|}{ Specifications } \\
\hline Crane Type & $\begin{array}{l}\text { Single trolley, overhead traveling } \\
\text { 3-motor, pendant control }\end{array}$ \\
Hook lift (vertical distance) & $28 \mathrm{ft}$ above floor level \\
Travel speeds: & \\
Bridge & 10 to $45 \mathrm{fpm}$ in 4-step increments \\
Trolley & 8 to $37 \mathrm{fpm}$ in 4-step increments \\
Hoist & $\begin{array}{l}10 \text { to } 30 \mathrm{fpm} \text { in 5-step increments } \\
\text { with precise inching control }\end{array}$ \\
\hline
\end{tabular}

Table 3-3. SPTF Overhead Crane Specifications

\section{3-30. FACILITY MAINTENANCE.}

3-31. Facility maintenance is performed by Atomics International personnel in accordance with the schedule outlined in Table 3-4. Maintenance activities will normally be performed by the custodian, with the help of members of the SPTF crew as required.

3-32. ROUTINE MAINTENANCE. Checklists used in the performance of routine maintenance of the facility and service systems are presented in Appendix $B$ of this manual. These checklists are included in the Facility Operations Logbook. The person(s) performing maintenance operations appearing on the checklist shall initial and date each item as it is completed. Space is provided for remarks pertaining to status or condition of item. Defective or malfunctioning facility equipment is reported in the Facility Operations Logbook (Section 4). 


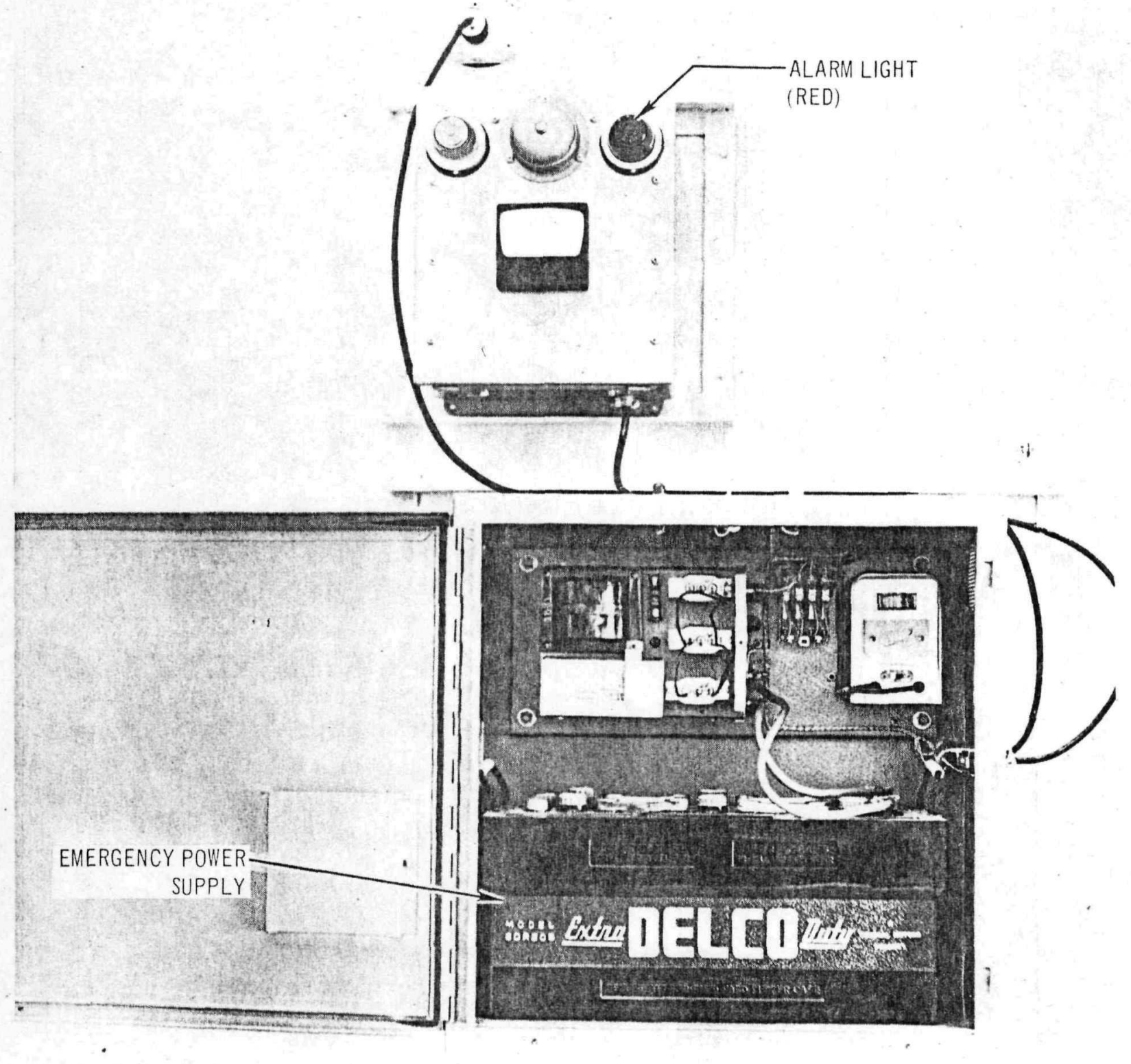

$7561-10115$

$11-15-64$

Figure 3-6. Radiation Detector Located in High Bay 


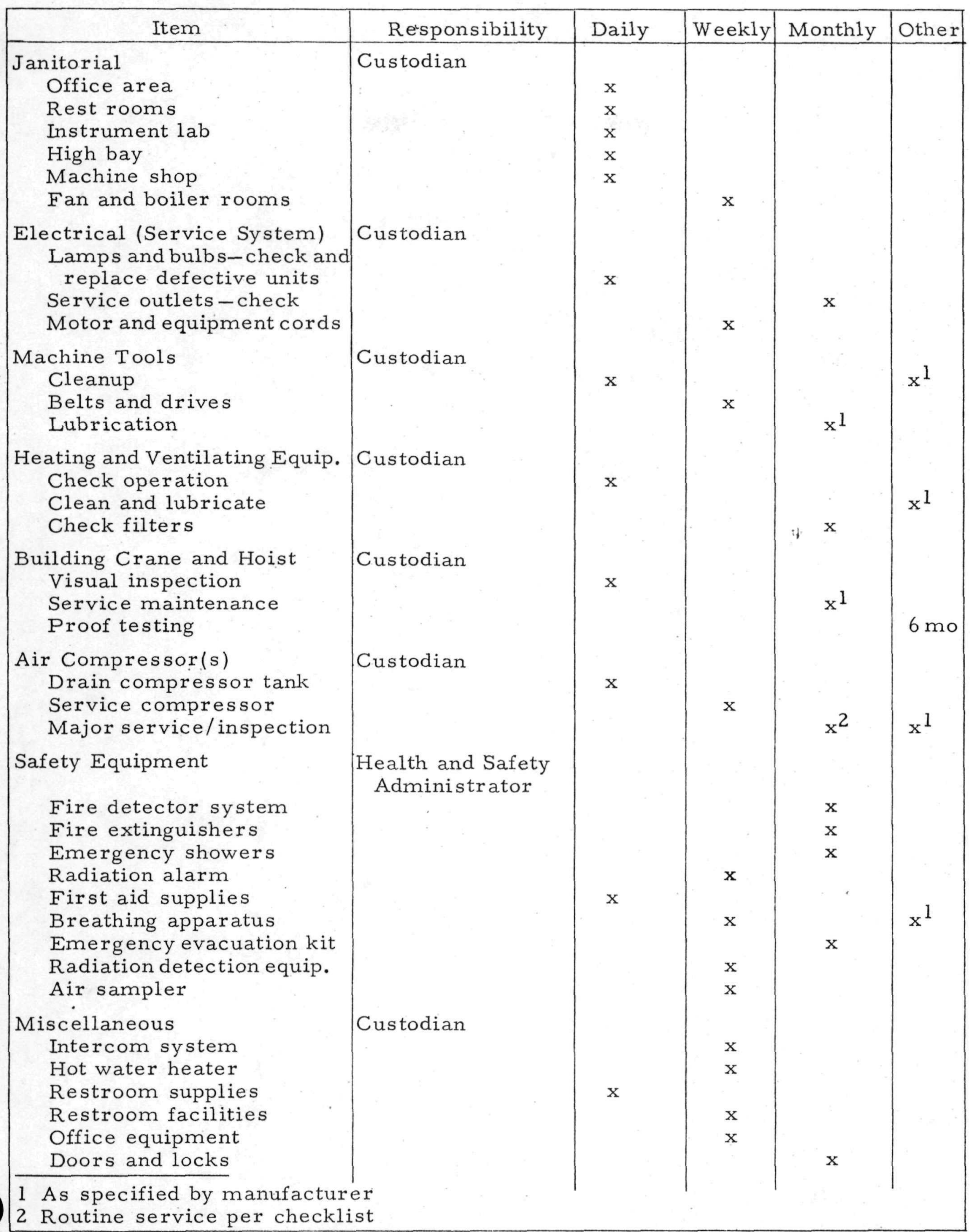

Table 3-4. SPTF Building and Equipment Maintenance Schedule 


\section{3-33. SECURITY.}

34. The entire area surrounding the SPTF is fenced off by a chain link fence. Two personnel gates and one vehicle gate are provided for access. Guard service is provided in compliance with VAFB and AEC security regulations. A 24 hour guard service is provided at the facility. The industrial security plan applicable to the SPTF, is presented in Appendix A. 


\section{SECTION IV}

\section{ADMINISTRATIVE REQUIREMENTS}

4-1. Atomics International, as the manufacturer of the SNAP $10 \mathrm{~A}$ nuclear power units, is responsible for NPU prelaunch operations conducted at VAFB. Activities scheduled for completion at VAFB are carried out by the launch operations unit comprised of AI personnel. This unit is responsible for NPU prelaunch operations beginning with shipment of the SNAP 10A units from Santa Susana (AI Field Laboratory, Building 019, Canoga Park) through installation and final checkout of the NPU on the launch vehicle.

\section{4-2. FIELD UNIT ORGANIZATION.}

4-3. The SPTF, which serves as a base of operations for the AI-VAFB field unit, is staffed and operated by AI personnel. Overall direction of the SNAP 10A prelaunch operations conducted at VAFB, including the SPTF, is the responsibility of the AI Engineering Supervisor (paragraph 4-9). The basic field unit organization is shown in Figure 4-1.

4-4. The SPTF is operated on an $8 \mathrm{hr}$ day shift basis during the NPU prelaunch operation; $24 \mathrm{hr}$ coverage is provided as schedules demand. The basic operations crew consists of the following personnel:

Test Conductor

Asst. Test Conductor(s)

Technician(s)

Mechanic(s)

These personnel are responsible for performance of receiving inspection, verification checkout, final reassembly, test data reporting, and operation of auxiliary systems as required for the prelaunch test program. The actual number of persons in each category varies according to the operation in progress, but in no case will the number be less than two. Additional support personnel are available to the SPTF staff as required. 


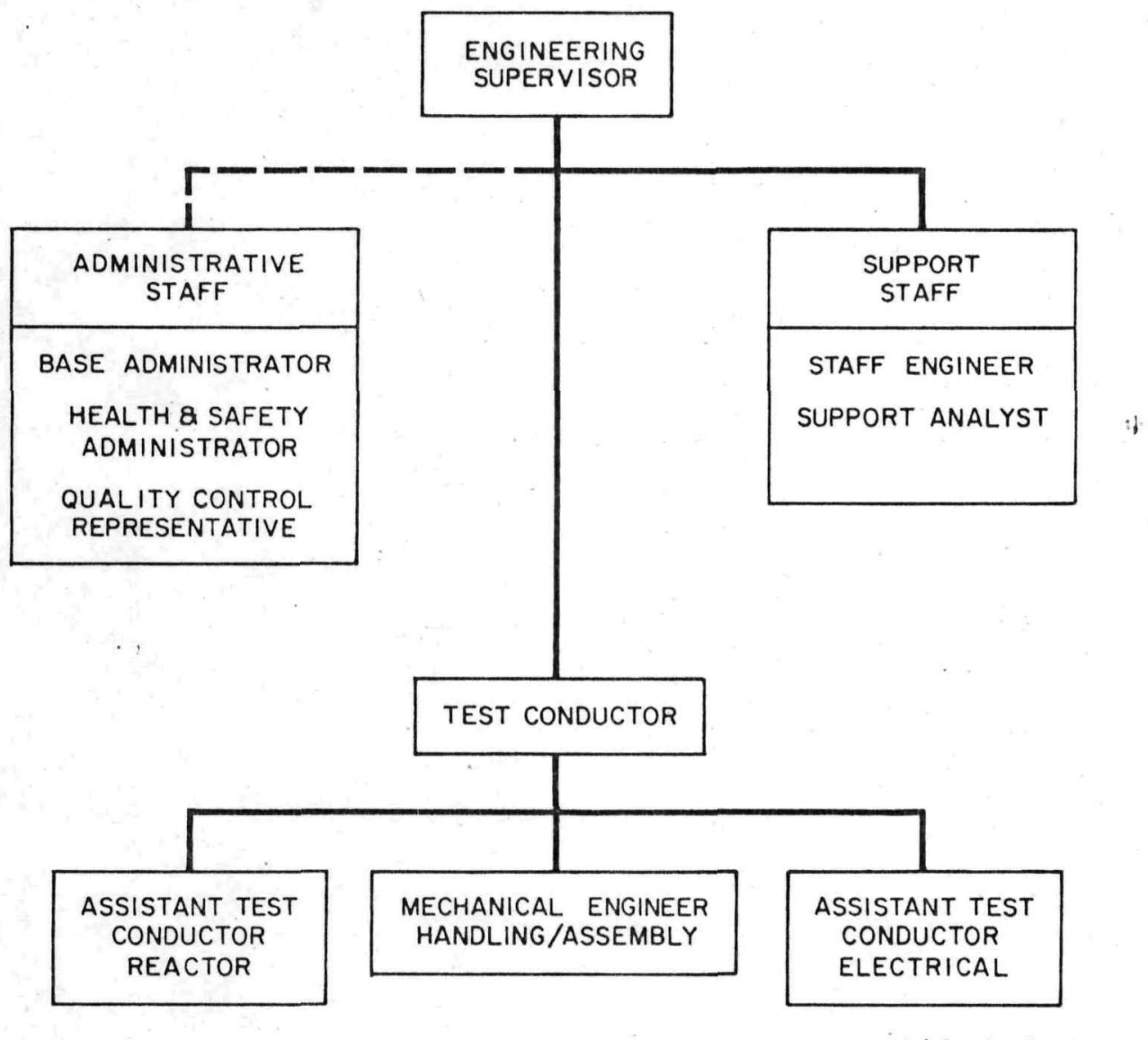

$7561-10131$

Figure 4-1. SNAP 10A Prelaunch Operations Field Unit Organization 


\section{4-5. OPERATING PHILOSOPHY.}

4-6. Operation of the SPTF is governed by the practices and standard operating policies of the Atomics International Division of North American Aviation, Inc. All facility operations and activities are conducted in a manner consistent with standard company policies and procedures. Safety practices must at all times meet the requirements of the AI Health and Safety Section. Personnel assigned to the facility are trained and evaluated before being given the responsibility of performing the tasks assigned them.

\section{4-7. JOB DESCRIPTION AND RESPONSIBILITIES.}

4-8. Individual job descriptions relating to the VAFB field operations unit are summarized in the following paragraphs. Included are the several categories of personnel who, although not directly engaged in prelaunch operations, are required in support of a field operation.

4-9. ENGINEERING SUPERVISOR. The Engineering Supervisor is responsible for all SNAP 10A prelaunch operations. In addition, he coordinates the safety and security training programs, working with the Base Administrator and the Health and Safety Administrator.

4-10. He is the primary contact for associate contractor and Air Force relations regarding launch-interface coordination and is capable of assuming the duties of the Test Conductor, if required.

4-11. Responsibilities and duties of the Engineering Supervisor include planning, direction, and coordination of the master prelaunch operations plan. This plan includes the transporting, receiving, inspection, reassembly checkout, and interface checking activities conducted at the SPTF and PALC-2. He is responsible for the planning and coordination of direct support activities such as manuals, $\log$ books, data reports and records, and procedures.

4-12. BASE ADMINISTRATOR. The Base Administrator is responsible for the nontechnical phase of the prelaunch program. As a member of the AI field operations support group, he reports to the Engineering Supervisor in a staff capacity, serving in a liaison capacity regarding administrative matters.

4-13. Responsibilities and duties of the Base Administrator include, but are not limited to the following: Personnel records and relocation, industrial and VAFB security liaison, visitor arrangements, AI policies and procedures as related to 
field operations, company provided transportation, work schedules, budget control, d training as related to industrial security. He is also responsible for administration and supervision of facility maintenance and repair activities.

4-14. TEST CONDUCTOR. The AI Test Conductor is the designated engineer in charge of all SNAP 10A operations at VAFB and PALC-2. Reporting to the Engineering Supervisor, he works in conjunction with three assistant test conductors who are individually responsible for a particular phase of testing activity. The Test Conductor is thoroughly familiar with the complete NPU system and operational cycle, instrumentation and tolerances, and the electrical ground support equipment.

4-15. Responsibilities and duties include determining the validity of test results, decisions regarding systems malfunction and recommendations regarding the subsequent course of action. He also assists the Engineering Supervisor on matters regarding personnel performance and liaison with the associate contractors and the Air Force launch conductor.

4-16. ASSISTANT TEST CONDUCTOR, REACTOR SUBSYSTEM. As an advisor to the Test Conductor, the Assistant Test Conductor (ATC) for the reactor subsystem is responsible for the integrity of the reactor, reflectors, shield, controller, and all associated components.

4-17. Duties include making recommendations regarding the validity of technical data, reactor subsystem performance, and action required to correct a malfunction. 4-18. MECHANICAL ENGINEER. The Mechanical Engineer in charge of AGE mechanical equipment is responsible for NPU handling, shipping and assembly operations. He is responsible for the integrity of the mechanical ground support equipment, NPU system handling and system reassembly subsequent to acceptance testing. He works with the Test Conductor, ATC for reactor subsystem, and ATC for electrical systems in a coordinated prelaunch operations effort.

4-19. It is his duty to make recommendations concerning handling procedural changes and/or action to be taken in the event of NPU damage incurred during handling or assembly operations. He also initiates action for the repair of any malfunctioning of the mechanical ground support equipment.

4-20. ASSISTANT TEST CONDUCTOR, ELECTRICAL SYSTEMS. The ATC for SNAP 10A electrical systems is responsible for the integrity of the electrical controls, instrumentation, power supplies, signal conditioning, and system wiring, orking with the Test Conductor and other ATC's in a coordinated effort. 
4-21. Duties include making recommendations regarding electrical malfunctions and subsequent action required to resolve the problem. He also initiates action in the event electrical system components require repair or replacement.

4-22. REACTOR SUBSYSTEM TECHNICIAN. The Reactor Subsystem Technician assists in reactor subsystem checkout, makes necessary adjustments, and installs the reactor safety devices, interlocks, and special instrumentation and controls. As a member of the prelaunch operations unit, he works under the direction of the reactor subsystems ATC.

4-23. ELECTRONICS TECHNICIAN. Assistance in electrical checkout of the SNAP 10A system and related ground support equipment is provided by the electronics technicians assigned to the prelaunch operations program. Personnel in this classification will, under the direction of the electrical systems ATC, make modifications or repairs to the flight system and/or supporting equipment as called for by engineering drawings or change notices.

4-24. AGE TECHNICIAN. Structures/mechanical AGE technicians are assigned to the prelaunch operations unit to assist in NPU handling, transport, and assembly operations. Working under the direction of the handling/assembly ATC, the AGE technician(s) will make such repairs and modifications to the NPU system and/or ground support equipment as required. Responsibilities also include operations and maintenance of the machine shop and tools available at the SPTF.

4-25. SUPPORT ANALYST. As a staff member reporting to the Engineering Supervisor, the Support Analyst is responsible for adherence to and maintenance of the overall prelaunch logistics plan. This includes monitoring of the checkout and assembly procedures, procedure verification, issuing support parts usage data, and insuring that replacement parts are available. Duties also include monitoring and initiation of revisions to the operations and maintenance manuals to ensure that they are correct and complete. This includes constant perusal of the operations logbook to ensure that all steps are being recorded and that any deviations or malfunctions have been recorded.

4-26. STAFF ASSISTANT. As staff assistant to the Engineering Supervisor, the responsibilities of this position include preparation of SPTF activities reports (paragraph 4-50) and conducting special investigations at the direction of the Engineering Supervisor. Duties include preparation and distribution and maintenance of the routine reports required in support of facility operation. 
4-27. SUPPORT EQUIPMENT ENGINEER, ELECTRONICS. The electronics bupport Equipment Engineer is responsible for the maintenance and operation of the NPU electrical support equipment, including the NPU systems test sets, shipping container monitoring equipment, and the electrical laboratory equipment. His duties include analysis of electrical malfunctions and the direction of related isolation and repair activities, including verification of equipment following completion of repair(s).

4-28. QUALITY CONTROL REPRESENTATIVE. As a representative of the AI Quality Control Section serving in a staff capacity to the Engineering Supervisor, the Quality Control (QC) representative is responsible for inspection and acceptance of each SNAP $10 \mathrm{~A}$ prelaunch checkout step, activity, replacement and/or repair. Acceptance of test results and related activities is indicated by the inspector's sign-off in the NPU verification log.

4-29. The QC representative also assists in analyzing test data and in diagnosing malfunctions, his prime responsibility being to ensure that NAA quality standards are maintained. In this respect, he serves in an advisory capacity, working with the test conductors and technicians regarding proposed changes, recommendations and repairs.

4-30. It is the inspector's responsibility to monitor and report on NPU prelaunch operational activities to ensure that AI quality control standards are maintained. This entails checking on and assuring that all documentation relating to NPU operations are current at all times.

4-31. He also maintains liasion with the Western Contract Management Region (WCMR) QC representative for mutual assurance that documented inspection and test procedures are adequately performed.

4-32. HEALTH AND SAFETY ADMINISTRATOR. The Health and Safety Administrator is responsible for the establishment and conduct of the SPTF industrial health and safety programs, to ensure compliance with VAFB and AI health and safety codes, regulations, and policies (Section V). He is responsible for the inspection and acquisition of maintenance and calibration of all SPTF safety and firefighting equipment including protective clothing, portable radiation survey instruments, personnel monitoring devices, radiation alarm system, and attendant records. 
4-33. Duties include periodic inspection of work operations as regards industrial health and safety, ascertaining that unsafe conditions are corrected, instruction and training of SPTF personnel on matters relating to radiation safety, industrial health and safety, fire and radiation safety measures, and evacuation drills. In addition, he has an interagency liaison function as regards all matters involving SNAPSHOT safety.

4-34. As a representative of the AI Health and Safety section, the Health and Safety Administrator reports to the Engineering Supervisor in a staff capacity. Reporting responsibility includes the preparation of a weekly SPTF health and safety report.

4-35. DOCUMENTATION AND REPORTING REQUIREMENTS.

4-36. In scope, the documentation program is comprised of manuals, logbooks, and reports. Records used in conjunction with prelaunch operations at VAFB are, for the most part, maintained in logbook form. In respect to the documentation program, all personnel assigned to the SPTF must be cognizant of the following:

a. SPTF and PALC-2 operations must be completely documented.

b. Verbal instructions must be documented prior to work initiation.

c. The only documents recognized as deviation authority are the Procedure/ Design Change Notice and Engineering Order (EO).

4-37. TECHNICAL MANUALS. A set of seven manuals are used to provide descriptions, operations, and procedures relating to the prelaunch program. The seven manuals used to define prelaunch operations are:

a. NAA-SR-MEMO-9351, Shipping Procedures, SanSu to SPTF (Vol. I) and Shipping Procedures, SPTF to PALC-2 (Vol. II).

b. NAA-SR-MEMO-9353, SPTF Facility Operations.

c. NAA-SR-MEMO-9352, NPU Prelaunch Operations - SPTF.

d. NAA-SR-MEMO-9359, NPU Prelaunch Operations - PALC 2.

e. NAA-SR-MEMO-9356, AGE Operation and Maintenance, Mechanical (Vol. I) and AGE Operation and Maintenance, Electrical (Vol. II).

Contents of these manuals are subject to continual evaluation and verification. Changes are issued as revision notices, utilizing the Procedure/Design Change Notice. 
38. LOGBOOK AND DATA RECORDING STANDARDS. Basic requirements for book entries and data recording during the VAFB prelaunch operations are outlined in the following paragraphs. All personnel making logbook or data entries are responsible for observing these requirements:

a. Logbook entries shall be made in chronological order.

b. Reproducible pen shall be used in making logbook entries, and when recording data, as these records will be reproduced for review and data reduction.

c. Logbook entries should be in summary form, but must be legible and sufficiently comprehensive as to be self-explanatory.

d. If an incorrect entry has been made, a single line should be drawn through it and the correct entry made in the space above the line, followed by the initial of the person making the entry. Erasures are not permitted.

e. Standard abbreviations and symbols must be used in logging entries and recording data. Use of nonstandard abbreviations is to be avoided.

f. Logbook entries provide a permanent record of VAFB field unit operations, and as such, are subject to frequent review by AI management personnel. Thus the logbooks and records are a reflection of personnel performance. Profanity and derogatory remarks are not to be used in logbook entries.

4-39. LOGBOOKS.

4-40. All operations relating to prelaunch operations conducted at VAFB are recorded in logbooks designed to cover a specific activity. The individual logbooks are as follows:

a. NPU Verification Log (NAA-SR-MEMO-10537)

b. Facility Log (SPTF)

c. Telecon Log

d. Instṛumentation Maintenance Log

e. AGE Maintenance Log

Of these, the NPU Verification Log is the key document associated with the VAFB prelaunch program. It is the only document which provides a complete record of all action taken to prepare the SNAP $10 \mathrm{~A}$ NPU for flight; input and usage is shown

\footnotetext{
aphically in Figure 4-2. A complete description of the individual logbooks and
} Instructions for use are provided in paragraphs 4-4l through 4-50. 


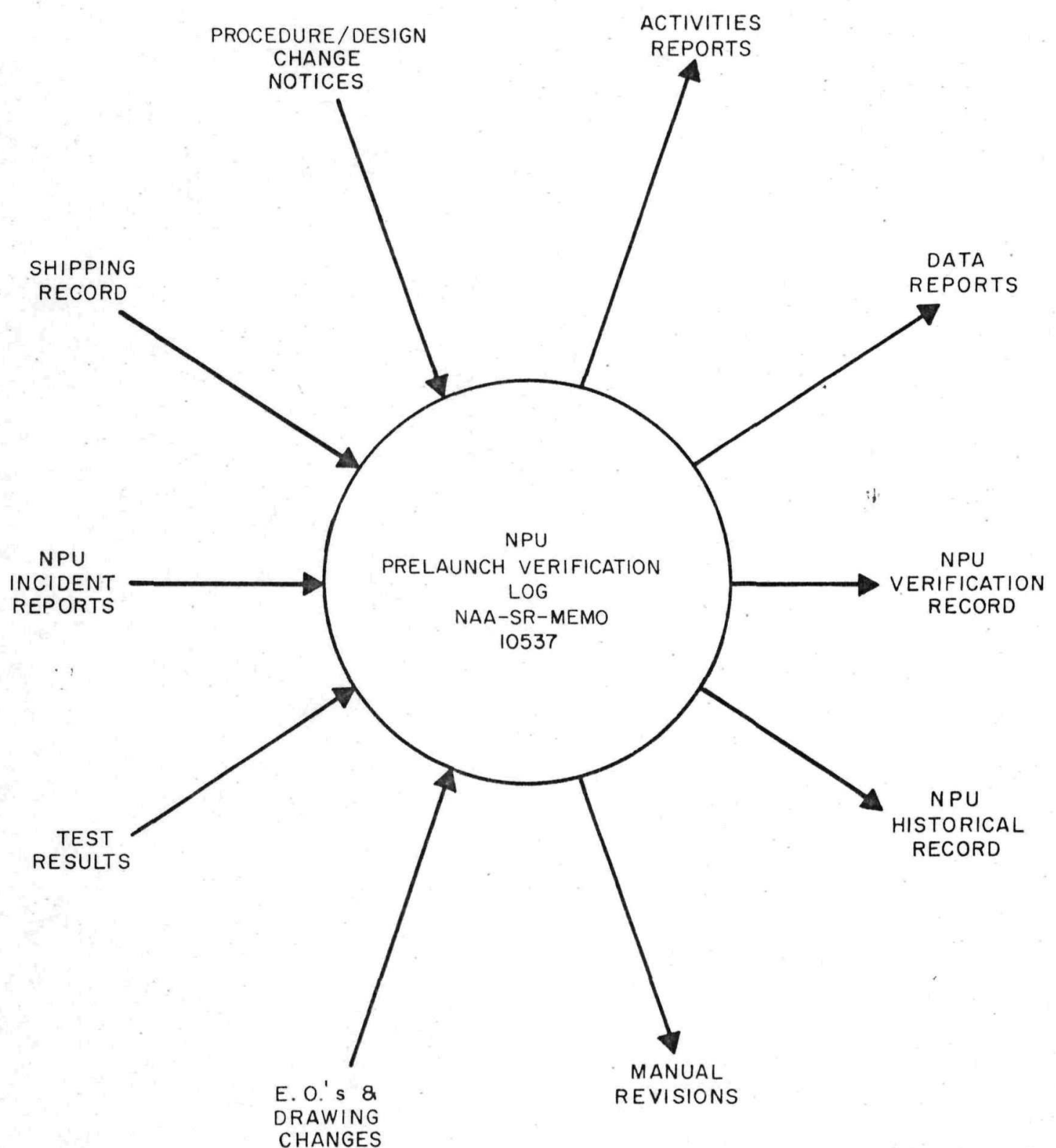

$7561-10116$

Figure 4-2. Chart Illustrating NPU Verification Logbook Input and Usage 
4-41. NPU VERIFICATION LOG. This document shall always accompany the U as it alone provides a complete record of all activities related to NPU prelaunch activities. The logbook is divided into three major sections which relate to activities taking place in Santa Susana, the SPTF, and PALC-2, respectively. Support documents pertinent to log entries are inserted in the appendix of the related volume thus ensuring that each volume provides complete documentation of the applicable activity.

\section{NOTE}

Completion of this document is the responsibility of the Test Conductor, or his designee, for a given pnase of the prelaunch operation.

Each section is divided into several subsections which contain preprinted checkout steps in detail. Each page contains approximately 10 steps in order to provide adequate space for signatures, dates, deviation references, and supplementary information. An addendum sheet (paragraph 4-71) is also available for use in providing further explanation of any unusual action concerning a given step of the checkout procedure.

4-42. Pages of the logbook are reproducible and must be filled out with reproducible pen. At the start of each working day, the unit secretary makes three copies of the page(s) covering activities of the preceding day. One copy is inserted in a duplicate $\log$ which is kept in the Engineering Supervisor's office; the remaining two copies are forwarded to the SNAP 10A Chief Project Engineer at Canoga Park. The original page(s) are returned to the master logbook. A sample page with instructions for completion is shown in Figure 4-3.

\section{NOTE}

In the event of an emergency evacuation, the Engineering Supervisor will attempt to remove the NPU Verification Log from the SPTF.

4-43. FACILITY LOGBOOK. The Facility Logbook provides a chronological record of non-NPU activities related to SPTF operation. The logbook is located at the receptionist desk for use by both day and shift personnel. Entries relating to Cility operation and activities are the responsibility of the Engineering Supervisor designee. Pertinent logbook entries include, but are not limited to, the following: 


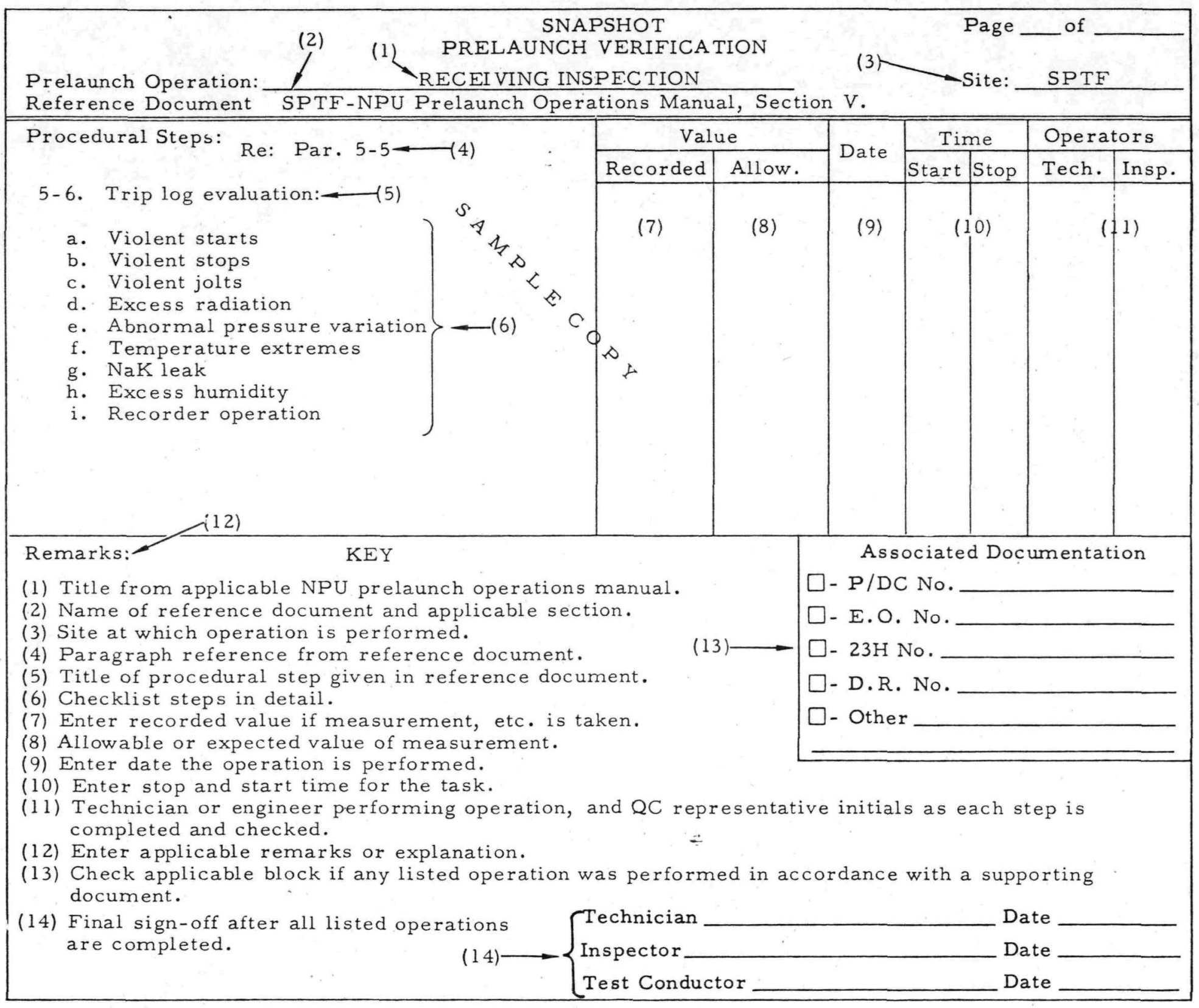


a. Preventive maintenance action on facility and/or systems.

- Building modification(s).

c. Evacuation drills.

d. Shift-end summaries.

A sample logbook page with instructions for completion is shown in Figure 4-4.

4-44. VISITORS REGISTER. Definitions and procedures relating to visitors are presented in the SPTF Security Plan (Appendix A). All visitors are required to register before entry to the SPTF is permitted. The form used for registration is illustrated in Figure 4-5.

4-45. In the event of an emergency evacuation, AI personnel hosting a visitor shall direct the visitor to the emergency evacuation area.

4-46. TELECON LOGBOOK. The Telecon Logbook provides documentation of all business calls handled at the SPTF. A brief summary of every business conversation is entered in the Telecon 10 , to avoid possible misunderstanding and duplication of effort as the result of verbal communications.

4-47. Individual form pads are provided at each phone in the SPTF for use by all employees who either initiate or receive a telephone call for business purposes. It is the responsibility of each employee to record the conversation and forward the copy to the unit secretary for filing in the Telecon Logbook. Entries shall include the following information:

a. Date, time, and names of caller and person called.

b. Place called (outgoing) or origin of call (incoming).

c. Purpose of the call (summarize briefly).

When action is required, as the result of a telephone conversation, the form becomes an AVO unless a change in previously documented procedure is involved. In the latter case, a Procedure/Design Change Notice is required to initiate action. The page format used for the Telecon Log is shown in Figure 4-6.

4-48. INSTRUMENTATION MAINTENANCE LOG. This logbook is used to record maintenance, repair, and calibration of electronic and mechanical test instruments. Logbook entries shall contain sufficient detail, including diagrams when applicable, to be clearly understood by other trained personnel. The form shown in Figure 4-4 used for this log. 


\section{ATOMICS INTERIVATIONAL}

A Ditision of North American Aviation, Inc.

(1) - FACILITY OPERATIONS

\section{(2) ITEM/TASK DESCRIPTION}

1. Practice emergency evacuation drill

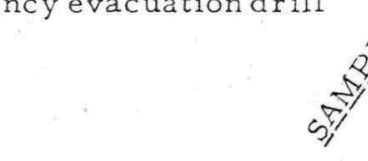

\section{* SNAPSHOT*}

OPERATIONS SUPPORT LOG

$\square$ - A.G.E. MAINT./MOD.

$\square$ - INSTRUMENTATION CALIB /REPAIR

A.G.E. MAINT./MOD. $\square \square$

SITE TINIE DATE SIGNATURE

\section{EXPLANATION OF NUMBER KEYED ITEMS}

(1) Page indentification: check this box for all pages inserted in facility log.

(2) Describe item or task in this column, identifying same by sequential number.

(3) Enter related explanatory remarks, using matching sequential number.

(4) Indicate site at which operation was performed, i. e., SPTF, PALC-2

(5) Enter start anci stop time.

(6) Enter date on which task or operation was performed.

(7) Signature of person performing the task or operation.

$$
\text { NOTE }
$$

$$
1
$$

This same basic form is used for the Facility Log; AGE Log, and Instrument Log. In each case the procedure for using the form is the same. Check the appropriate block at the top of the page to indicate the logbook to which the page applies.

(4)

Startstop

1. Practice drill initiated by sounding fire alarm, Building evacuated in orderly fashion and all personnel accounted for. Conducted short briefing on evacuation procedures 
DOD PERSONNEL ACKNOWLEDGE FAMILIARITY WITH AFPI 1.402 (C) ANO 53-404.2 (K)

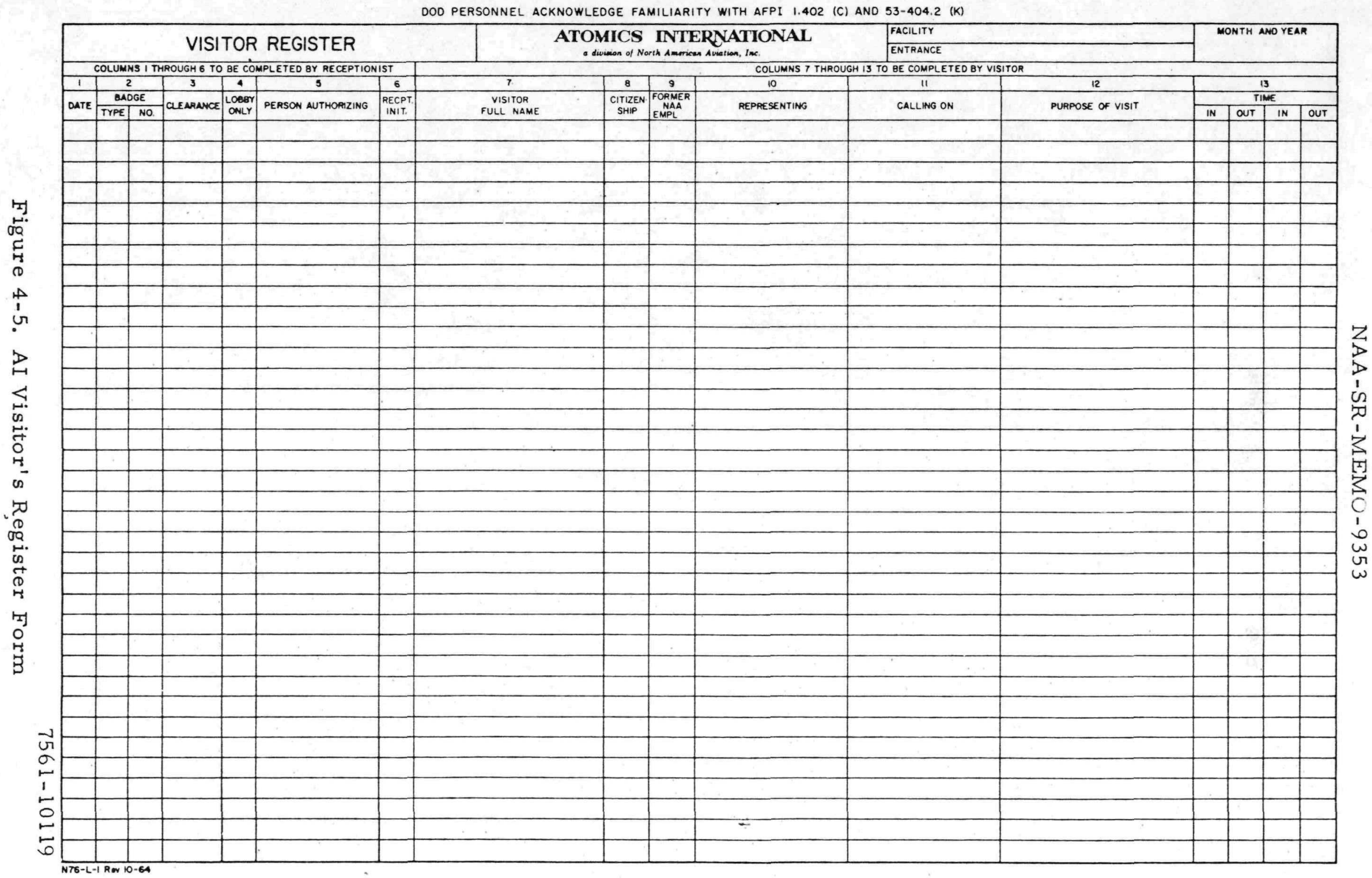

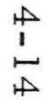




$$
\text { NAA-SR-MEMO-9353 }
$$

Paragraph 4-48 to 4-53

The logbook shall remain in the instrument laboratory at all times. Entries are the responsibility of instrument personnel who perform the particular operation. changes in logged entries are permitted without permission of the person responsible for the entry. Copies of the entries shall be made available to the Support Analyst for possible inclusion in the activities reports. Responsibility for logbook accuracy and completeness rests with the Support Equipment EngineerElectrical.

4-49. AGE MAINTENANCE LOG. The AGE Maintenance Log provides a record of all maintenance, repair and/or calibration of AGE equipment. Using the same form as that shown in Figure 4-4, the $\log$ is divided into two major sections, one covering the electrical AGE equipment, the other the mechanical AGE equipment. Maintenance of support equipment is accomplished at the SPTF; the configuration control and records of AGE action taken at the facility are recorded in this document. Copies of logbook entries and related Procedure Design Change Notices which affect AGE design are forwarded to Canoga Park for drawing revisions.

\section{NOTE}

In the event the NPU is affected as a result of AGE malfunction or procedure, an entry as to cause, effect, and correction must be made in the appropriate logbook.

4-50. Responsibility for maintaining the logbook rests with the Mechanical Engineer in charge of handling and assembly. However, it is the duty of the Handling/ Assembly Technicians to log the required information.

\section{4-51. REPORTING REQUIREMENTS.}

4-52. Periodic reports are used to keep management and project personnel, and other agencies associated with the project, informed as to prelaunch activities and progress. The reporting activity also serves to round out the overall documentation program, resulting in a chronological summary of field unit operations. Basic reporting requirements applicable to the VAFB prelaunch operations program are described in paragraphs 4-53 through 4-65.

4-53. THE MORNING (DAILY) REPORT. This report summarizes the previous day's activities, providing a brief recap of SPTF and/or NPU operations. The morning report serves to keep management and staff personnel informed of prelaunch operations progress as well as problems encountered. The report is prered by the Staff Assistant, using input provided by the Test Conductor, and distributed per a distribution list provided by the Engineering Supervisor. The 
report is prepared by the Staff Assistant, using input provided by the Test Conductor, and telephoned directly to the Program Manager's office at Canoga Park headquarters. Distribution will be per a list provided by the Program Manager.

4-54. WEEKLY ACTIVITIES REPORT. A report covering prelaunch activities is prepared on a weekly basis for AI headquarters management and project personnel. This report provides a current account of prelaunch operations activities and progress. It is a concise summary of information provided in logbook entries and other records used at the facility.

4-55. The report is prepared by the Engineering Supervisor's staff and is subject to his approval. Key individuals responsible for each phase of prelaunch activity are required to submit weekly reports covering activities under their jurisdiction, for inclusion in the report. The individual reports should follow the following 4-step format:

a. Schedules for the week (report period),

b. Schedules accomplished to data,

c. Current or potential problems and suggested solutions, and

d. General information or recap of activities.

4-56. The weekly activities report is due at Canoga Park headquarters no later than Wednesday of the week following the report period.

4-57. HEALTH AND SAFETY REPORTS. Reporting of activities and incidents relating to industrial health and safety is the responsibility of the Health and Safety Administrator. These reports are submitted to the Industrial Health and Safety section at Canoga Park. This reporting function covers the two areas described in the following paragraphs.

a. Weekly Activities Report: This is a routine report covering the industrial and nuclear safety aspect of prelaunch operations at VAFB. The report is included with the weekly report covering field operations activities, to provide complete coverage of all field activities.

b. Lost time due to incidents (AI Form 92).

c. For any injury requiring medical aid, State Form 5020 is prepared and submitted to the State of California.

d. For any injury incurred by an employee (AI Form 74K). 
4-58. INCIDENT REPORTS. Internal reporting requirements for incidents at AFB are as follows:

a. Report from AI Engineering Supervisor to AI Industrial Security,

b. Report from AI Engineering Supervisor to AI management, through proper channels, and

c. Report from the AI Health and Safety Administrator to the Chief, AI Health and Safety Section.

In no case shall an internal report covering an incident at VAFB constitute an official release of information concerning these incidents. The reports will be classified in accordance with appropriate AEC or DOD directives, or, in the absence of such classification requirements, will be designated as "Company Official" until released by AI management.

4-59. All incidents involving personal injury, property damage, unusual events (contamination) or situations will be reported to the AEC in accordance with the AEC manual and AI-SOP B-24.

\section{NOTE}

Internal reporting requirements include auto accidents which occur while an employee is on company business.

4-60. QUARTERLY PROGRESS REPORT. This report is prepared by the Staff Assistant, using the information contained in the weekly reports. Upon approval by the AI Engineering Supervisor, the report is forwarded to the AI project unit at Canoga Park. This report is due in the headquarters office no later than two weeks subsequent to the quarter being reported.

4-61. EMPLOYEE EXPENSE REPORT. Each employee is required to submit a weekly expense report (Sunday through Saturday) in accordance with AI-SOP F-10, Section V, "Travel and Travel Expense."

4-62. DATA REPORT. The data report is used to document test completion data and equipment malfunctions or anomalies and to report that condition to the responsible project personnel. Initiation of the Data Report Form is at the discretion of the Test Conductor and/or the Support Analyst. The intent is to report all malfunctions, removals, replacements, repairs and completion of a test sequence. e discretionary part of initiating this report is based upon a judgment of whether a given out-of-tolerance condition is a malfunction or operational anomaly. 
4-63. A malfunction must be reported by means of the Data Report even if shift personnel correct the trouble. In this manner information is provided for maintainability and reliability analysis. Additional analysis of a given malfunction is at the discretion of the project staff. Complete instructions for use of the document are given in the Division Operating Manual (DOM), procedure 1-8. A sample of the form is shown in Figure 4-7. Upon completion of the form, a copy is filed in the office of the Engineering Supervisor and the remainder of the package is forwarded to the Reliability Data Center at Canoga Park.

\section{NOTE}

Use of this form is redundant to a degree as the NPU Verification Log will also contain the information and will reference all supporting documents.

4-64. TOPICAL REPORTS. A review and summarization of the NPU prelaunch operations program conducted at VAFB shall be presented in a topical (NAA-SR) report following culmination of the SNAPSHOT effort. Additional reports may be initiated as deemed necessary to provide historical documentation of the SNAPSHOT program.

4-65. CONTROL FORMS. A minimum of forms are used to achieve configuration control throughout the VAFB prelaunch operations program. Each is designed to simplify form usage without compromising the overall objectives of the program.

\section{4-66. PROCEDURE/DESIGN CHANGE NOTICE.}

4-67. This is the primary document authorizing a change to the approved NPU prelaunch procedures, SPTF operations (excluding administration) and health and safety procedures. The document provides the means for initiating modifications and/or changes as the need arises. In this respect it supplements the NPU Verification Log, providing a written record showing authorization for the modification and/or change. Copies of P/DCN's which affect the technical manuals will be forwarded to each manual holder.

4-68. A sample of the form is shown in Figure 4-8; its use is applicable to the following conditions:

a. To supplement a verbal instruction from the Test Conductor or Engineering Supervisor regarding alteration of a procedure, removal, repair, or replacement of a component. 


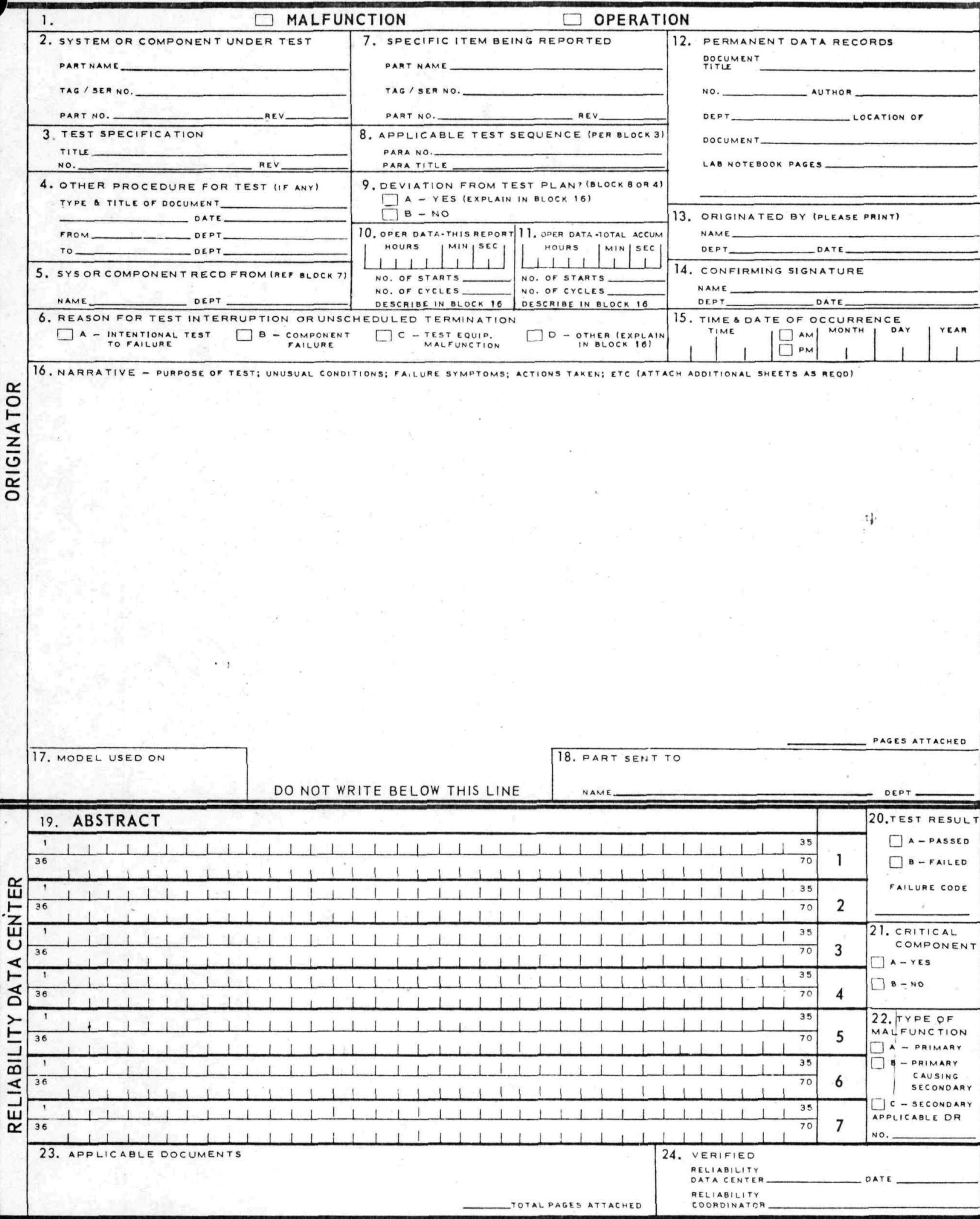

Figure 4-7. Data Report Form 


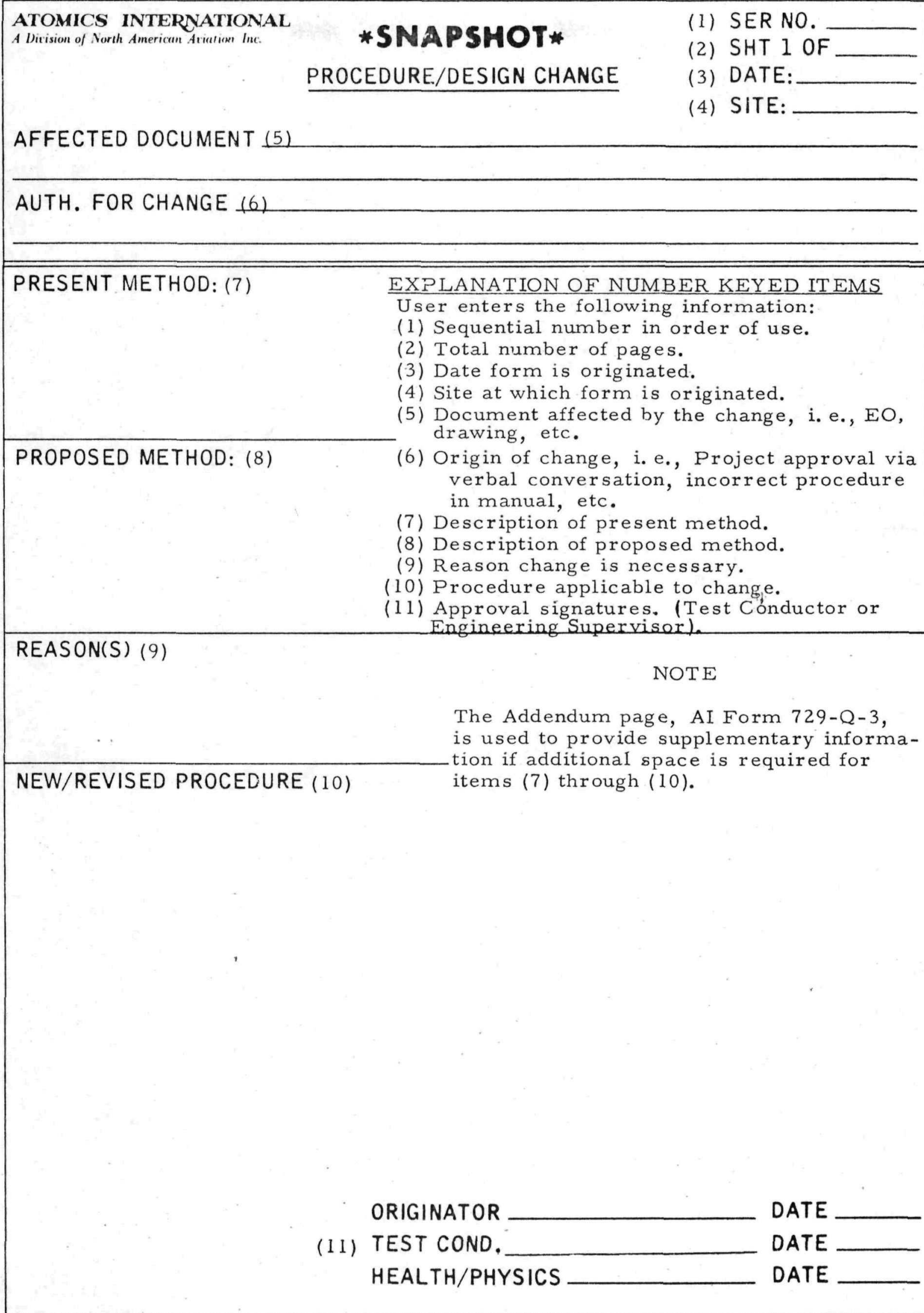

FORM 729-Q-3 NEW 9-64 (PAGE 1)

Figure 4-8 . Procedure/Design Change Form 


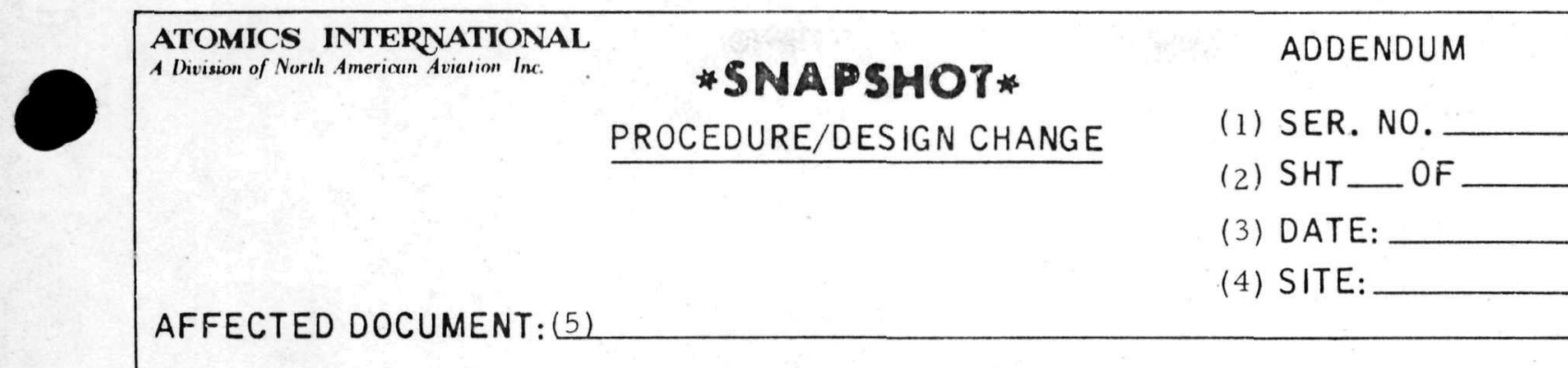

SUPPLEMENTING INFORMATION: (6)

EXPLANATION OF NUMBER KEYED ITEMS

(1) Serial number from applicable P/DC page.

(2) Sequential page number of total number of pages.

(3) Date form is originated; should be same as that shown on P/DC page.

(4) Site at which form is originated.

(5) Same information as appears on applicable P/DC page.

(6) Continuation of information or data carried over from applicable P/DC page. Include drawings, sketches and/or data as may be necessary to clarify the change.

(7) Approved Signatures, Test Conductor or Engineering Supervisor.

ORIGINATOR DATE:

(7) TEST COND. DATE: HEALTH/PHYSICS DATE:

Figure 4-9. Addendum Page for Procedure/Design Change Form 
b. To supplement and document a verbal instruction, regarding any of the aforementioned changes, from the SNAP'10A Chief Project Engineer at AI headquarters. In the event an interpretation of a specific procedural requirement or out-oftolerance condition is involved, use of the form is at the Test Conductor's discretion since a change may or may not be involved. If an out-of-tolerance condition is accepted, and no change is involved, the reason for accepting the condition is recorded in the NPU Verification Log in order to maintain documentation continuity. 4-69. FORM CONTROL. To provide a means of form control, the P/DCN form is available only from the unit secretary. At time of issue, a serial number is assigned to the form and also recorded in a serialization log which is maintained by the secretary. Distribution of the completed and approved form is as follows:
a. Original and one copy to a P/DCN master file.
b. One copy to the related section of the master NPU Verification Log.
c. One copy to the duplicate NPU Verification Log.
d. Three copies to SNAP 10A Project Office at AI headquarters.
e. One copy to Support Analyst.

4-70. ENGINEERING ORDERS (EO). Engineering Orders will not be originated at VAFB. In the event the headquarters project unit originates an EO which is applicable to NPU-VAFB prelaunch operations, the EO will be worked as received at VAFB. No additional authorization documentation is necessary.

\section{NOTE}

Engineering Orders released by the SNAP 10A Project unit will not be supplemented by a Procedure/Design Change Notice.

4-71. ADDENDUM PAGE, NPU VERIFICATION LOG. This form is used to provide additional information concerning a given task or malfunction, such as expanding a description, when there is insufficient space for this detail in the logbook page. The form is completed in the same manner as the NPU Verification Log sheet (Figure 4-3) by the person making the entry in the logbook. The form is then inserted in the logbook, adjacent to the affected checkout step and/or additional documentation, if any. A sample page is shown in Figure 4-10. 
Page _of

Prelaunch Operation: Site:

Procedural Step(s) Ref.

Associated Documentation $\square$ - P/DC No.

$\square$ - E.O. No.

$\square-23 \mathrm{H}$ No.

$\square$ - D.R. No.

$$
\square \text { - Other }
$$

Technician Date Inspector Date Test Conductor Date 
4-72. MATERIAL REQUEST. This form is used by all employees when requesting NPU or AGE-related materials and/or spare parts stocked in the SPTF. The form provides a means of maintaining a perpetual inventory, to facilitate restocking and maintenance of an adequate stock on hand. Use of the form, which is shown in Figure 4-11, is self-explanatory.

4-73. INVENTORY CONTROL CARD. Primarily the responsibility of the Maintenance Technician, the inventory control card is used in maintaining a perpetual inventory of all accountable items stocked at the SPTF. Individual cards are used for each item stocked, and are maintained in alpha-numerical order. The card, which is illustrated in Figure 4-12, is maintained according to standard practices for perpetual inventory control.

\section{4-74. SPTF OPERATING RULES.}

4-75. The general rules pertaining to SPTF operations and activities are summarized in the following paragraphs. These rules are not all-inclusive but are intended to supplement those set forth in other sections of this and companion manuals relating to the VAFB prelaunch program.

4-76. TECHNICAL DIRECTION. The Test Conductor, or his designee, is in immediate charge of all NPU tests, operations, and/or activities performed in the SPTF and NPU activities at PALC-2. He has full authority to terminate any operation or test in progress if, in his opinion, personnel or equipment are endangered.

4-77. SAFETY. Standard safety practices as set forth in the AI Safety Standards Manuals are applicable to all SPTF operations. All personnel assigned to the SPTF are expected to be familiar with, and to comply with, these practices and the SPTF safety rules set forth in Section V of this manual.

4-78. PERSONNEL CONDUCT. Personnel assigned to the SPTF and VAFB prelaunch program shall conduct themselves in accordance with established policies and procedures of Atomics International.

4-79. USE OF AGE EQUIPMENT. The movement of SNAP 10A units and components in and about the facility shall be done with the AGE equipment designed for this purpose. The Mechanical Engineer in charge of handling and assembly, or his designated alternate, shall direct all such movements. 


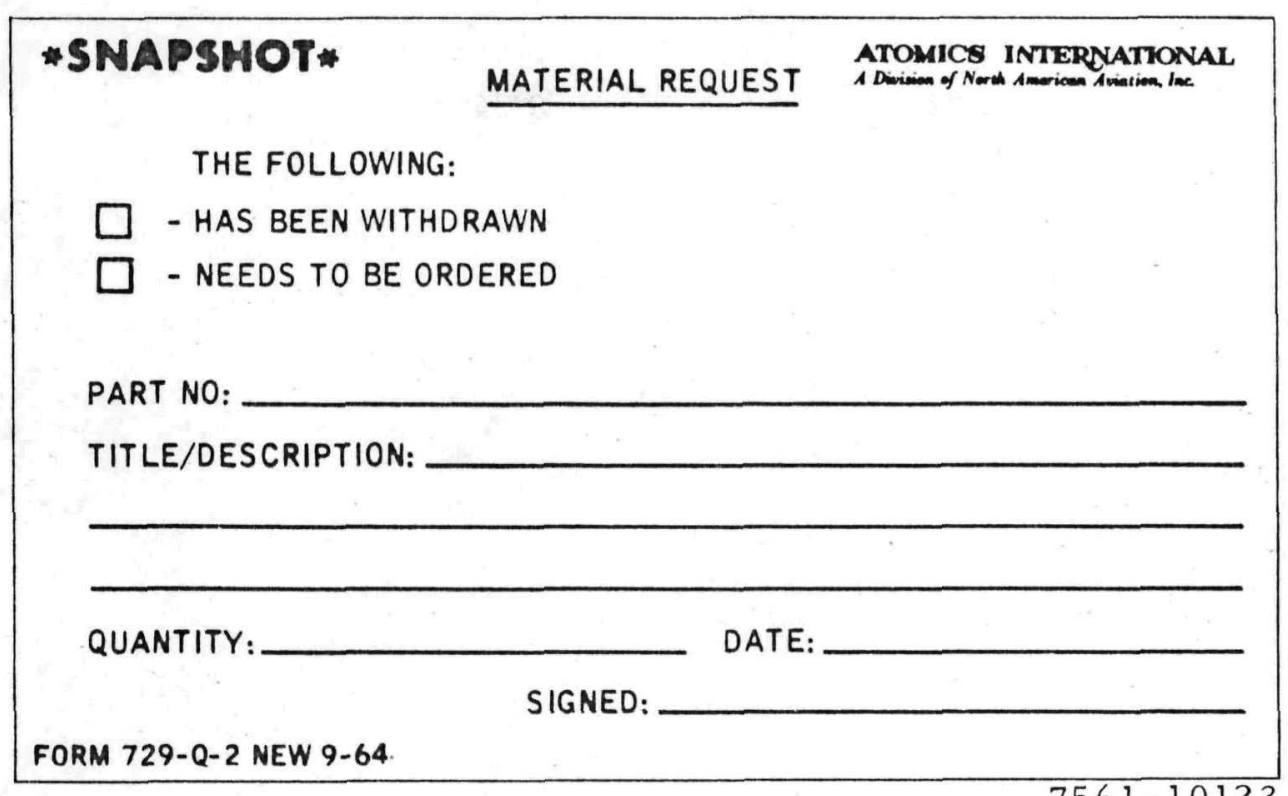

Figure 4-11. SPTF Material Request Form

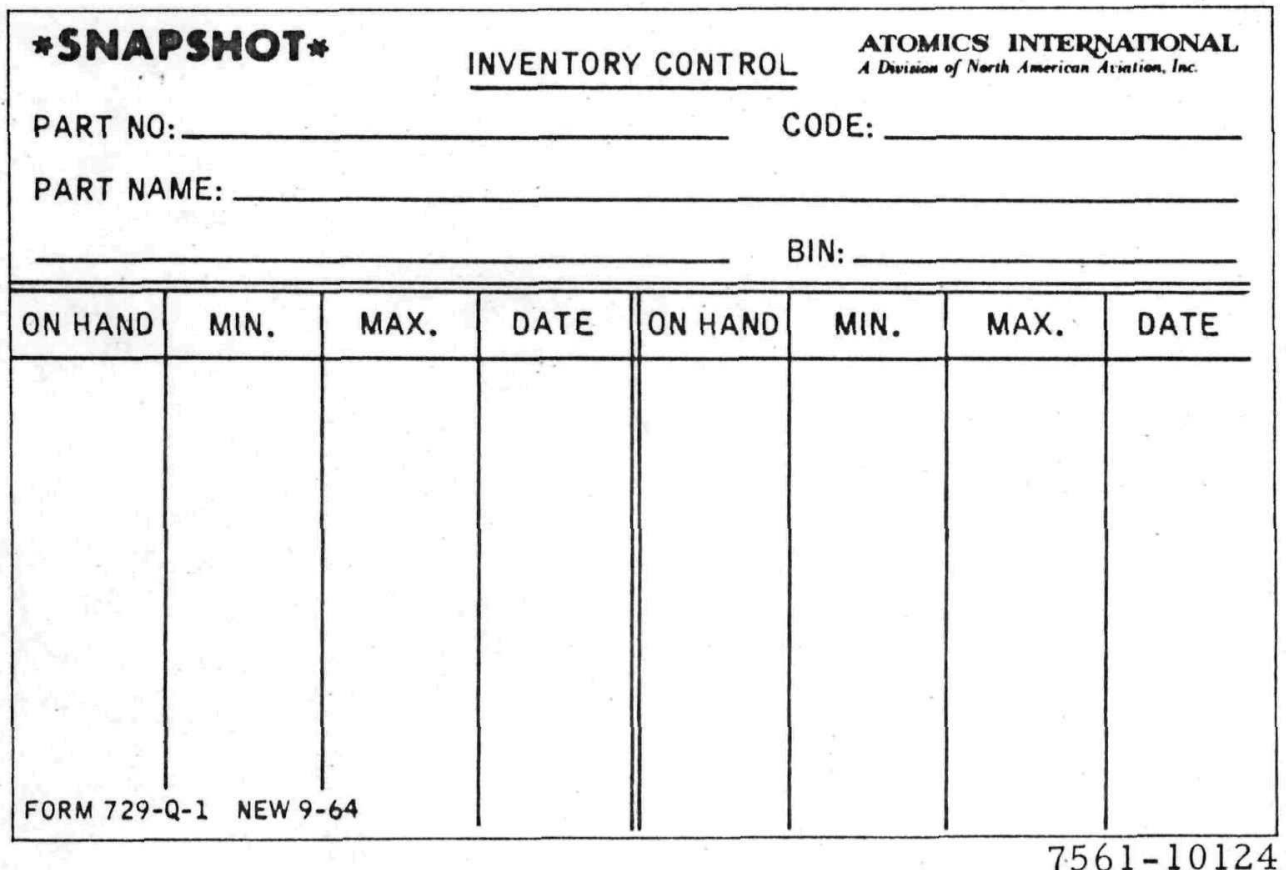

Figure 4-12. Inventory Control Form Used At The SPTF 
4-80. STOCK CONTROL. A Material Requisition form shall be used for withdrawal of parts and supplies stocked in the storage room. The form shall be completed for such removal, regardless of whether or not an attendant is present. In the event it is necessary to return materials to AI headquarters, appropriate packaging materials will be obtained and the materials packaged at the SPTF. Packaging of hazardous materials shall be carried out under the direction of the Health and Safety Administrator. Arrangements for return shipments will be made by the Base Administrator.

4-81. TEST LIMITS. Established limits set forth in test and operations procedures shall not be exceeded without specific approval of the Engineering Supervisor or Test Conductor. In the event such approval is forthcoming, a Procedure/Design Change notice shall be initiated.

4-82. ENTRY INTO HIGH BAY AREA. The number of persons in the high bay area shall be limited when SNAP $10 \mathrm{~A}$ units are stored therein or when tests are in progress. Entry limitations are at the discretion of the Engineering Supervisor, or, when a test is in progress, the Test Conductor. During assembly operations, only persons with specific work assignments are permitted in the area; any exception is at the discretion of the Test Conductor. During performance of a testing or assembly operation, permission for entry into the roped-off work area adjacent to the SNAP 10A unit is at the discretion of the Test Conductor.

4-83. PERMISSIBLE NUMBER OF SNAP UNITS IN THE SPTF. No more than two SNAP units shall be permitted in the high bay area at any given time.maintaining a minimum separation distance of 12 feet. The high bay access door shall be kept locked when a NPU is in the building. Keys to this door are controlled by the Engineering Supervisor and Base Administrator.

4-84. DESIGN CHANGES. NPU design changes, modifications or repairs are not permitted unless authorized by a Procedure/Design Change notice or an Engineering Order (paragraph 4-70) which bears the necessary approval signatures.

4-85. INDUSTRIAL SECURITY.

4-86. Industrial security measures maintained at the SPTF shall be in accordance with the Security Plan presented in Appendix A.

4-87. TRAINING.

4-88. Safety training is emphasized at the SPTF to ensure that all personnel are familiar with applicable procedures and equipment. Training activities are confined primarily to the safety aspect of VAFB prelaunch operations. Briefing 
sessions are conducted as necessary to indoctrinate personnel in AEC and VAFB urity measures.

4-89. On-site safety training includes, but is not necessarily limited to, emergency procedures, evacuation drills, and SPTF operations. The safety training program conducted at the SPTF is under the direction of the Health and Safety Administrator. Training activities are coordinated with the Engineering Supervisor and Test Conductor to avoid interruption of prelaunch operations schedules and to ensure that operations personnel are cognizant of applicable safety procedures. 4-90. Safety training includes evacuation drills (Section V) which are conducted periodically to familiarize facility personnel with evacuation procedures. In addition, operations personnel are instructed in emergency procedures and assigned specific duties to follow in the event of an incident requiring emergency action. 


\section{SECTION V \\ INDUSTRIAL AND NUCLEAR SAFETY}

5-1. SPTF SAFETY PROGRAM.

5-2. The SPTF safety program is designed to maintain safety requirements es tablished by Atomics International and the AEC. Responsibility for the industrial health and safety of all individuals at the SPTF rests with the SPTF Engineering Supervisor. Support in this responsibility is provided by the Health and Safety Administrator who provides guidance, makes recommendations and assists in ensuring compliance with the safety regulations. Strict operational and administrative procedures are followed to assure safe operation of the facility and to minimize radiological hazards.

5-3. HAZARDS ANALYSIS. The SNAP $10 \mathrm{~A}$ prelaunch test program conducted at the SPTF is planned to preclude the possibility of the NPU reactor achieving a critical configuration. The SPTF Safeguards Analysis NAA-SR-MEMO-8685, considers two types of accidents, nuclear and non-nuclear, with the conclusion that only non-nuclear accidents are credible. Both types are discussed in paragraphs 5-4 and 5-6. Potentially hazardous materials associated with SPTF operations are listed in Table 5-1.

\begin{tabular}{|c|c|c|c|}
\hline $\begin{array}{l}\text { Material or } \\
\text { Condition }\end{array}$ & $\begin{array}{l}\text { Source or } \\
\text { Item }\end{array}$ & $\begin{array}{l}\text { Amount } \\
\text { Present }\end{array}$ & Remarks \\
\hline Fission products & SNAP $10 \mathrm{~A}$ unit & $\left|\begin{array}{c}\sim 10 \mathrm{mc} \\
\text { (negligible })\end{array}\right|$ & $\begin{array}{l}\text { Residual product resulting } \\
\text { from acceptance tests }\end{array}$ \\
\hline Lithium-hydride & $\begin{array}{l}\text { NPU radiation } \\
\text { shield }\end{array}$ & $\sim 180 \mathrm{lb}$ & $\begin{array}{l}\text { Standard safety precautions } \\
\text { applicable }\end{array}$ \\
\hline Beryllium & $\begin{array}{l}\text { NPU reactor reflec- } \\
\text { tor as sembly }\end{array}$ & $731 b$ & $\begin{array}{l}\text { Standard safety precautions } \\
\text { applicable }\end{array}$ \\
\hline $\mathrm{NaK}$ & $\begin{array}{l}\text { NPU power conver- } \\
\text { sion system }\end{array}$ & $291 \mathrm{~b}$ & $\begin{array}{l}\text { Standard safety precautions } \\
\text { applicable }\end{array}$ \\
\hline Uranium fuel & NPU reactor & $341 \mathrm{mc}$ & $\begin{array}{l}\text { No significant amount re- } \\
\text { leased in the event of an } \\
\text { accident }\end{array}$ \\
\hline
\end{tabular}

Table 5-1. Potential Hazards - NPU Operations 
5-4. NUCLEAR HAZARDS. The possibility of an accident causing reactor iticality is judged incredible because: (a) no nuclear testing will be performed in the SPTF, and (b) mechanical safeguard components and controlled administrative procedures are used to ensure subcriticality under all conditions.

5-5. The mechanical safeguard components listed in Table 5-2 are designed to provide positive assurance of a subcritical condition. Reactor safeguards are illustrated in Figure 5-1. Only by deliberate physical alteration of the protective features would it be possible to add enough reactivity for the reactor to become critical.

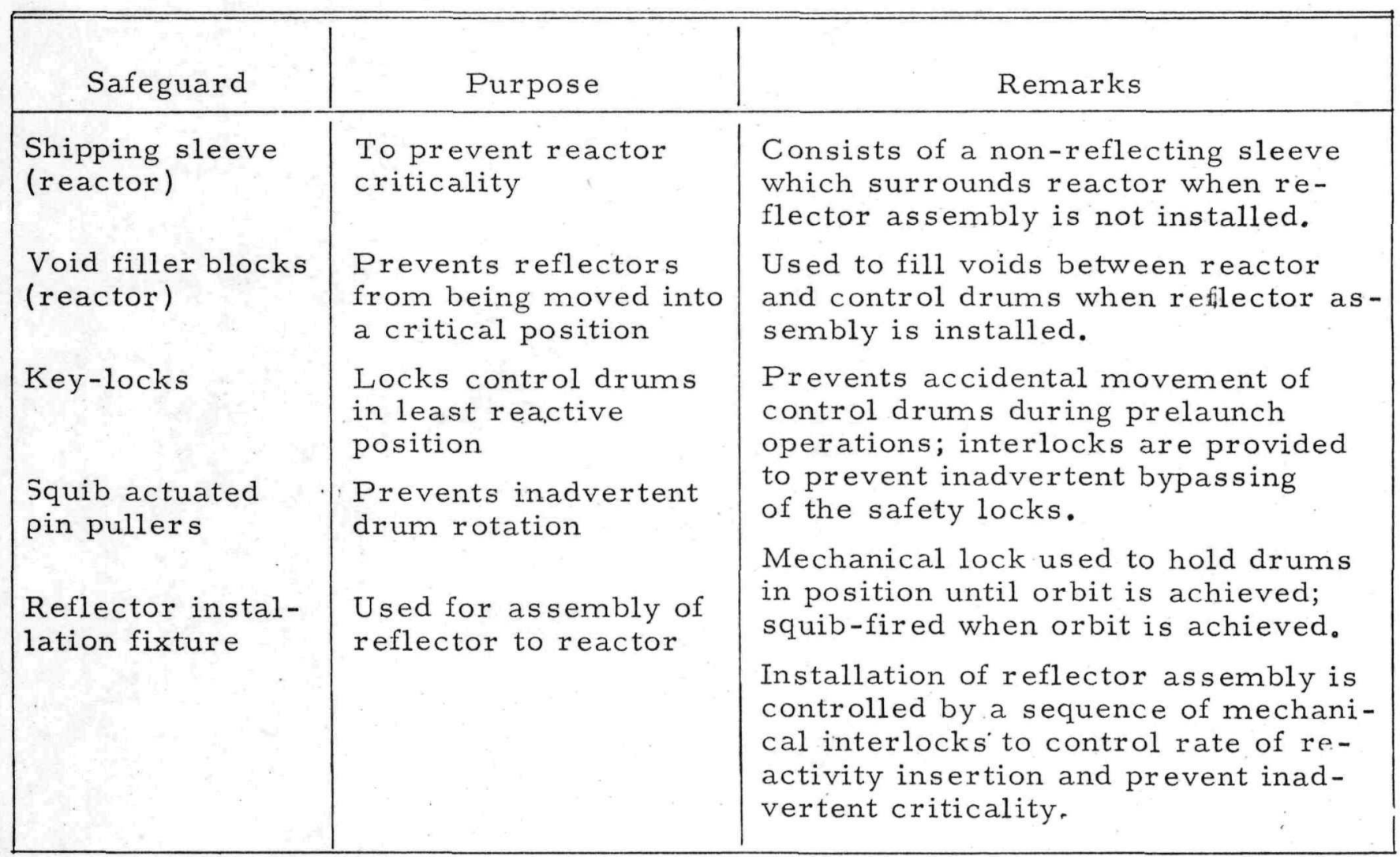

Table 5-2. NPU Mechanical Safeguards

5-6. NON-NUCLEAR HAZARDS. The presence of lithium-hydride, NaK, and beryllium present potential hazards in the event of a non-nuclear incident during prelaunch operations conducted at the SPTF and PALC-2. The safeguards analysis indicates that the most hazardous accident would be one resulting from a NaK fire. Therefore, a NaK fire in the immediate vicinity of the reactor core is defined as the Maximum Credible Accident (MCA). 


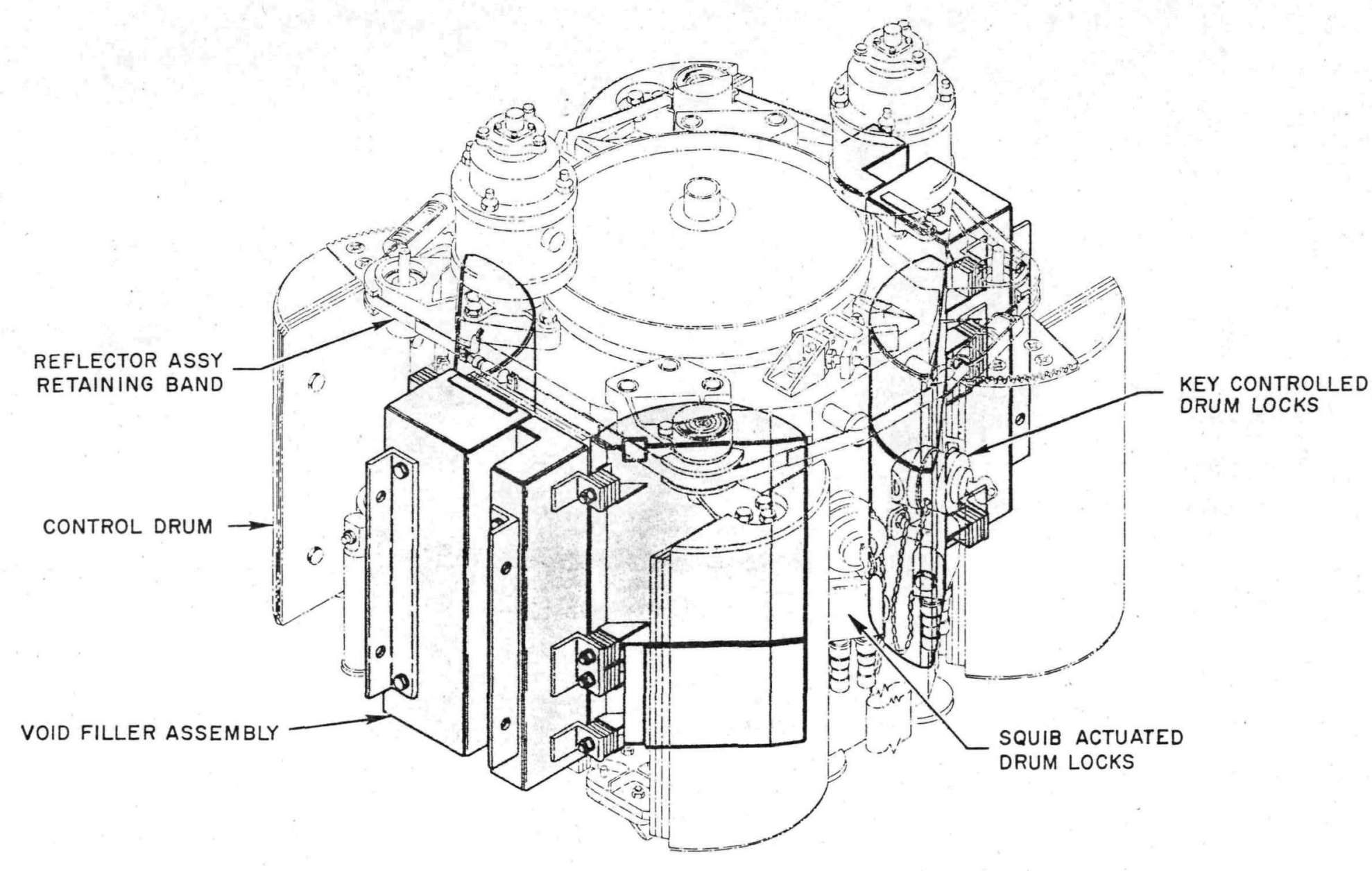


The consequences of a fire of this nature are explained in detail in the feguards Analysis, NAA-SR-MEMO-8685. The conclusion is that an incident of this type provides ample time for personnel to either leave the facility or to put on proper respiratory equipment. The safeguards analysis also establishes that all operations performed in the SPTF are adequately protected by features in NPU design, test and handling equipment design and operating procedures, and building design and location.

5-8. SODIUM-POTASSIUM HAZARDS ( $\mathrm{NaK}$ )。 NaK is an alloy of the metals sodium $(\mathrm{Na})$ and potassium $(\mathrm{K})$, the composition of which may vary slightly but within specific limits. Composition of NaK used in the NPU is $22 \%$ sodium by weight and $78 \%$ potassium by weight. This forms the lowest melting point $\left(9.95^{\circ} \mathrm{F}\right)$ of the two metals and is therefore known as eutectic NaK.

5-9. Typical of alkali metals, NaK is very reactive chemically. Auto ignition occurs readily when $\mathrm{NaK}$ is exposed to normal atmospheric conditions. NaK fumes resulting from combustion are hazardous and necessitate that protective equipment be worn by personnel combating NaK fires. Fire fighting and cleaning materials such as water, carbon tetrachloride, trichloroethylene and $\mathrm{CO}_{2}$ are dangerous when placed in contact with $\mathrm{NaK}$.

\section{CAUTION}

Only dry powder extinguishers such as calcium carbonate or MET-L-X are to be used in combating NaK or LiH fires.

5-10. LITHIUM HYDRIDE HAZARDS. The NPU radiation shield contains lithium hydride which, by itself, presents essentially the same potential hazards as does NaK. However, as the lithium hydride is in massive form and is completely contained within the shell of the shield there is little possibility of the material presenting a hazardous condition during NPU prelaunch operations conducted at the SPTF. 5-11. BERYLLIUM HAZARDS. Beryllium is a hard, grayish light-weight metal having a melting point of $2332^{\circ} \mathrm{F}$ and a density of $1.85 \mathrm{gm} / \mathrm{cm}^{3}$. Metallic Be is used in solid form for the neutron reflector as sembly in the SNAP I0A reactor as sembly.

5-12. Be oxidizes readily when exposed to air; the oxide is a white powder having a melting point of $4586^{\circ} \mathrm{F}$. The resulting oxide $(\mathrm{BeO})$ is toxic and it, as well as direct, prolonged exposure to Be, is hazardous. For this reason, proper personnel otective measures must be observed when working with or about beryllium. 
5-13. Be or BeO must enter the body or skin in order to cause damage. The more common methods of entry are through the mouth, nose, eyes and skin abrasions. Standard personnel protective measures consist of wearing proper protective clothing and observing the exposure limits. Personnel protective measures and exposure limits are listed in Table 5-3.

\begin{tabular}{|c|c|}
\hline Work Condition & $\begin{array}{c}\text { Protective Measure or } \\
\text { Exposure Limit }\end{array}$ \\
\hline Be present in immediate work area & Area posted as a Be controlled area. \\
\hline Possible physical contact with Be & Rubber or vinyl gloves required. \\
\hline Excessive Be surface contamination & $\begin{array}{l}\text { Green trimmed coveralls and shoe covers } \\
\text { required. }\end{array}$ \\
\hline $\begin{array}{l}\text { Avg. airborne concentration of } \mathrm{Be} \\
\text { is }>2 \mu \mathrm{gm} / \mathrm{m}\end{array}$ & $\begin{array}{l}\text { Respiratory protection, in addition to the } \\
\text { above listed items, is required. }\end{array}$ \\
\hline
\end{tabular}

Table 5-3. Personnel Protection, Beryllium Hazards

\section{5-14. INDUSTRIAL HEALTH AND SAFETY.}

5-15. RESPONSIBILITY. The provisions of Atomics International Safety Standard No. 3 applies to all operations performed by AI personnel at VAFB. The Health and Safety Administrator assigned to the SPTF is responsible for supervising and assisting in implementing the safety practices set for th in this manual and in pertinent AI safety manuals. The scope of responsibilities and activities are given in Table 5-4.

5-16. FIRST AID SUPPLIES. First aid supplies are maintained in a first aid cabinet located in the corridor on the wall across from the facility rest rooms. Any supplies removed from the cabinet must be noted and signed for on the first aid log sheets provided in the cabinet. The Health and Safety Administrator must also be informed of any injury regardless of how minor it may seem.

5-17. EMERGENCY EVACUATION KIT. A special evacuation kit containing first aid supplies and radiation monitoring kit, all mounted on a wheeled cart, is located just outside the guard shack. This kit is for emergency use only and shall not be used as a source of supply for first aid items. The cart shall be taken to the emergency assembly area in the event of an emergency evacuation of the SPTF (par. 5-59). 


\begin{tabular}{l|l|l}
\hline Responsibility & Scope $\quad$ Action
\end{tabular}

\section{Personnel} Education and Training

Personnel Monitoring Program
Industrial hygiene

Safety practices

Radiation protection methods and practices

Fire fighting methods

Evacuation drills

Film badges

Dosimeters

Personnel exposure records

Radiation monitoring equipment

Area Monitoring

Radiation surveys

Beryllium surveys

Periodic air sampling

Location film badges

Hazard Evaluation

Group and individual instruction

Preparation and distribution of safety bulletins, standards, etc.

General guidance during performance of specific work projects

Is sue personnel monitoring equipment. Maintain personnel exposure records Maintain and check monitoring equipment
SPTF operations NPU prelaunch operations
Conduct periodic surveys

Conduct surveys as required by the operations or activities in process

Maintain related records and documentation

Acquire maintenance and calibration of instruments

Oversee implementation of safety practices

Serve as an advisor, and make recommendations as regards safety, to SPTF personnel

Designate controlled areas

Render first aid and maintain related records and equipment

Maintain and is sue personnel protective equipment and clothing

Place in operation and check periodically.

Alarm systems

SPTF activities

NPU prelaunch activities

Emergency evacuations

Interagency liaison

Nuclear and nonnuclear incidents

Personnel injury reports

Routine safety reports matters relating to industrial health and safety, to assure compliance with $\mathrm{AI}$ and VAFB safety practices.

Perform hazard evaluation - ascertain safety of reentry.

Provide AI representation on safety matters.

Prepare and submit pertinent reports.
Serve in an advisory capacity as regards

Table 5-4. Health and Safety Responsibilities and Activities at SPTF 
5-18. SAFETY PRECAUTIONS AND PRACTICES.

5-19. STANDARD SAFETY RULES. Standard practices outlined in AI Safety Standards Manuals shall be observed at all times. Rules applicable to the use and operation of machine tools, shop and building equipment, electrical systems and equipment, personnel protective equipment, etc., are applicable toSPTF operations and activities. Absence of any of the standard safety practices from this manual does not void application and enforcement of the applicable rules.

5-20. FIRST AID. All injuries, regardless of how slight, must be reported to the Health and Safety Administrator, or in the event of his absence, to the individual's immediate supervisor who is responsible for relaying the information to the Health and Safety Administrator. In the event of personnel injury, first aid equipment is available from the kit maintained in the low bay corridor. Arrangements have been made to utilize medical facilities in Lompoc, if needed. VAFB medical facilities are available to SPTF personnel only in the event of an emergency.

5-21. FILM BADGES. Film badges will be issued to all personnel assigned to the SPTF. Visitors who enter the high bay area must wear film badges if they enter a radiological area. The Test Conductor is responsible for ensuring that visitors are issued a film badge before entering a controlled area (par. 5-74).

5-22. DOSIMETERS AND PORTABLE SURVEY INSTRUMENTS. Dosimeters will be issued to persons working in the restricted area around the NPU. The individual dosimeters are issued by the Health and Safety Administrator who is responsible for reading and recharging the instruments. Portable radiation survey instruments will be maintained on a two-month calibration schedule. Duplication of instruments is provided so that monitoring capability is not dis rupted during calibration of the instruments at Atomics International headquarter facilities.

5-23. RADIATION ALARM SYSTEM. The radiation alarm system shall be in operation when an NPU is present in the SPTF. The Test Conductor shall inform the Health and Safety Administrator when an NPU enters the building. The Health and Safety Administrator will then place the alarm system in operation. Supplementary monitoring, in the event the alarm system is temporarily inoperative, shall be provided.

5-24. In the event the Health and Safety Administrator is absent, the Test Conductor shall make certain that the alarm system is on and operating when an NPU is brought into the building, or that supplementary monitoring is provided. 
5-25. CONTAINMENT OF HAZARDOUS MATERIALS. Only containers meeting alth and Safety requirements shall be used for containment and/or shipment of toxic, flammable, explosive, corrosive or radioactive materials. A cabinet for the storage of flammable liquids is located outside the machine shop rear exit. Containers for toxic, corrosive or radioactive materials will be clearly marked and labeled for the use intended.

5-26. TRANSFER OR SHIPMENT OF HAZARDOUS MATERIALS. Packaging and transfer or shipment of hazardous materials shall be carried out under the supervision of the Health and Safety Administrator who shall monitor, label and maintain the records required to assure compliance with applicable regulations.

5-27. PYROTECHNICS. Pyrotechnics shall not be stored in the SPTF. Pyrotechnics related to the SPTF prelaunch operations shall be stored in the magazines provided by VAFB.

NOTE

Pin pullers will be loaded, but not stored in the STPF.

5-28. Loading of the NPU pin pullers with pyrotechnic squibs will be accomplished in the STPF. The loaded pin pullers are placed in an approved Air Force carrying. case and returned to the storage magazine until required.

5-29. NaK HANDLING PRECAUTIONS. Only in the event of an emergency condition will personnel working at the STPF be directly exposed to NaK hazards. In the event of such condition ( $\mathrm{NaK}$ leak incurred in shipping or handling), the NPU may be drained prior to return to Canoga Park. Specific procedures for draining NaK are provided in NAA-SR-MEMO-9352, NPU PRELAUNCH OPERATIONS - STPF.

\section{NOTE}

NaK draining, if required, shall be done only by personnel instructed in $\mathrm{NaK}$ handling procedures.

5-30. Safety precautions relative to NaK handling are set forth in Health and Safety procedure G-5. The following handling precautions a re applicable to any situation volving personnel exposure to $\mathrm{NaK}$.

a. Protective clothing consisting of coveralls, shoe covers, cotton gloves, and face mask shall be worn in any operation involving possible exposure to NaK. 
b. Respiratory equipment is to be worn when combating a NaK fire.

c. Waste containers containing at least 2 or 3 inches of white mineral oil should be used to catch NaK drippings, or

d. Cover NaK drippings with dry calcium carbonate.

\section{WARNING}

Keep water or moisture away from $\mathrm{NaK}$ as the combination is violently reactive.

e. Use only approved fire extinguishers in combating NaK fires (Par. 5-48).

5-31. HYDROGENOUS LIQUIDS. The available volume of any hydrogenous (hydrogen-bearing) liquids stored in the high bay shall at no time exceed a total of fifteen gallons. This is to preclude the possibility of the liquid serving as a reflector if it should be in the proximity of the reactor. This includes water, most mineral oils, paints, etc.

5-32. Containers for liquids and chemicals shall be properly labeled and shall not be used for other purposes. Food containers shall not be used for the storage of hazardous liquids or chemicals.

5-33. Use and/or handling of flammable or hazardous liquids or chemicals shall be under the supervision of qualified persons as directed by the Health and Safety Administrator.

5-34. WASTE HANDLING AND DISPOSAL. Disposal operations involving hazardous materials shall be monitored by, and under the direction of, the Health and Safety Administrator. Beryllium contaminated waste shall be handled in accordance with prescribed safety procedures. No radioactive waste handling is anticipated during NPU prelaunch operations.

5-35. Combustible and non-combustible scrap shall be separated into different containers for disposal. Broken glass shall be placed in a separate container designated for that purpose.

5-36. Oily rags and rags saturated with combustible chemicals must be disposed of in a metal container having a self-closing lid and not allowed to accumulate in benches and work areas. 
5-37. PROTECTIVE CLOTHING. The Test Conductor shall ensure that personne1 signed to tasks involving work with or about radioactive or hazardous materials, ear the protective clothing specified in the AI Safety Regulations, or as recommended by the Health and Safety Administrator.

5-38. Hard Hats.

5-39. Hard hats shall be worn by all persons working in the high bay area.

5-40. Eye Protection

5-41. Suitable eye protection shall be worn by all persons engaged in chipping, grinding, welding or brazing operations, and by persons using equipment designated as requiring eye protection.

5-42. TAGS AND LABELS. Warning tags or labels restricting the use or operation of equipment, or entry of a restricted area, must be observed and shall not be removed by anyone other than the originator of the tag. All tags must be signed and dated by the person initiating the tag.

5-43. HAND TOOLS. Only the approved tools in good condition shall be used at the STPF. Broken or defective tools are to be turned in at the stock room. Handtools shall be maintained and used in accordance with the following safe precautions:

a. All hand tools shall be kept in good repair and shall be used only for the purpose for which they were designed.

b. Tools shall not be left on scaffolds, ladders, or overhead working space when not in use.

c. Throwing tools from one location to another, from one employee to another, or dropping them from one level to another shall not be permitted.

d. Clamps or safety bars shall be used to secure work being drilled with hand drills.

5-44. MACHINERY AND EQUIPMENT. Motorized equipment such as fork-lifts and tugs will be provided by VAFB as required. AI personnel shall not operate this equipment.

5-45. Shop Machines and Power Tools

5-46. Power equipment shall be operated by authorized personnel under the cognizance of the Test Conductor. The following safety precautions apply to use and operation of power tools and machines.

a. Loose clothing or jewelry shall not be worn around moving machinery.

b. All machine guards shall be in place prior to operation.

C. All power transmission belts shall be totally enclosed. 
d. Appropriate eye protection sha'll be used.

e. "Automatic start" equipment shall be plainly labeled.

5-47. AGE Mechanical Equipment.

5-48. AGE equipment shall be operated under the cognizance of the Mechanical Engineer in charge of handling and assembly operations.

5-49. CRANE AND HOISTS. Only authorized personnel shall operate the building crane and hoist. When the crane and/or hoist is used in handling or moving the NPU, the operation shall be conducted under the direction of the Mechanical Engineer. Safety precautions relating to crane and hoist operation are set forth in AI Health and Safety procedure B-34.

5-50. Inspection.

5-51. Crane and hoisting equipment shall be inspected daily, on a visual basis, during the period that prelaunch operations are being performed in the SPTF high bay. Proof loading to $111 \%$ of equipment capacity shall be done every six months. 5-52. LADDERS AND SCAFFOLDS. Ladders and scaffolds provided at the SPTF shall be used in accordance with the following rules:

a. Portable ladders shall be equipped with non-skid feet.

b. Each section of a ladder shall not exceed 30 feet in length.

c. Stepladders over 20 feet in length shall not be used.

d. Portable ladders with such a pitch that the horizontal distance from the wall to the foot of the ladder exceeds one-fourth the unsupported length shall not be used.

5-53. NPU Work Platform.

5-54. The NPU work platform shall be used for work on the NPU unit, in place of ladders, when the NPU is mounted on its support fixture. Use of ladders for work at the top of the NPU is limited to special operations performed under the direction of the Mechanical Engineer.

5-55. ELECTRICAL SYSTEMS AND EQUIPMENT. Electrical maintenance shall be performed by or under the supervision of an electrician. Electrical equipment which is tagged OUT OF SERVICE shall not be returned to service until the DO NOT OPERATE tag is removed by an electrician or the person who originally installed the tag. 
5-56. Globes and Lamps.

57. Globes and light bulbs shall not be replaced without first notifying the Test Conductor to ascertain that replacement will not interfere with work in progress.

5-58. Electrical Circuits.

5-59. Circuits shall be de-energized before performing electrical repairs or maintenance.

5-60. Portable Lights.

5-61. Portable lights shall be of a type meeting Health and Safety specifications. Light cords, fixtures, and stands which are obviously in need of repair shall not be used in the SPTF.

5-62. Electrical Grounding.

5-63. Grounding of portable electric hand tools is mandatory to preclude the possibility of shock hazard to the tool user. Tools not equipped with a three prong polarity plug shall not be used.

5-64. WELDING. Welding operations at the SPTF shall be performed in the machine shop unless permission to carry out a welding operation elsewhere is obtained from the Test Conductor. In all cases, fire extinguishing equipment must be available in the immediate vicinity of the welding operation. Welding operations performed at the SPTF shall be in accordance with AI Health and Safety procedure B-38.

5-65. GAS CYLINDERS. Gas cylinders, other than those in immediate use shall be stored outside the SPTF on the concrete pad adjacent to the east side of the high bay to preclude the possibility of fire or explosion. Cylinders used for gas welding shall remain chained in the cylinder cart except when exchanged for fresh cylinders. Empty cylinders shall be stored outside the building in the area provided for cylinder storage. The following rules are applicable to gas cylinders:

a. Cylinders shall be handled with care and must be protected against excessive heat.

b. Cylinders containing oxygen shall not be stored with combustible materials or cylinders containing combustible gases or nitrogen. 
c. Cylinder valves shall be closed when cylinders are not in use. Valves on empty cylinders shall always be closed.

d. Valve protection caps shall be in place when cylinders are not in use.

e. A hand cart shall be used when transferring cylinders.

f. Cylinders with leaky valves or fittings, which cannot be corrected by closing the valve, shall be taken into an open, outside area away from any source of ignition and slowly drained of gas. The cylinder shall be tagged with a description of the defect before it is returned to the distributor.

g. Cylinder valves, couplings and regulators shall be kept free of grease or oil.

h. Cylinders shall be adequately secured at all times. Crescent wrenches, pliers, etc., shall not be used on bottled gas system connections.

5-66. FIRE PRECAUTIONS. Fire protection equipment is covered in detail in paragraph 3-24 of this manual. Emergency procedures to be followed in event of fire in the SPTF are outlined in paragraph 5-94 of this manual.

5-67. Although the SPTF is constructed of noncombustible materials, the possibility of fire exists due to the materials present in the facility. The three sources of potential fire stems from:

a. NaK spill or leak,

b. Electrical equipment malfunction, or

c. Other combustibles such as wood, paper, oils, etc.

5-68. NaK Fires.

5-69. In the event of a $\mathrm{NaK}$ fire, the following action is to be taken:

a. Actuate the fire alarm manually.

b. Isolate the fire, if possible.

c. Smother the fire with MET-L-X or with calcium carbonate from one of the portable extinguishers.

\section{WARNING}

Do not use $\mathrm{CO}_{2}$,water or other liquid type fire extinguishers in combating a $\mathrm{NaK}$ fire as a violent reaction may result. 
5-70. Electrical Fires.

71. Fires resulting from malfunction of electrical equipment or wiring present the potential hazard of electrical shock. The following action is to be taken in combating fires of this nature:

a. Open the circuit breakers or deenergize the circuit for the equipment involved.

b. Actuate the fire alarm manually.

c. Use portable $\mathrm{CO}_{2}$ extinguishers to combat the fire.

\section{WARNING}

Do not use water to combat fires which involve energized electrical circuits.

5-72. Other Fires.

5-73. Fires involving combustible materials such as wood, paper, oils, solvents and similar materials may be extinguished with either the $\mathrm{CO}_{2}$ or watertype extinguishers depending upon the nature of the materials. Action is to be taken as

follows:

a. Determine the nature of the emergency and actuate the fire alarm.

b. Combat the fire using the proper type extinguisher。

\section{WARNING}

In the high bay, use $\mathrm{CO}_{2}$ extinguishers for fires other than $\mathrm{NaK}$ fires as no water is allowed in the high bay.

\section{5-74. DESIGNATION OF CONTROLLED AREAS.}

5-75. Potentially hazardous areas shall be designated as controlled access areas by the Health and Safety Administrator. These areas are set apart by the use of appropriate signs and barricades. Entry into these areas is in accordance with related Health and Safety approval and procedures, and with permission of the Test Conductor. Tagged, barricaded or locked areas are restricted entry areas and shall be respected as such.

5-76. The following basic rules apply to controlled access areas:

a. Personnel entry shall be by permission of and in accordance with Health and Safety approval and procedures. 
b. Personnel monitoring and/or safety equipment as dictated by the Health and Safety requirements shall be worn while in these areas.

c. No smoking, eating or drinking is allowed in controlled access areas.

5-77. RADIATION AREA. When an NPU is installed in the high bay of the SPTF, the area around the NPU is roped off and designated as a radiologically controlled area (Figure 5-2). The size of this area is dictated by the radiation level surrounding the NPU at the time the unit is received at the SPTF. In no event will the dose rate outside this controlled area be in excess of $2 \mathrm{mrem} / \mathrm{hr}$.

5-78. Persons working within this area are considered radiation workers and will be issued film badges and pocket dosimeters. Smear surveys, to detect the presence of possible radioactive contamination, are taken as the need is indicated by the operations in progress.

5-79. Spot air sampling and smear surveys, to measure possible beryllium contamination, are carried out as the need is evidenced by operations in progress. Responsibility for the surveys rests with the Health and Safety Administrator. 5-80. BERYLLIUM AREA. Upon removal of the beryllium reflector assembly from its shipping/storage container, the area immediately surrounding the reflector assembly is designated a beryllium (Be) area. This is a controlled access area in which both basic and specifically related safety rules apply.

5-81. Rubber or vinyl gloves must be worn for any operation involving physical handling of the reflectors. No additional protective clothing is required unless a smear survey of the area indicates surface contamination levels in excess of $1 \mu \mathrm{gm} / 100 \mathrm{~cm}^{2}$. No respiratory protection is required unless air samples indicate airborne contamination levels in excess of $2 \mu \mathrm{gm} / \mathrm{m}^{3}$ (see Table 5-3, par. 5-13). Smears to detect the presence of Be contamination are taken routinely when operations involving the reflectors, which could result in contamination, are carried out. 5-82. When the beryllium reflector assembly is placed on the reactor, the area surrounding the reactor is designated a. Be area as well as a radiation area.

5-83. RADIOGRAPHIC OPERATIONS. NPU prelaunch operations do not require any radiographic operations nor is the need anticipated during the normal course of prelaunch activities. However, in the event it is necessary to conduct radiographic inspections in the SPTF, the entire high bay area is temporarily designated as a radiologically controlled area. Radiation dose rates delivered to the low bay area, as the result of radiographic operations, will in no event be allowed to exceed $2 \mathrm{mrem}$ in any one hour. 


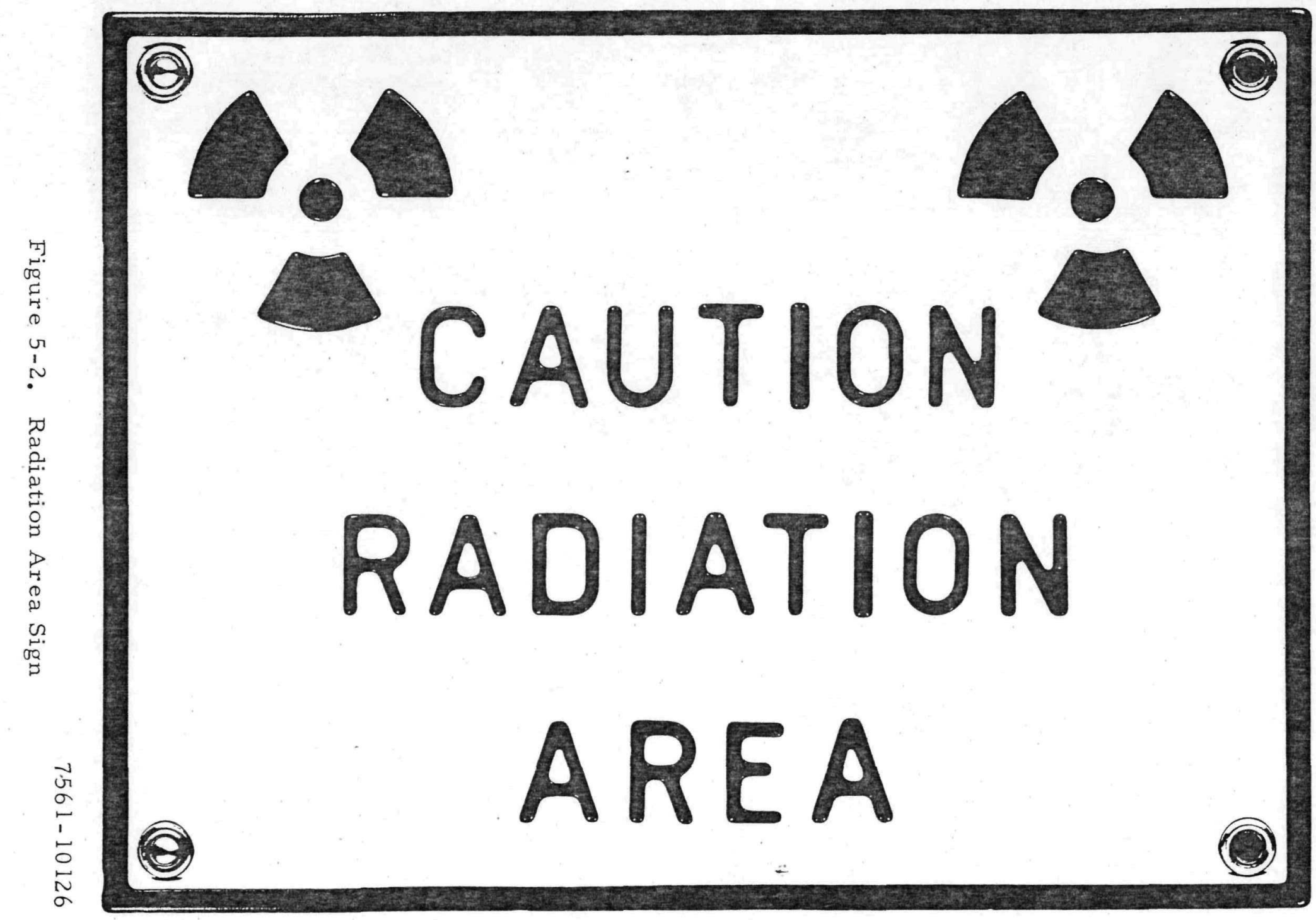

$u$
1
$a$

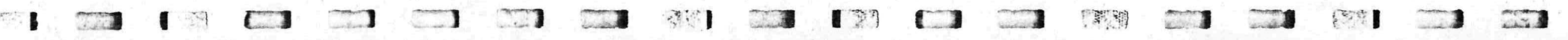


5-84. KEY CONTROL. Control of the keys used to actuate the NPU reflector safety locks is as follows:
a. One set with Engineering Supervisor.
b. One setwith $A I C$ Reactor subsystem.
c. One set with Test Conductor.

Each set of keys is attached to a retractable key holder and is the responsibility of the individual to whom the set is assigned.

\section{5-85. EMERGENCY EVACUATION.}

5-86. Emergency evacuation procedures will be initiated in the event it becomes necessary to evacuate the SPTF for reasons of personnel safety. Events which may require evacuation of the facility include, but are not limited to, the following:
a. Practice evacuation drills
b. A fire of major proportions
c. Radiation alarm

5-87. EMERGENCY ASSEMBLY AREA. The emergency assembly area (EAA) is located at a point approximately 1000 feet down the access road as shown in Figure 5-3. All SPTF personnel except those having emergency action responsibility will rapidly proceed to the EAA when the evacuation signal is given. The security guard will maintain telephone communication between the EAA and VAFB control center until relieved of the responsibility.

5-88. EVACUATION NOTICE. In the event of an emergency condition of major proportion, notice to evacuate the facility will be given by one or more of the following methods:

a. Verbal instructions by operating personnel in the immediate vicinity of the emergency condition.

b. Public address announcement, by means of intercom system.

c. Siren alarm.

5-89. EMERGENCY EQUIPMENT. An emergency kit containing portable radiation survey instruments, personnel dosimetry devices, decontamination supplies, and first aid supplies is maintained next to the guard station located just inside the facility fence. This kit will be taken to the EAA during an emergency evacuation. The equipment included in the kit consists of the following: 

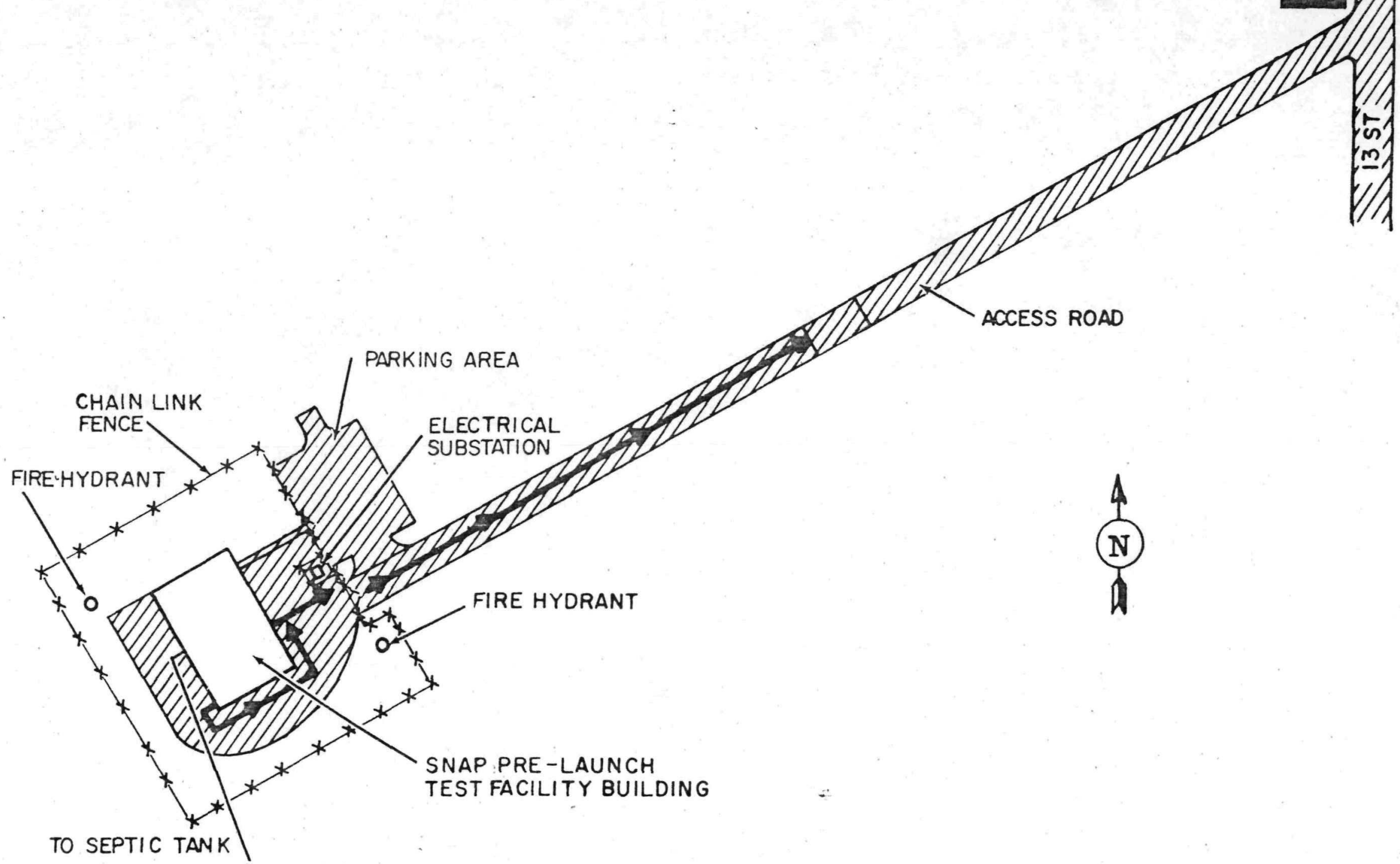

ACCESS ROAD 
a. 2 gamma detection instruments

b. 1 Self-contained breathing apparatus

c. 2 Sets protective clothing

d. 1 Portable battery powered light

e. First Aid supplies

f. Decontamination supplies

g. 2 Filter-type respirators

h. List of names and phone numbers of key AI personnel.

5-90. Two sets of portable breathing apparatus are maintained in a readily accessible location in the main corridor outside the men's locker room. Operations personnel will use the equipment as directed by the Test Conductor. Maintenance and periodic inspection of all emergency equipment is the responsibility of the Health and Safety Administrator.

5-91. EVACUATION DRILLS. Practice evacuation drills are conducted at least once during each six-month period to ensure that facility personnel are familiar with evacuation procedures. The drills may, at the discretion of the Engineering Supervisor, be scheduled in addition to those required by VAFB regulations. All facility personnel are expected to participate in the practice drills.

5-92. Reentry Following Emergency Evacuation.

5-93. Reentry of the facility following an emergency evacuation is at the discretion of the Engineering Supervisor, acting with the advice and recommendations of the Health and Safety Administrator. The facility will not be reoccupied until it has been determined and announced that the building is safe for occupancy.

5-94. EMER GENCY PROCEDURES.

5-95. Individual responsibilities and action to be taken in the event of an emergency at the SPTF are presented in Tables 5-5 through 5-9. 


\begin{tabular}{|c|c|}
\hline $\begin{array}{l}\text { Personnel } \\
\text { Effected }\end{array}$ & Responsibility and/or Action \\
\hline Person discovering the fire & $\begin{array}{l}\text { a. Give verbal alarm if fire alarm has not } \\
\text { activated. } \\
\text { b. Actuate alarm manually by breaking glass in } \\
\text { alarm box. } \\
\text { c. Take assigned fire station or proceed as } \\
\text { directed by the person in charge. }\end{array}$ \\
\hline $\begin{array}{l}\text { Engineering Supervisor } \\
\text { or his designee }\end{array}$ & $\begin{array}{l}\text { d. Assess magnitude of danger, give evacuation } \\
\text { signal if fire is of such extent as to endanger } \\
\text { personnel. } \\
\text { e. Ascertain that assigned fire stations are covered. } \\
\text { f. Report fire to AEC base representative. } \\
\text { g. Evaluate extent of damage following control } \\
\text { of the fire. Notify AI Headquarters control } \\
\text { center. }\end{array}$ \\
\hline $\begin{array}{l}\text { Test Conductor, or } \\
\text { his designee }\end{array}$ & $\begin{array}{l}\text { h. Shut down ventilation system if fire is in high bay. } \\
\text { i. Direct fire fighting activities of the auxiliary } \\
\text { firemen until help arrives. } \\
\text { j. Maintain constant surveillance of the fire and } \\
\text { efforts at control; order evacuation if conditions } \\
\text { are such as to endanger personnel. }\end{array}$ \\
\hline SPTF Auxiliary Firemen & $\begin{array}{l}\text { k. Take up assigned fire stations. } \\
\text { 1. Take action as required to confine or minimize } \\
\text { fire damage. }\end{array}$ \\
\hline Security Guard & $\begin{array}{l}\text { m. Restrict entry to the facility until the VAFB } \\
\text { fire department arrives; direct traffic. }\end{array}$ \\
\hline $\begin{array}{l}\text { Health and Safety } \\
\text { Administrator }\end{array}$ & $\begin{array}{l}\text { n. Advise and assist as necessary to minimize } \\
\text { personnel hazards. }\end{array}$ \\
\hline
\end{tabular}

Table 5-5. Fire-Building Occupied 


\begin{tabular}{|c|c|}
\hline $\begin{array}{c}\text { Personnel } \\
\text { Effected }\end{array}$ & Responsibility and/or Action \\
\hline \multicolumn{2}{|c|}{$\begin{array}{l}\text { NOTE } \\
\text { In the event evacuation of the facility is required, the } \\
\text { following procedures are applicable. }\end{array}$} \\
\hline $\begin{array}{l}\text { Engineering Supervisor } \\
\text { or his designee }\end{array}$ & $\begin{array}{l}\text { o. Give emergency evacuation signal. } \\
\text { p. Ascertain that all personnel not involved in } \\
\text { fire dighting operations evacuate the facility. } \\
\text { q. In the event fire control cannot be effected, } \\
\text { proceed to EAA and verify that all personnel } \\
\text { are accounted for. } \\
\text { r. Evaluate extent of damage and determine if } \\
\text { safe reentry may be effected, following con- } \\
\text { trol of fire. } \\
\text { s. Notify AI headquarters control center. }\end{array}$ \\
\hline $\begin{array}{l}\text { Test Conductor, or } \\
\text { his designee }\end{array}$ & $\begin{array}{l}\text { t. Procure NPU verification log, if possible. } \\
\text { u. Proceed to EAA. }\end{array}$ \\
\hline Security Guard & $\begin{array}{l}\text { v. Obtain emergency evaucation } \\
\text { cart; proceed to point down access } \\
\text { road near EAA. }\end{array}$ \\
\hline $\begin{array}{l}\text { Health and Safety } \\
\text { Administrator or } \\
\text { his designee. }\end{array}$ & $\begin{array}{l}\text { w. Retreat to EAA and render first aid as required. } \\
\text { x. Ascertain adequacy of EAA for safety. } \\
y \text {. Assist in evaluating conditions for safe reentry } \\
\text { of the facility. }\end{array}$ \\
\hline Other Personnel & $\begin{array}{l}\text { z. Evacuate facility in orderly fashion. } \\
\text { aa. Assemble at EAA and await further instructions } \\
\text { from Engineering Supervisor or designee. }\end{array}$ \\
\hline
\end{tabular}

Table 5-5. Fire - Building Occupied (Continued) 


\begin{tabular}{|c|c|}
\hline Personnel & Responsibility and/or Action \\
\hline Security Guard & $\begin{array}{l}\text { a. Notify VAFB fire department. } \\
\text { b. Notify AI Engineering Supervisor or designee } \\
\text { on standby alert. } \\
\text { c. Obtain emergency evacuation cart. } \\
\text { d. Retreat to point on access road adjacent to EAA. } \\
\text { e. Restrict entry to facility until arrival of VAFB } \\
\text { fire department or AI representative. } \\
\text { f. Continue to restrict entry of personidel not } \\
\text { directly related to the fire fighting effort, or as } \\
\text { directed by the AI representative. }\end{array}$ \\
\hline $\begin{array}{l}\text { Engineering Supervisor } \\
\text { or Designee }\end{array}$ & $\begin{array}{l}\text { g. Notify AEC base representative and Health } \\
\text { and Safety Administrator. } \\
\text { h. Proceed to SPTF to assist as required. } \\
\text { i. Direct VAFB fire department personnel if } \\
\text { radiation alarm has sounded. } \\
\text { j. Evaluate extent of damage after fire is } \\
\text { extinguished. } \\
\text { k. Notify AI Headquarters control center. }\end{array}$ \\
\hline
\end{tabular}

Table 5-6. Fire Directly Involving NPU Power System, Building Unoccupied 


\begin{tabular}{|c|c|}
\hline \hline Personne1 & \multicolumn{1}{|c|}{ Responsibility and/or Action } \\
\hline Security Guard & a. Notify VAF B fire department. \\
b. Attempt to control fire until arrival of VAFB \\
fire department.
\end{tabular}

Tabel 5-7. Fire Not Directly Involving NPU Power System, Building Unoccupied 
NAA -SR-MEMO-9353

\begin{tabular}{|c|c|}
\hline $\begin{array}{l}\text { Personnel } \\
\text { Effected }\end{array}$ & Responsibility and/or Action \\
\hline $\begin{array}{l}\text { Engineering Supervisor } \\
\text { or his designee }\end{array}$ & $\begin{array}{l}\text { a. Shutdown ventilation system by means of } \\
\text { master switch. } \\
\text { b. Retreat to EAA. } \\
\text { c. Account for personnel as they arrive at EAA, } \\
\text { verifying that all personnel have evacuated the } \\
\text { SPTF. } \\
\text { d. Notify AEC base representative if representa- } \\
\text { tive is not present at the facility at time of } \\
\text { evacuation. } \\
\text { e. Notify AI Headquarters control center. }\end{array}$ \\
\hline $\begin{array}{l}\text { Test Conductor } \\
\text { or his designee }\end{array}$ & $\begin{array}{l}\text { f. Procure NPU verification } \log \text { if possible. } \\
\text { g. Retreat to EAA. } \\
\text { h. Assist Health and Safety Administrator in } \\
\text { making facility reentry as required. }\end{array}$ \\
\hline Security Guard & $\begin{array}{l}\text { i. Pick up emergency evacuation cart. } \\
\text { j. Retreat to EAA. } \\
\text { k. Notify VAFB Control Center of emergency } \\
\text { condition. } \\
\text { 1. Restrict entry to the facility until otherwise } \\
\text { instructed by the Engineering Supervisor. }\end{array}$ \\
\hline $\begin{array}{l}\text { Health and Safety } \\
\text { Administrator }\end{array}$ & $\begin{array}{l}\text { m. Retreat to EAA. } \\
\text { n. Provide guidance to Engineering Supervisor in } \\
\text { directing activities at EAA. } \\
\text { o. Direct first aid or decontamination as required. } \\
\text { p. Ascertain adequacy of EAA for safety. } \\
\text { q. Make or authorize reentry into facility with } \\
\text { portable radiation monitoring instruments. } \\
\text { NOTE } \\
\text { Initial reentry will, in all cases, be } \\
\text { made by two or more persons. }\end{array}$ \\
\hline Other Personnel & $\begin{array}{l}\text { r. Evacuate facility in orderly fashion, as } \\
\text { rapidly as possible. } \\
\text { s. Assemble at the EAA and await further instruc- } \\
\text { tions from the Engineering Supervisor or } \\
\text { designee. }\end{array}$ \\
\hline
\end{tabular}

Table 5-8. Radiation Alarm - Building Occupied 


\begin{tabular}{|c|c|}
\hline $\begin{array}{l}\text { Personnel } \\
\text { Effected }\end{array}$ & Responsibility and/or Action \\
\hline Security Guard & $\begin{array}{l}\text { a. Obtain emergency evacuation cart. } \\
\text { b. Retreat down access road to point near EAA. } \\
\text { c. Notify VAFB control center of nature of } \\
\text { emergency. } \\
\text { d. Instruct VAFB control center to notify AI } \\
\text { Engineering Supervisor and Health and } \\
\text { Safety Administrators or designees on } \\
\text { standby alert, providing names and tele- } \\
\text { phone numbers. } \\
\text { e. Restrict entry into the facility until arrival of } \\
\text { the } 392 \text { AMG and/or responsible AI } \\
\text { representative. }\end{array}$ \\
\hline $\begin{array}{l}\text { Engineering Supervisor } \\
\text { or Designee }\end{array}$ & $\begin{array}{l}\text { f. Notify AEC base representative. } \\
\text { g. Notify Health and Safety Administrator. } \\
\text { h. Proceed to facility to ascertain cause of alarm. }\end{array}$ \\
\hline $\begin{array}{l}\text { Health and Safety } \\
\text { Administrator }\end{array}$ & $\begin{array}{l}\text { i. Notify AI Headquarters control center. } \\
\text { j. Proceed to facility and assist Engineering } \\
\text { Supervisor in ascertaining cause of alarm. } \\
\text { k. Make or authorize reentry into facility with } \\
\text { detection instruments } \\
\text { NOTE } \\
\text { In the event the Health and Safety } \\
\text { Administrator is not available, re- } \\
\text { entry into the facility may be affected } \\
\text { by the Engineering Supervisor, de- } \\
\text { signee, or authorized member of the } \\
\text { 392 AMG in accordance with pre- } \\
\text { scribed safety procedures. }\end{array}$ \\
\hline
\end{tabular}

Table 5-9. Radiation Alarm - Building Unoccupied 


\section{SECTION VI}

\section{AEROSPACE GROUND EQUIPMENT (AGE)}

6-1. Ground handling and checkout equipment is available at the SPTF for the performance of prelaunch inspection, testing and reassembly operations conducted at the facility. This equipment also provides the backup support required for launch pad operations. A list of the equipment available and its function is given in Table 6-1. AGE operation and maintenance instructions are presented in NAA-SRMEMO-9356, Vols. I and II.

6-2. ELECTRICAL SYSTEM TEST SET, TSM-2A.

6-3. The electrical system test set TSM-2A is used for prelaunch validation tests on the SNAP unit system prior to mating the unit to the launch vehicle. The set is used to verify that the electrical circuits and subsystems are performing as designed and are functionally satisfactory for flight. The test set is designed for rapid evaluation of functional test results with a minimum of data reduction. Essential readouts are automatically displayed and recorded. Typical application at the SPTF is illustrated in Figure 6-1.

6-4. TSM-2A is connected to the SNAP power unit by means of test plugs and jumper cables. Under test conditions, the power unit undergoes simulated orbital startup operation including all of the failure modes. Simulated firing of squib release mechanisms is accomplished by means of high pressure gas operation of event marker switches, control drum limit switches and control drum movement. 6-5. A chronological record of TSM-2A operation and maintenance is maintained in the AGE logbook (paragraph 4-49). Entries are the responsibility of the Assistant Test Conductor, Electrical and include, but are not limited to the following:

a. Identification of test performed.

b. Period of TSM-2A operation in hours or fraction thereof.

c. Inspection, test or calibration of TSM-2A.

d. Maintenance performed on TSM-2A.

e. Anomalies in equipment operation. 


\begin{tabular}{|c|c|}
\hline $\begin{array}{l}\text { Equipment } \\
\text { Item }\end{array}$ & Purpose or Use \\
\hline SNAP Unit Shipping Equipment & $\begin{array}{l}\text { Used for shipment of SNAP } 10 \mathrm{~A} \text { components } \\
\text { to the SPTF, and from SPTF to the launch } \\
\text { complex, including storage at SPTF. }\end{array}$ \\
\hline SNAP Unit Handling Fixture & $\begin{array}{l}\text { Provides means for support and handling of } \\
\text { the SNAP } 10 \mathrm{~A} \text { unit. }\end{array}$ \\
\hline Tilt Sling & $\begin{array}{l}\text { Used in conjunction with the overhead crane } \\
\text { and handling fixture, to rotate the NPU from } \\
\text { vertical to horizontal position and vice versa. }\end{array}$ \\
\hline Hydra-Set & $\begin{array}{l}\text { Hydraulically actuated device for insertion } \\
\text { in the hoisting line, to provide fine control } \\
\text { of lifting operations. }\end{array}$ \\
\hline Vertical Handling Yoke & $\begin{array}{l}\text { Provides method for vertical handling with } \\
\text { overhead hoist when SNAP unit is not in } \\
\text { handling fixture. }\end{array}$ \\
\hline Work Platform & $\begin{array}{l}\text { Variable height work platform used to pro- } \\
\text { vide easy access to any portion of vertically } \\
\text { positioned SNAP unit. }\end{array}$ \\
\hline Vertical Support Stand & $\begin{array}{l}\text { Provides means for vertical mounting of } \\
\text { SNAP unit during assembly operations. }\end{array}$ \\
\hline Reflector Installation Fixture & $\begin{array}{l}\text { Special fixture used for installation and/pr } \\
\text { removal of the reflector assembly and } \\
\text { shipping sleeve on the reactor vessel. }\end{array}$ \\
\hline In-plant Dolly & $\begin{array}{l}\text { Used for in-plant movement of the as sembled } \\
\text { SNAP unit and handling fixture. }\end{array}$ \\
\hline Shield Installation Fixture & $\begin{array}{l}\text { Used to hold and position the radiation shield } \\
\text { assembly during installation, or removal } \\
\text { from, the SNAP unit. }\end{array}$ \\
\hline Shield Handling Sling & $\begin{array}{l}\text { Provides the means for handling the radiation } \\
\text { shield with overhead hoist. }\end{array}$ \\
\hline $\begin{array}{l}\text { Center of Gravity Locating } \\
\text { Equipment }\end{array}$ & $\begin{array}{l}\text { Provides precise method for determining CG } \\
\text { and weight of the SNAP unit. }\end{array}$ \\
\hline $\begin{array}{l}\text { Reflector Installation Procedure } \\
\text { Checkout Fixture (Simulated } \\
\text { Reactor). }\end{array}$ & $\begin{array}{l}\text { Serves as a support and checkout stand for } \\
\text { the reflector assembly during testing } \\
\text { operations. }\end{array}$ \\
\hline Mating Dolly & $\begin{array}{l}\text { Holds the assembled SNAP unit in the hori- } \\
\text { zontal position while at the same time pro- } \\
\text { viding a variety of adjustments for exact } \\
\text { positioning. }\end{array}$ \\
\hline Shipping Sleeve Shield & $\begin{array}{l}\text { Serves as a non-reflecting shipping and hand- } \\
\text { ling ring to protect personnel from neutron } \\
\text { reflection created by water and/or any other } \\
\text { reflecting medium. }\end{array}$ \\
\hline Electrical System Test Set, Type 2A & $\begin{array}{l}\text { Used to verify that SNAP unit electrical cir- } \\
\text { cuits and subsystems are performing as } \\
\text { designed. }\end{array}$ \\
\hline Guide Fixture & $\begin{array}{l}\text { Provides means for guiding handling fixture } \\
\text { during installation or removal from NPU. }\end{array}$ \\
\hline
\end{tabular}

Table 6-1. Summary of Aerospace Ground Equipment 


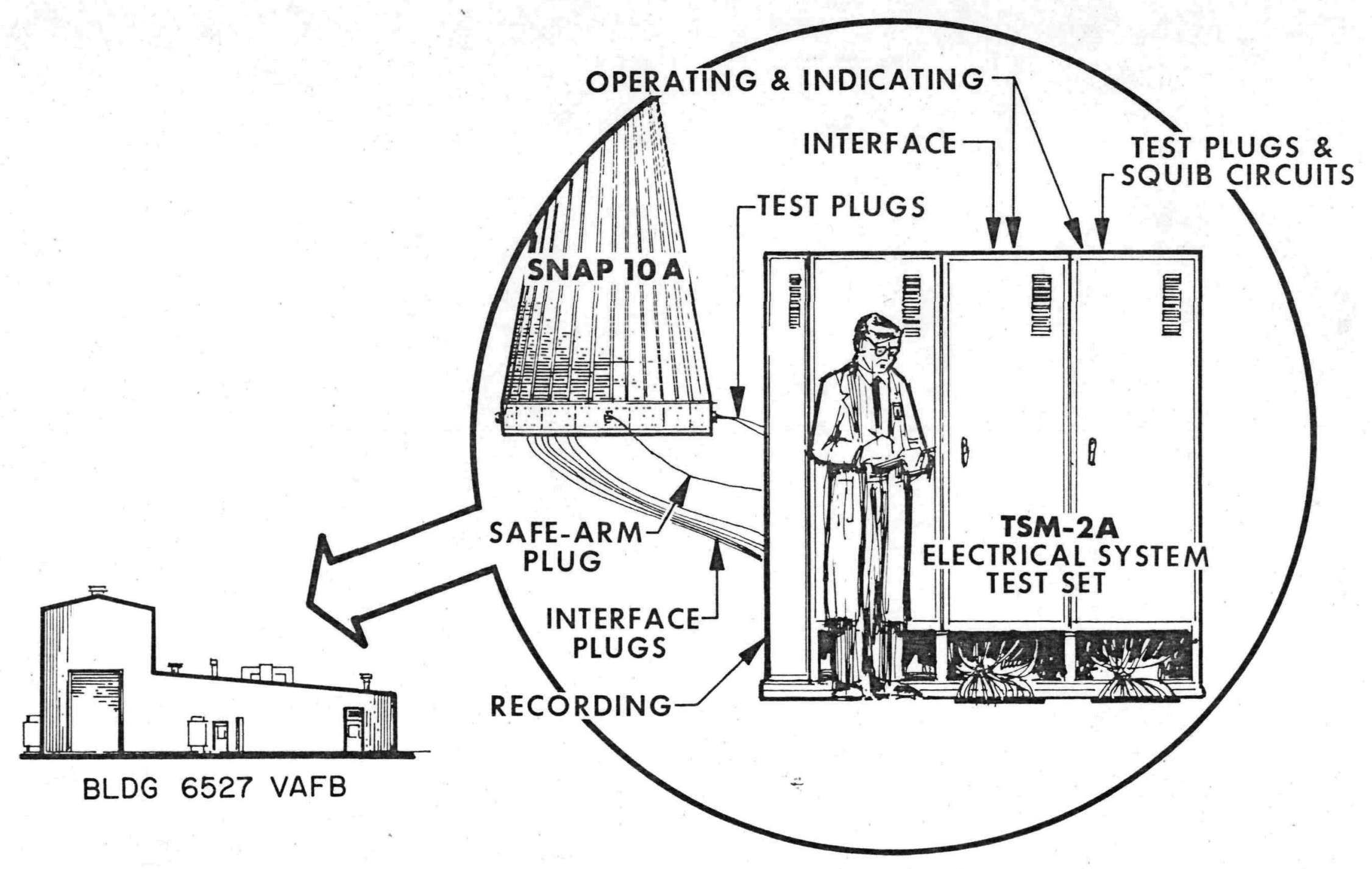




$$
\text { NAA-SR-MEMO-9353 Paragraphs 6-6 to 6-9 }
$$

6-6. INSTALLATION AND VALIDATION. As TSM-2A is a portable unit opering on standard $110 \mathrm{v}$ ac current it does not require special installation or special wiring. The test set is located in the high bay NPU assembly and checkout area (Figure 3-4) and can be moved about as necessary to facilitate its use in NPU testing operations. Standard service outlets are available to provide power for the unit which is equipped with a plug-in line cord. Checkout and validation of TSM-2A is the responsibility of the Assistant Test Conductor, Electrical.

6-7. MECHANICAL AGE.

6-8. The mechanical aerospace ground support equipment is designed specifically for handling and transporting of the SNAP unit and components during the shipping, testing and reassembly phases of prelaunch operations. All equipment items were thoroughly inspected and operationally checked when installed at the facility. References for the description, operation and maintenance of individual items of equipment are included in Table 6-1.

6-9. The AGE logbook is used to provide a means of documenting significant facts relating to the operation and maintenance of mechanical AGE equipment.' Logbook entries are the responsibility of the Mechanical Engineer and include, but are not limited to the following:

a. Chronological record of equipment inspections and tests.

b. Maintenance performed on equipment.

c. Anomalies in equipment operation.

Typical mechanical AGE components are shown in Figure 6-2. 


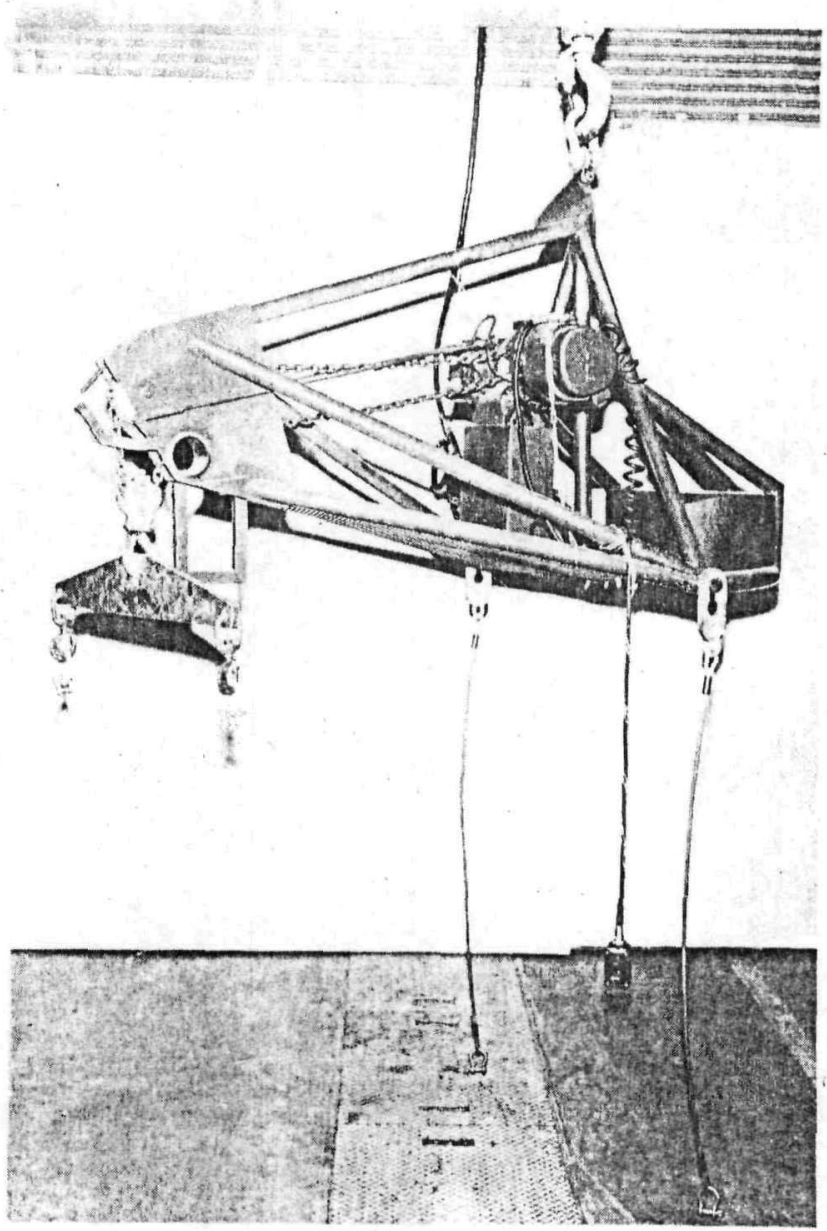

Tilt Sling

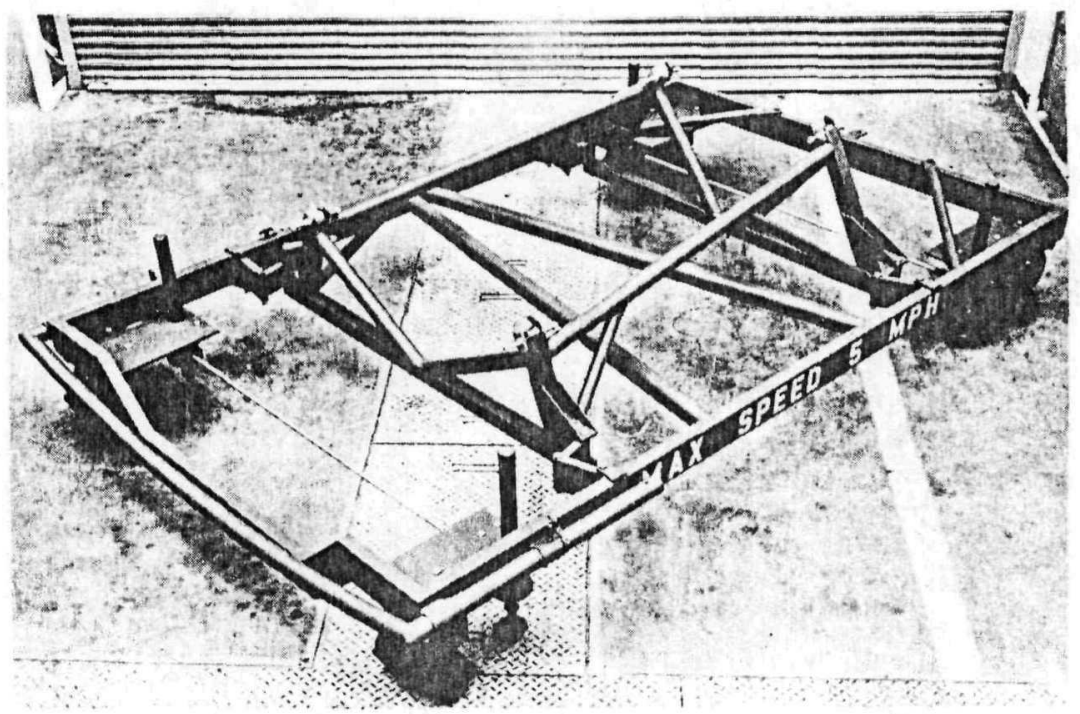

NPU Mating Dolly

$7561-10135$

Figure 6-2. Typical AGE Mechanical Equipment Used in NPU Prelaunch Operations 


\section{APPENDICES}

Appendix

Page

A. STPF Security Plan .................... A-2

B. SPTF Readiness Checklist .............. B-1

C. Facility Acceptance Checklist.......... C -1

D. SPTF Equipment Specifications........ D-1

E. SPTF Maintenance Checklist.......... E-1

Checklists and tables included in this appendix were designed to facilitate verification of facility readiness and acceptance. Included are facility equipment lists which identify major items of equipment installed at the SPTF. 
APPENDIX A

BUILDING 6527, VAFB'

SECURITY PLAN

\section{GENERAL}

A. Program Responsibility

1. The following security plan is applicable to Building 6527 at Vandenberg Air Force Base, California, during its occupancy by U.S. Atomic Energy Commission and Atomics International personnel during the SNAPSHOT Program, which is scheduled for the Spring of 1965.

2. The SNAPSHOT Program involves the delivery by Atomics International of a Nuclear Power Unit to furnish electrical power to the payload of a space satellite.

3. Building 6527 is designed for the final as sembly and checkout of Nuclear Power Units (NPU). The NPU consists of a compact nuclear reactor and its associated Power Conversion System (PCS).

4. Building 6527 will be activated as a security interest upon the receipt and storage of documents classified as high as SECRET in both the Restricted Data and Defense Information categories. Subsequently, the components and assemblies of the NPU's will be received and stored preparatory to their assembly, checking and transport to PALC-2. At this latter point, the NPU will be mated to a vehicle furnished by LMSC for pre-flight checks and final launch.

5. Each NPU is classified CONFIDENTIAL Restricted Data because of materials and composition thereof. Visual access to the NPU does not reveal classified information.

6. The NPU is the responsibility of AI under the terms of Contract AT-(11-1)-GEN-8 with the U. S. Atomic Energy Commission acting through their Canoga Park Area Office.

B. Security Responsibility

1. Safeguarding of the building prior to classified occupancy rests with AI, although gate and building keys are furnished to VAFB for emergency use in event of fire or catastrophe.

2. Upon classified activation of Building 6527, the 4392 Aerospace Support Group (ASG) will furnish Air Police guard coverage at the building on a 24-hour per day, 7 days a week basis. The assigned Air Police personnel will possess DoD Final SECRET clearances, which have been certified to the Canoga Park Area Office of the U. S. AEC for access to Restricted Data. 
3. The Air Police function is the physical protection and access control over the security area, and its contents in accordance with requirements established by $\mathrm{AI}$ and CPAO through appropriate Command at VAFB.

4. The AI and AEC personnel assigned to Building 6527 are responsible for operations and controls within the fence line and the building.

a. The AEC Base Representative is responsible for all local action requiring approval of the $A E C$.

b. The AI Administrative Representative is responsible for all local action requiring approval of AI.

C. Description of Security Interest

1. Site Location

a. Building 6527 is located in the central southern portion of VAFB about 900 feet west of 13 th Street. The building is approximately 89 feet $x 61$ feet, with a high bay area equipped with an overhead crane, and the remainder of the building consists of smaller work rooms and offices. The building is surrounded by a security fence with one vehicle gate and two personnel gates. A ginard post building is located adjacent to the most northerly personnel gate in the east fence line.

b. The fence line constitutes the perimeter of the security area at all times that classified matter is in the area.

c. A secondary site of security interest is the Point Arguello Launch Complex \#2 (PALC-2). At this site, the NPU will be mated to the launch vehicle for non-nuclear checkout; and later be mated and launched into orbit.

2. Elements of Security Interest

a. Documents classified as high as SECRET Restricted Data consisting of reports, drawings, specifications, and schedules, will be used and stored within Building 6527 during the SNAPSHOT, Program.

b. Materials, consisting of nuclear fuel elements, various bearings, radiation shields, thermo-electric modules, and the like, are classified as high as CONFIDENTIAL Restricted Data. However, the classified aspects of the hardware are not visually accessible. These materials will be located within Building 6527 during assembly of the NPU and the NPU will be located at PALC-2 subsequently for a test mating to the launch vehicle and the final mating for actual launch.

c. An AEC facility approval will be required prior to the receipt or generation of classified documents or material. 


\section{PERSONNEL CLEARANCES}

A. AEC and AI Operating Personnel

1. Personnel assigned to SNAPSHOT at Building 6527 for 30 days or longer shall possess " $Q$ " Access Authorizations which have been certified on Form AEC-277 by CPAO to the 6595th ATW. A list of such personnel will be furnished to the Air Police guard post at the building by the proper Command at VAFB.

a. Additions or replacements to the personnel list will be processed through AI Industrial Security by AI Personnel Department in sufficient time to permit clearances to be sent to the 6595th ATW.

b. Deletions from the personnel list will be immediately communicated to the Building 6527 guard and to the Security Officer of the 6595th ATW by the AI Administrative Representative.

(1) Transfers back to AI Canoga Park will be reported in writing to AI Industrial Security by the AI Administrative Representative.

(2) Terminations will be handled by the AI Administrative Representative in accordance with AI Standard Qperating Policies D-44, pertaining to off-site employees.

\section{B. Air Police Guards}

1. Air Police Guards assigned to duty at Building 6527 must have final DOD SECRET or TOP SECRET clearances certified by appropriate VAFB Command to CPAO, which will relay the information to the AEC Site Representative and to AI Industrial Security for relay to the AI Administrative Representative at VAFB.

2. Emergency replacements of Air Police guards may have their personnel clearances certified by telephone to the CPAO Base Representative at Building 6527; with written certification to follow through channels outlined in the paragraph preceding.

C. VAFB Personnel

Officers and men of the 6595th ATW who require access to Building 6527 or to data associated with the SNAPSHOT Program on a continuing basis, will have their clearances certified to the Canoga Park Area Office of the AEC, and their names will be added to the list of those persons permitted free access to the security area.

D. Visitors

1. Definition

a. AEC and AEC Contractor Personnel

Any $A E C$ or $A E C$ contractor personnel visiting or assigned to Building 6527 for any period less than 30 days will be handled as a visitor; and will require a "Q" clearance. 
b. DoD and DoD Contractor Personnel

All DoD and DoD contractor personnel requiring access to Building 6527 will be handled as visitors except those on the permanent access list.

c. Subcontractors, Suppliers, Vendors, Repairman, Deliveryman, Etc.

Any subcontractor, supplier, vendor, repairman, delivery personnel, and the like, will be handled as visitors.

2. Notification of Visit

a. Classified visits to Building 6527 will be processed on Form AEC-277 for all AEC, AEC contractor, DoD and DoD contractor personnel through their cognizant security offices to CPAO; although any such visits by NASA personnel may be processed on NASA Form-405 in the same manner. Approved visits will then be routed from CPAO to the AEC Site Representative, and to AI Industrial Security. The AEC Site Representative will transmit information to the 6595th ATW for their release to 4392 Aerospace Support Group, and he will also advise the AI Administrative Representative. The AEC Site Representative has authority to approve telephonic certification for visits.

(1) Classified visits by unannounced AEC, AEC contract,or, DoD, or DoD contractor visitors will be referred to the AEC Base Representative at Building 6527 for decision regarding entry and badging, and any such visits approved for classified access must be confirmed in writing.

b. Unclassified visits by U.S. citizens require the verbal approval of the AI Administrative Representative, or in his absence, any other AI Supervisor assigned to Building 6527; except that unclassified visits to the AEC Base Representative in the building will require his verbal approval prior to admission.

3. Registration of Visitors

a. All visitors (cleared and uncleared) must sign and complete the visitor register form maintained at the guard post at Building 6527, and be appropriately badged before entry. The guard will enter the departure time when retrieving the badge.

b. Completed pages of the visitor register will be routed to the AI Administrative Representative for transmission to AI Industrial Security.

c. Blank registration sheets will be furnished to the guard post by the AI Administrative Representative.

d. AEC and AI assigned personnel and 6595th ATW personnel on the access list will be admitted by the Air Police Guard at Building 6527 on the basis of an access list furnished to him; and be admitted to the area without registration. Verification of identification will be at the discretion of the guard in accordance with VAFB policy. 
E. Badges

1. AEC and AI Assigned Employees

a. The AI Administrative Representative will assure that proper VAFB forms are executed by AEC and AI assigned personnel, and that appropriately coded VAFB badges are issued. These badges indicate the areas at VAFB to which the wearer is authorized admission; therefore, must be worn in accordance with VAFB regulations.

b. Assigned personnel will wear their coded VAFB badge at all times while at VAFB and at Building 6527, (to assist the guard in personal recognition).

c. Forgotten or misplaced badges will be handled by the Air Police guard in accordance with VAFB practices.

\section{Cleared Visitors}

a. AEC and AEC contractor personnel whose " $Q$ " clearance has been certified and approved by the AEC, will be issued a blue visitor badge upon registration at the guard post at Building 6527. No escort is required. The badge will be picked up at termination of the visit each day.

b. DoD and DoD contractor personnel whose SECRET or TOP SECRET clearance has been certified and approved by the AEC will be issued a green visitor badge upon registration at the guard post at Building 6527. No escort is required. The badge will be picked up at termination of the visit each day.

3. Uncleared Visitors

a. U.S. citizens whose visit has been approved by the AEC Base Representative or the AI Administrative Representative, or other AI Supervision at Building 6527, shall be issued red visitor badges at the time of registration at the guard post. Escort by an AEC or AI assigned employee is required prior to entry to the area. The badge will be picked up at termination of the visit.

b. Uncleared aliens, including immigrant aliens, will not be admitted to the area.

4. Lost or Unrecovered Visitor Badges

a. The Air Police guard will report to the AI Administrative Representative, the name, address, badge type, and badge number, of any badge which a visitor has alleged to have lost, or which is otherwise unaccounted for at the end of each working day. 
b. The AI Administrative Representative will contact the visitee, and make such other search as appears logical to find the badge at Building 6527. If not located, the AI Administrative Representative will direct a letter to the visitor and request return of the badge, or an explanation of the circumstances of loss if he does not have the badge. Failure to recover a badge shall be reported in writing to AI Industrial Security.

\section{PHYSICAL SECURITY}

\section{A. Perimeter Fence Control}

1. Guard Post

a. The guard post in the shack at the main employee entrance gate will be manned by armed Air Police assigned by the 4392 Aerospace Support Group (ASG) during all day shift working hours of the AEC and AI assigned personnel.

b. The assigned guard will control the entry of all persons and vehicles into the fenced area and Building 6527 in accordance with post orders issued by the 4392 nd ASG in accordance with standard VAFB regulations and with the requirements which were furnished to VAFB by AEC/AI.

c. The main employee gate shall be locked by the guard at all times that his duties prevent him from maintaining observation and positive control over this gate and its usage.

d. One master key will be issued to and controlled by the assigned guard, and will be kept in the guard shack. Building keys will be controlled by the AI Administration Representative.

2. Vehicle Gate and Emergency Exit Gate

a. The vehicle gate and the emergency exit gate shall be kept locked at all times when not in use.

b. The assigned guard on duty shall personally control the entry and exit through these gates.

3. Fence Inspection

The assigned guards shall inspect the security fence at least once

- each night; and shall report any deficiency to the AI Administrative

Representative on the following work day unless the deficiency is so aggravated as to require immediate action; in which case the AI Administrative Representative should be notified by telephone.

B. Area Access Control

1. The assigned guards shall not admit any person through any gate without appropriate registration and badging in accordance with preceding instructions outlined herein. 
2. AEC and AI assigned personnel are responsible for the control of all visitors and the property brought into the area, as well as the escort of all uncleared visitors, to assure that there is no breach of information or physical security.

C. Area Patrols

1. The assigned guards shall lock all gates when AEC and AI assigned personnel have left at the end of the day; and shall patrol the area and Building 6527 in no less than four hour intervals thereafter until the start of the next day shift, when he will assume a fixed post at the main employee gate.

2. The patrols through Building 6527 will include an examination of file cabinets containing classified data to insure they are locked, and examination of documents which have not been locked up to assure that no classified documents are insecure.

3. The assigned guards on patrol shall make appropriate report of any classified file cabinets found unlocked, or classified documents found astray, in accordance with their guard orders.

D. Property Control

1. The assigned guards will not permit anyone to britg fire arms, cameras, or contraband material into the area; except those persons authorized to do so under VAFB regulations. Any other persons must check their cameras, firearms, or other contraband material with the Air Police at the guard shack, pending disposition in accordance with VAFB regulations.

2. The assigned guards will not check brief cases being hand-carried out of the area; but will require a property "Removal Pass" (Form $8-\mathrm{X}$ ) for any tools, equipment, machines, or other material which appears to be government property. The guard will compare the property with the description on the "Removal Pass" and assure that AEC or AI Supervision has signed the approval line before permitting removal. Upon removal, the guard will sign the bottom line after the word, "Guard," and route the Form 8-X to the AI Administrative Representative at Building 6527.

3. The AI Administrative Representative will furnish to the guard post at Building 6527, a list of names and sample signatures of AEC and AI Supervisors authorized to sign Form 8-X, "Removal Pass."

4. The AI Administrative Representative is responsible for establishing internal procedures which will assure the proper handling and accountability of all classified, as well as unclassified property and material in the security area; i.e., any SECRET material leaving the area for a transfer of custody to a person other than an assigned $A E C$ or AI employee, must be accomplished by use of a Classified Material Receipt (CMR), Form AEC-126. 
IV. DOCUMENT ACCOUNTABILITY AND CONTROL

A. Classified Mail Addresses and Delivery

1. Classified documents for AI personnel will be addressed as follows:

Atomics International

Division of North American Aviation, Inc.

P.O. Box 1687

Vandenberg Air Force Base

California

Attention: (Insert name of " $Q$ " cleared addressee)

2. Classified documents for AEC personnel will be addressed as follows:

Atomics International

Division of North American Aviation, Inc.

P.O. Box 1687

Vandenberg Air Force Base

California

Attention: M. W. Dickerson, USAEC, VAFB Site Representative

3. The AI Administrative Representative shall arrange for the pick-up and delivery of mail between the Post Office and Building 6527 by a "Q" cleared AI employee; and make necessary arrangements for him to sign registry receipts when required.

B. Document Accountability Records

1. Incoming Classified Documents

a. The original shipment of CONFIDENTIAL documents from AI or CPAO to Building 6527 which are already charged to the AI or CPAO assigned personnel of Building 6527 by Document Accountability Stations at AI or CPAO will not be logged by the AI Document Control Clerk at Building 6527.

b. All SECRET documents or documented CONFIDENTIAL documents from any source shall be delivered to the AI Document Control Clerk who shall maintain an incoming and an outgoing document $\log$.

c. The document log shall have line entries showing the consecutive number assigned to each individual incoming SECRET document, short title, or document number, date of document, classification, sender, and date received.

d. The Document Accountability Clerk will mark the line entry number of the log book on the cover or top page if it has no 
cover, of each SECRET or documented CONFIDENTIAL document as it is logged. The line number will be placed in the upper left corner in ink. The clerk will also execute and return any receipts to the sender.

2. Outgoing Classified Documents

a. No SECRET or documented CONFIDENTIAL document may be taken from or transmitted from the Building 6527 area to outside persons or facilities without passing through the Document Accountability Clerk for recordation purposes.

(1) The outside recipient must have an approved classified mail address on record before the Document Accountability Clerk will permit the document to be transmitted. AI Industrial Security will furnish classified mail addresses to the AI Administrative Representative for use by the Document Accountability Clerk. All requests for classified mail addresses shall be promptly forwarded to AI Industrial Security by the AI Administrative Representative, setting forth the precise name and address of the person, company, or agency; the document, hardware, as well as the classification and type (R/D and $D / I$ ) and the justification or purpose of the requirement.

AI Industrial Security will initiate appropriate action to obtain the classified addresses; i.e. AECM 2105 certification in the case of $R / D$, or an assurance in the case of $D / I$.

(2) The accountability clerk will prepare necessary Classified Material Receipts (Form AEC-126) and will enter necessary data in her outgoing log book.

(3) Classified documents will normally be dispatched via registered U.S. Mail, double wrapped, with the classification appearing only on the inner wrapper, and a Classified Material Receipt enclosed for all SECRET or documented CONFIDENTIAL matter. However, when the situation justifies handcarrying by a cleared person, the AI Administrative Representative, or the AEC Base Representative shall sign the authorization blocks of AI Form 703-F, and assure that the procedure appearing on the form is followed.

b. The Document Accountability Clerk will make log entries of each outgoing SECRET document (including documented CONFIDENTIAL documents) showing short title or description, document number, date, classification, addressee, date of transmittal.

c. The Document Accountability Clerk will also maintain a Tickler and follow-up on all CMR's for SECRET documents and documented CONFIDENTIAL documents. Follow-up inquiries shall be sent to addressee if the executed CMR is not received within 10 days of dispatch of the SECRET or documented CONFIDENTIAL 
document. If the addressee has not received the document, all information will be promptly furnished to AI Industrial Security for appropriate action.

\section{Internal Document Control}

a. The Document Accountability Clerk will maintain separate log sheets for all SECRET or documented CONFIDENTIAL documents received by her for delivery to the AEC Site Representative; as well as separate outgoing log sheets for classified data generated by him for external distribution.

b. The Document Accountability Clerk will prepare an 8-1/2" x $11^{\prime \prime}$ charge-out card for each classified document stored at Building 6527. This card shall be used to maintain records of internal accountability for documents in use within the Building. The charge-out card will have the following entries made thereon at the time of withdrawal of a document from the clerk's custody:

(1) Item number; which is the line number taken off the 1 og, and which has also been posted on the upper left hand corner of the cover, or first page of the report if it has no cover.

(2) Document number, which is the identifying number assigned by the originating agency.

(3) Title or brief description of document.

(4) Date of document.

(5) Series designation, which is the copy number and series affixed to all AEC SECRET documents, or documented CONFIDENTIAL AEC documents.

(6) Classification; which may be abbreviated by use of $\mathrm{S}$ for SECRET, C for CONFIDENTIAL; and by RD for Restricted Data and DI for Defense Information. At the time a document is withdrawn from file, the Document Accountability Clerk will have the borrower date and sign the charge out card, which she will then file in numerical sequence according to the item number.

c. Classified documents generated at Building 6527 must be properly stamped and handled by the originator and the Document Accoun-1 ability Clerk as follows:

(1) Drafts and Worksheets

(a) All drafts of technical data or information, as well as of administrative matter, which mention schedules or dates of any project at VAFB, must be reviewed by an AI Authorized Classifier for assignment of proper classification or non-classification as well as Group number. The originator will assure that such documents are stamped accordingly. 
(b) If the draft or worksheet is SECRET, it must be documented with the series entry being shown as "Draft 1," "Draft 2," etc. as the case may be.

(c) Any SECRET draft or worksheet which is to be dispatched to anyone outside the Building 6527 security area must be entered into accountability with the Document Accountability Clerk. Also, any classified draft or worksheet which is kept after the final document has been prepared must be entered into the document accountability system.

(d) Classified drafts or worksheets which become unaccounted for within Building 6527, shall be reported in the same manner as any other classified document.

(e) Drafts or worksheets shall be destroyed after they have served their purpose. This is accomplished by the Document Accountability Clerk if the document has been entered into her records; or by the originator if the document has not been entered into the record system. The method of destruction shall be by burning in a VAFB incinerator by a " $Q$ " cleared AI employee who will execute a Certificate of Destruction for retention by the Document Accountability Clerk.

\section{(2) Laboratory Notebooks}

(a) The front and back covers as well as the first and last pages of laboratory notebooks must be stamped with the highest classification of information entered therein, together with the appropriate Restricted Data or Defense Information stamp, plus the Group marking.

(b) Laboratory notebooks will not be destroyed; but will be returned to the AI Classified Library at Canoga Park when no longer needed at Building 6527.

\section{(3) Finalized Documents}

(a) Classified final documents shall be routed through the Document Accountability Clerk for recording purposes.

(b) Formal correspondence originated at Building 6527 will bear an identifying letter number in the upper right corner; such number being assigned by the AI Group Secretary. The outgoing letter numbers will be assigned as follows:

The last two digits of the current year are followed by the capital letters, AIV and a dash. After the dash, consecutive Arabic numerals will be assigned, starting with number one. Thus, the first outgoing letter in 1964 would bear the number: $64 \mathrm{AIV}-1$, whereas the first outgoing letter in 1965 would be numbered 65AIV-1, etc. 
(c) Incoming correspondence will be numbered by the Document Accountability Clerk in the lower left corner, starting with number one followed by AIV, then a dash and the last two digits of the year for the first letter received in the current year; and each successive incoming letter being numbered consecutively. The first letter received in 1964 would be marked "lAIV-64, etc.

(d) Destruction of classified formal documents shall be accomplished in the same manner as in paragraph IV.B. 3. c. (1). (e) above.

d. Losses of Classified Documents, or Material, or Special Nuclear Material (classified or unclassified)

(1) Off-site losses are those which occur outside the Building 6527 fenced area. These losses must be reported immediately to the FBI, to the CPAO Security Office, to the VAFB Security Police, and to AI Industrial Security at Canoga Park.

(2) On-site losses are those occurring within the Building 6527 fenced area. If the loss does not fall within the categories outlined in section VI.B. l.a.b.c. below, the AI supervision will immediately report details to AI Industrial Security; and institute a search of all logical places the material should or may have been placed. If unlocated within 48 hours, AI Supervision will have the last custodian execute Form $\mathrm{CH}-285$ in duplicate, and transmit both copies to AI Industrial Security.

\section{Classification - Authorized Classifiers}

1. The AI Classification Coordinator will designate the AI Operation Supervisor, and such other supervision of the Base Complement as may be necessary, as Authorized Classifiers.

2. Authorized Classifiers will review and certify the classification or non-classification of every technical document generated by AI at Building 6527.

3. The AI Document Accountability Clerk or originator will affix the proper classification, documentation, and extra marking upon all copies of classified data generated in Building 6527 at the time it is generated.

4. All classified documents must be stored in metal file cabinets secured with lock bars and three-position dial type changeable combination padlocks. These cabinets must have executed Form $730-\mathrm{N}-63$ attached. 
V. SHIPMENTS

A. Shipments of material (hardware, such as units, components, assemblies, subassemblies, etc.) to Building 6527 will be preceded by written notice to the AI Administrative Representative (and in some cases, the AEC Site Representative) giving item name, classification, method of shipment, time of departure, and estimated time of arrival.

B. The AI Administrative Representative (and/or the AEC Site Representative in some cases) will immediately follow the notification procedure in Section VI, in event there is evidence of sabotage, loss, or compromise. A delay in arrival of a shipment, which appears unreasonable and is unexplained, will be handled in the same manner, except that the FBI need not be notified until such time as loss of compromise is reasonably established.

C. Shipment of the SNAP reactors and components to Building 6527, is covered in a separate document to be called the AI Shipping Manual. It will govern shipments from AI to VAFB and to the launch pad.

D. Shipments between buildings or facilities at VAFB and/or Point Arguello will be preceded by telephonic notification by the AI Administrative Representative to the receiving building or facility. When bulky shipments are made from Building 6527 to other areas at VAFB and Point Arguello, the AI Administrative Representiative shall request the 6595th ATW scheduling office to obtain an escort from the 4392 Aerospace Support Wing.

VI. SECURITY INFRACTIONS AND VIOLATIONS

A. Infractions

1. Whenever the guard, or operational supervision at Building 6527 observes an infraction of security rules or practices, they shall cite the person responsible for the infraction. If there is no evidence of deliberate, willful, or grossly negligent disregard for security rules, and there is no evidence of actual or suspected compromise of classified information by unauthorized persons, the AI Administrative Representative will take the following action:

a. Interview the person responsible for the infraction regarding the cause.

b. Discuss remedial action.

c. Remind the person of the seriousness of his action; and of his personal responsibility.

d. Summarize the cause and corrective action and notify Industrial Security at AI Headquarters.

2. An unlocked classified file cabinet, or a classified document found unsecured after normal work hours will result in the custodian being telephoned at his home and directed to return to Building 6527 
to review the contents of the file to assure nothing is missing, or to secure the unattended document.

3. Atomics International Industrial Security will evaluate all infraction notices to determine whether the sanctions of NAA, Inc. Plant Rule No. 56 should be invoked.

B. Violations

1. Violations include but are not limited to:

a. Alleged or suspected criminal violation of a Federal Statute, such as: Atomic Energy Act of 1954; Internal Security Act of 1950; Title 18, U.S. Code, Sections relating to espionage, sabotage, treason, subversion, malicious mischief, etc.

b. Classified documents missing under circumstances indicating a violation of law.

c. Loss of Source or Special Nuclear Material.

2. Violations shall be reported to AEC Base Representative and 6595th ATW. The AEC Base Representative or his designated alternate will notify the Chief, Industrial Security, 4392nd Aerospace Support Group. The Federal Bureau of Investigation has the responsibility for investigating alleged or suspected criminal violations of the Federal Law. No investigations of such violations shall be conducted by representatives of the AEC or AEC Contractor. However, preliminary inquiry necessary to establish the probability of a violation is not an investigation and is not prohibited.

3. AI Supervision receiving information indicating actual or suspected violations of law, will immediately conduct a preliminary inquiry as may be necessary to establish the probability of a violation. If the probability exists, the AEC Base Representative will be notified immediately of all details. AI Supervision will then notify AI Industrial Security in writing (classified if necessary) of pertinent details.

All verbal notifications will be confirmed in writing.

VII. SECURITY EDUCATION

A. Operational Responsibility

1. The AI Administrative Representative shall provide a copy of this security plan to each person assigned to Building 6527, and assure their reading and understanding their responsibilities hereunder.

2. The AI Administrative Representative will disseminate Security Bulletins, Security instructions, changes in the security plan, and such other security advices as are received from the Industrial Security Office at Canoga Park. 
B. Continuing Security Education

1. Intermittently, AI Industrial Security Representatives will visit Building 6527, and will discuss with assigned personnel such security matters as appear applicable and pertinent at the time.

2. Visual aids such as security posters, calendar pads with security slogans, pencils with security slogans, etc. will be furnished to employees. Posters will be changed by the AI Administrative Representatives.

C. Termination Security Lecture

The AI Administrative Representative will have all terminating AI employees at Building 6527 read the instructions entitled, "Information For Persons Terminating AEC Security Clearances" as well as the printed matter on Form AEC-136 before executing the Security Termination Statement. He will also have each terminating employee read and sign Part II of DD Form 1464 when it and allied documents have been furnished by AI Industrial Security. Executed copies of Form AEC-136 and DD Form 1464 will be mailed to AI Industrial Security, Canoga Park.

\section{EMERGENCY ACCESS}

A. Personnel responding to emergencies may be admitted to Building 6527 under procedures established by VAFB. Names, employers and clearance status, if any, will be provided the AEC after-the-fact.

B. Other emergency procedures are covered in the Building and Summary Safeguards Report Document No. NAA-SR-MEMO-8685.

IX. LAUNCH OPERATIONS

When the SNAP Unit is transferred from Building 6527 to the launch pad, it will be under the continuous protective custody of a "Q" cleared AI employee at all times. All AF or AF contractor personnel requiring physical access to the SNAP Unit must possess an Active DoD SECRET Access Authorization and have such clearance and need-to-know for access to Restricted Data properly certified to the AEC. Guard control will be provided and access to the 119 level or above will be limited to those whose name appears on an access list to be jointly prepared and approved by 6595th ATW and AEC Base Representative. 
NAA-SR -MEMO- 9353

\section{APPENDIX B \\ SPTF READINESS CHECKLISTS}

These checklists are to be used by personnel installing or verifying installation of equipment at the SPTF. Each item on the list is checked off as installation and/or operability is verified. Pertinent remarks are entered in the remarks column. 
APPENDIX B

SPTF READINESS CHECK LIST

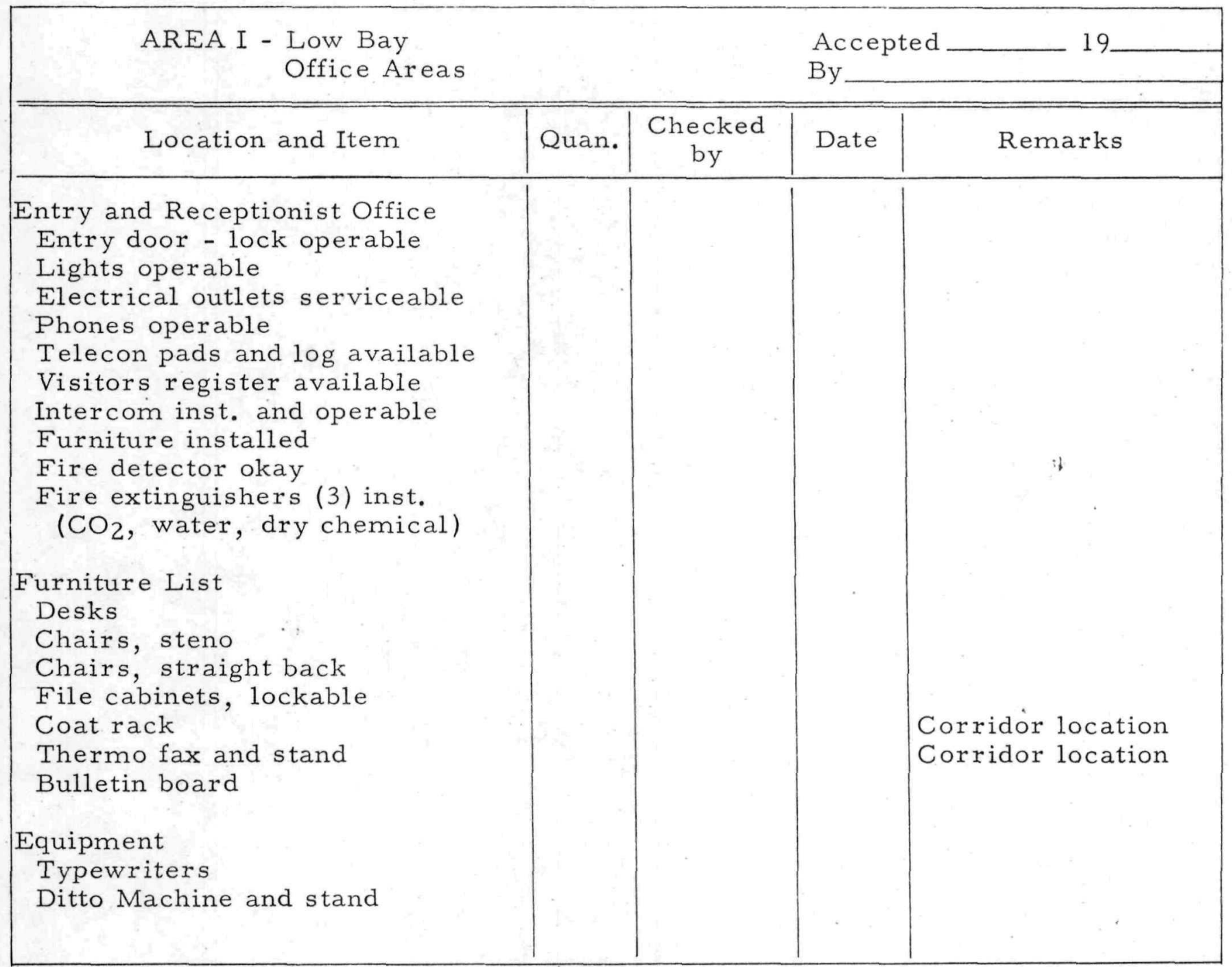

Additional remarks: 
Accepted 19

By

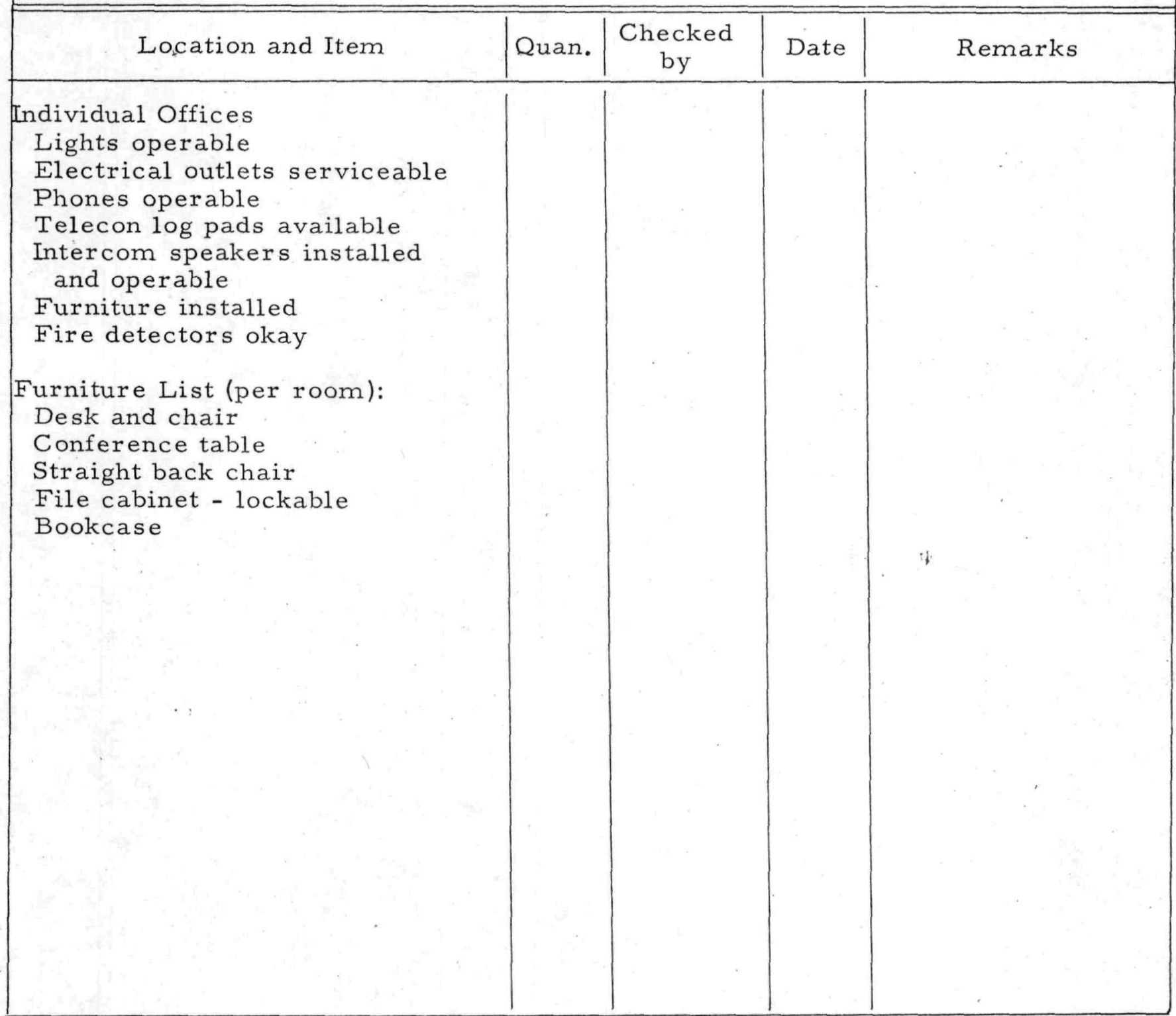

Additional remarks: 
By

Lights operable

Electrical outlets serviceable

Phones operable

Telecon log pads available

Intercom speakers installed and operated

Furniture installed

Fire detectors okay

Fire extinguishers installed

Water type - insp. current

Portable $\mathrm{CO}_{2}$ - insp. current

Furniture list:

Desks and chairs

Table

Straight back chairs

File cabinet

Bookcase

Chalkboard

Coat rack

\section{Equipment}

Adding machine

Calculator

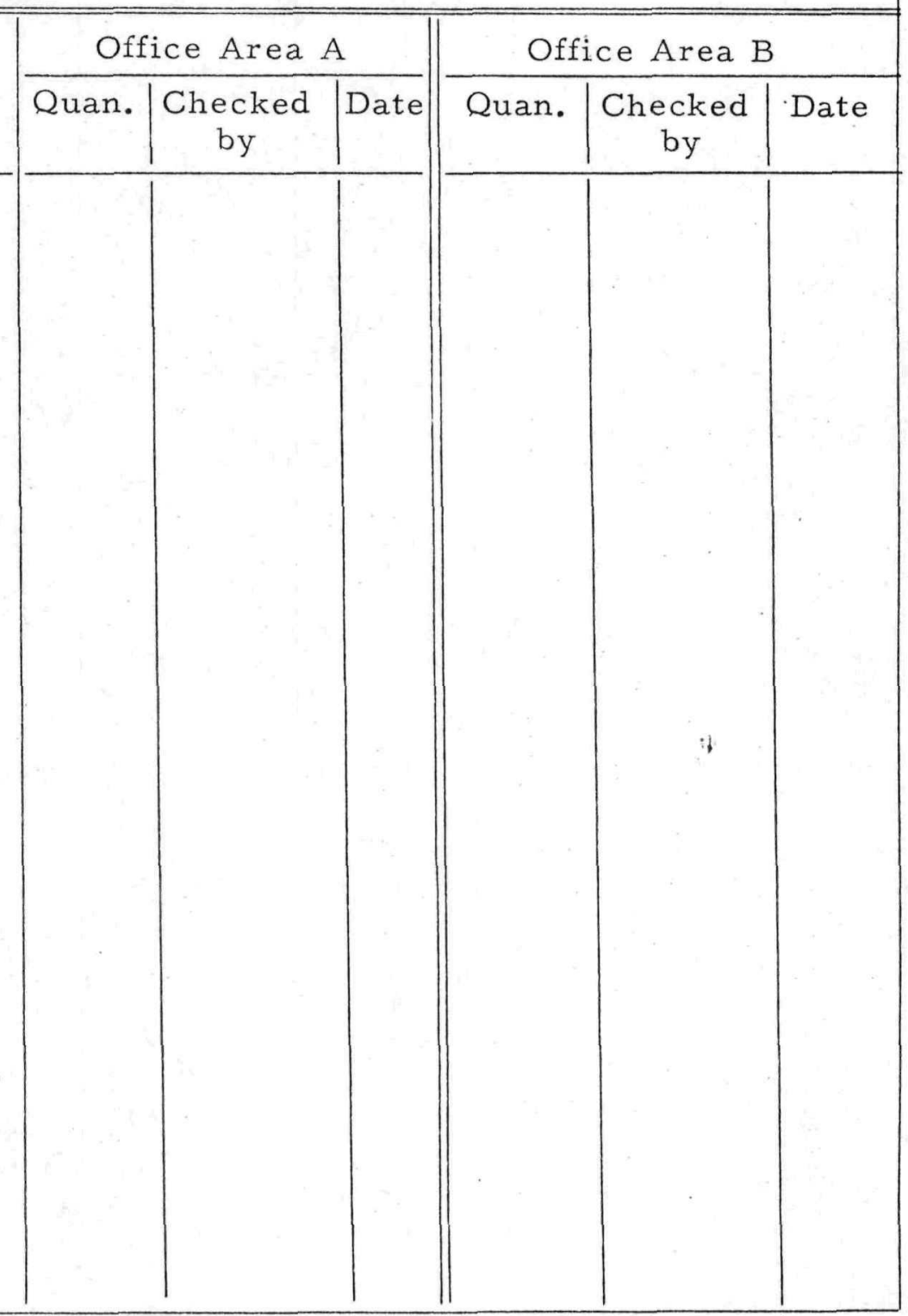

Remarks: 
AREA I - Low Bay, Service Facilities

Accepted 19

By

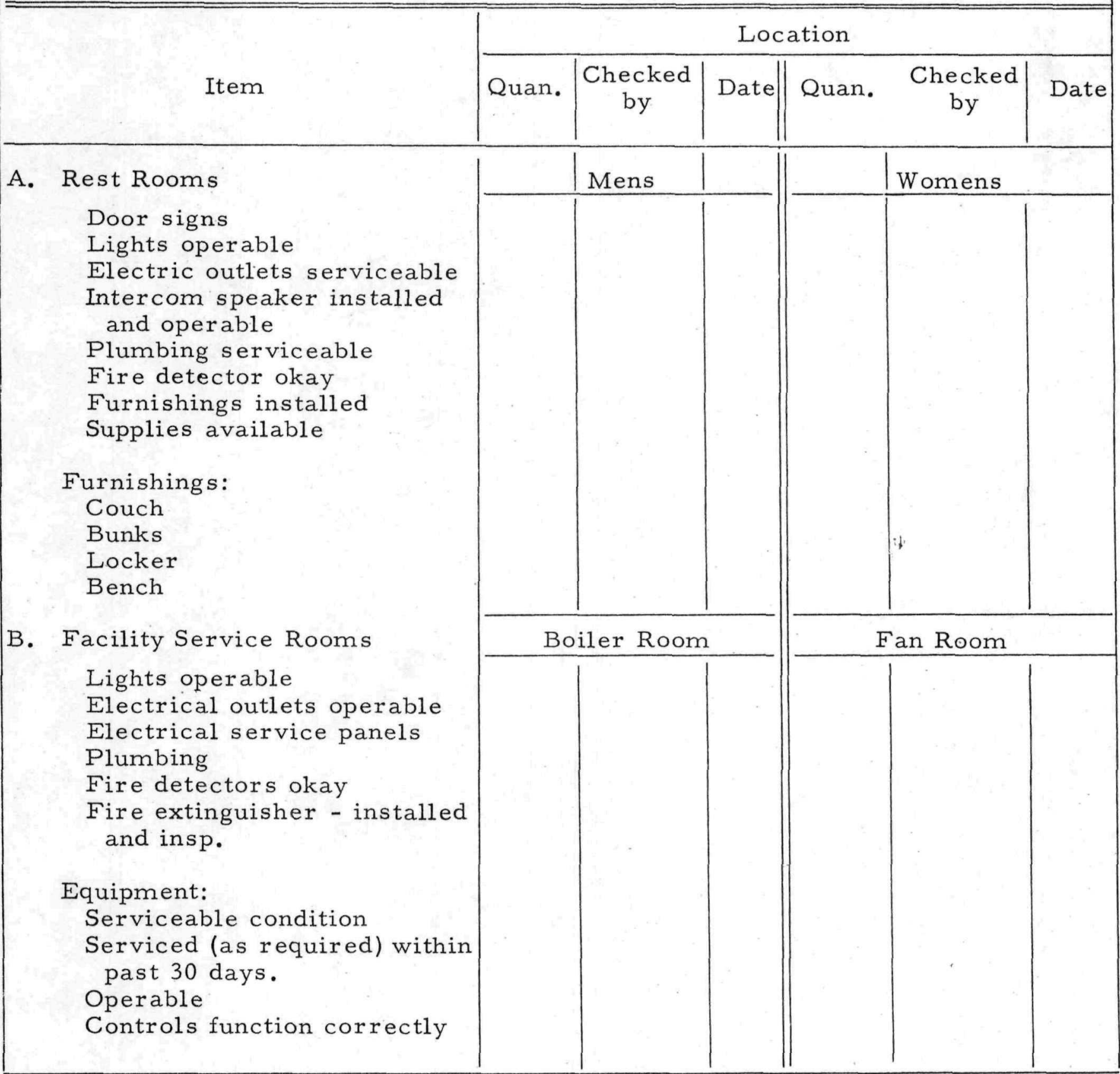

Remarks : 
By

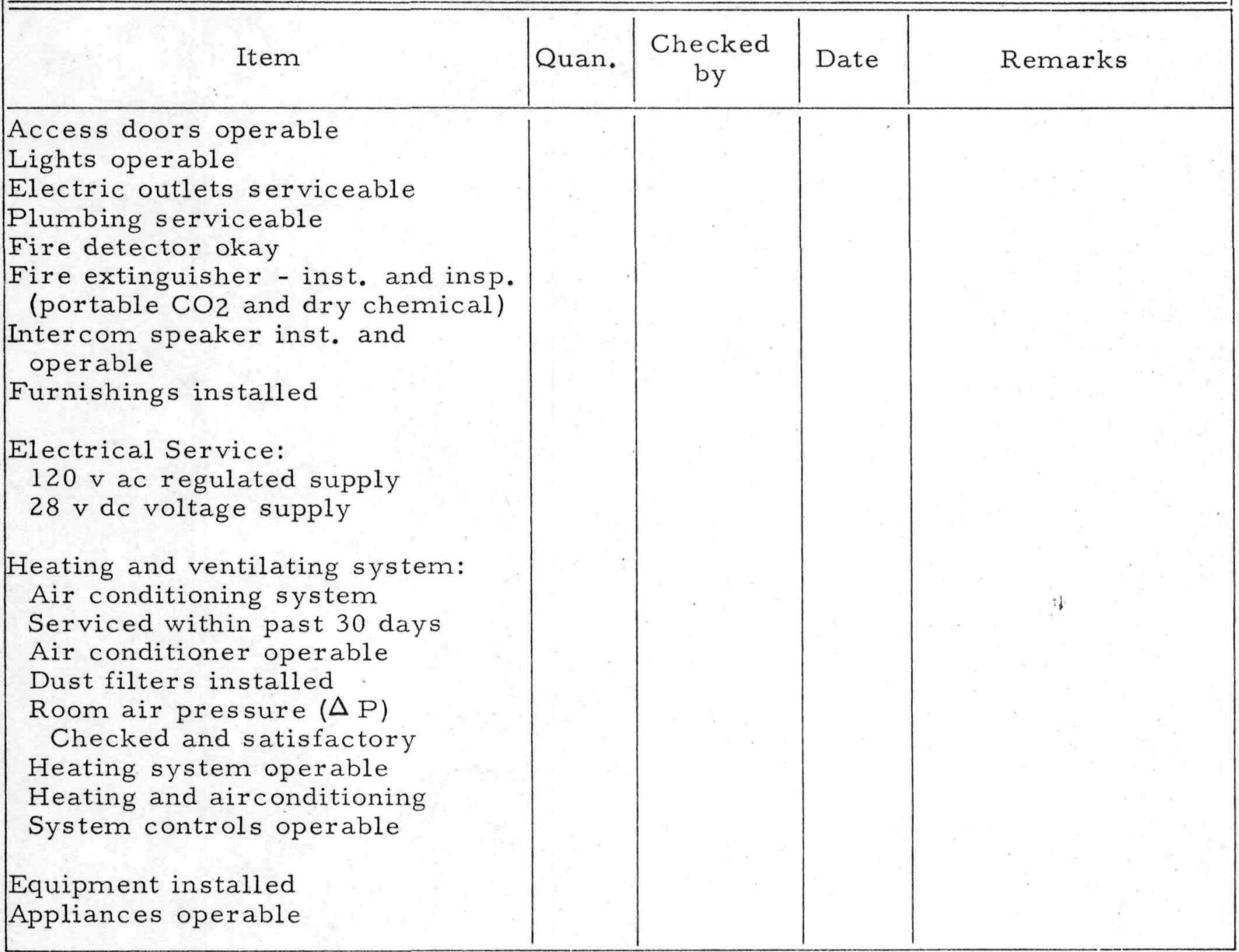

*See pertinent equipment list 
AREA I - Low Bay, Machine Shop

Accepted 19

$\mathrm{By}$

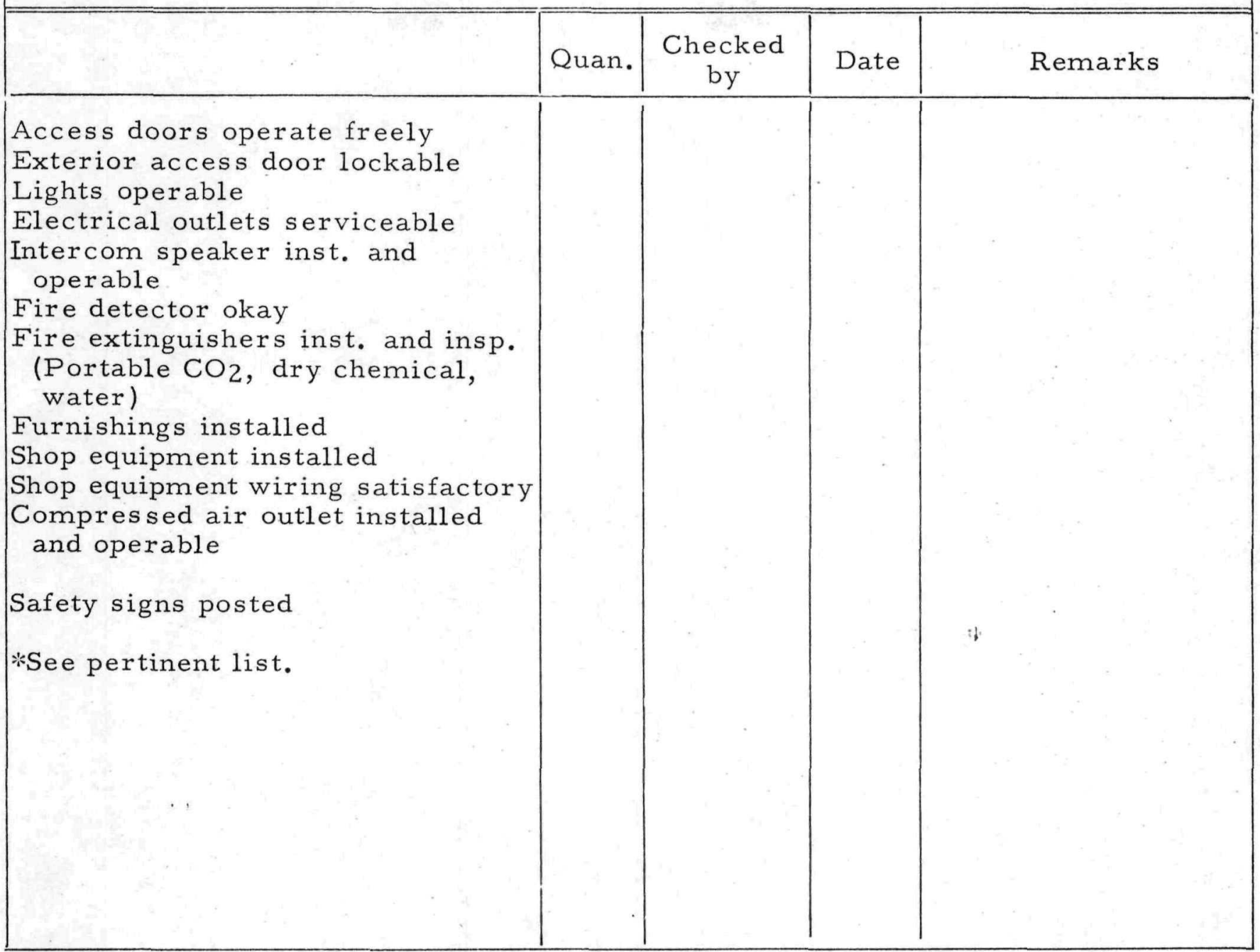

Additional remarks: 
A. Building and Equipment

Floor surface sealed

Trench covers in place

Roll-up door operable

Access doors operable

Exterior access doors lockable

Safety signs posted

Stockroom partitioning inst.

Furnishings installed

Phone installed and operable

Intercom speakers inst. and operable

B. Protective Equipment

Fire Detectors okay

Fire extinguishers inst. and insp.

Radiation alarm inst. and oper.

Breathing apparatus inst. and insp.

Warning horn operable

Emergency showers operable

Barricade posts and equipment available

C. Heating and Ventilating

Heating system controls operable

Air inlet shutters operable

Air pressure $(\Delta P)$

D. Handling Equipment

Crane - proof tested

Crane control operation satisfactory

Limit switch operation satisfactory

*See layout drawing.

Corridor location

Exterior location

psi 


\section{APPENDIX C \\ FACILITY ACCEPTANCE CHECKLIST}

Major items relating to facility acceptance are summarized in this list. Space is provided for AI, VAFB, and AEC signoff, to denote acceptance of the particular item or group of items as the facility is inspected. 


\section{APPENDIX C}

SPTF ACCEPTANCE CHECK LIST

\begin{tabular}{|cccc|}
\hline Item & $\begin{array}{c}\text { Checked } \\
\text { by }\end{array}$ & $\begin{array}{c}\text { Approved } \\
\text { by }\end{array}$ & Date \\
\hline
\end{tabular}

\section{A. BUILDING}

Doors, exterior and interior

Windows

Floors

Ceiling and roof

Partitioning and interior walls

Exterior condition

Crane - high bay area

B. SERVICE SYSTEMS

Electrical system

Heating system

Ventilating system

Air conditioning - Inst. room

Water and plumbing system

C. PROTECTIVE SYSTEMS

Fire detector and warning system

Radiation alarm system

Manual fire alarm.system

D. SAFETY EQUIPMENT

First aid kit

Fire extinguishers (all)

Breathing apparatus

Emergency showers

Exits marked

Caution and warning signs posted

E. SECURITY

Fence and entrance gates

Guard shack

Locks, building doors

Necessary signs posted

Emergency assembly area posted

Emergency first aid kit available

F. INSPECTION APPROVALS

Industrial Engineering

Health and Safety

SPTF Engineering Manager

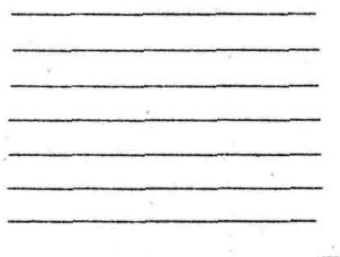

VAFB Fire Department

VAFB Flight Test Safety 


\section{APPENDIX D \\ SPTF EQUIPMENT SPECIFICATIONS}

Listed in tabular form are the major equipment items, manufacturer, model or type identification, voltage requirements, and location in the SPTF. The list provides a ready reference in the event vendor inquiry concerning parts or information is necessary. 
APPENDIX D

SPTE EQUIPMENT SPECIFICATIONS

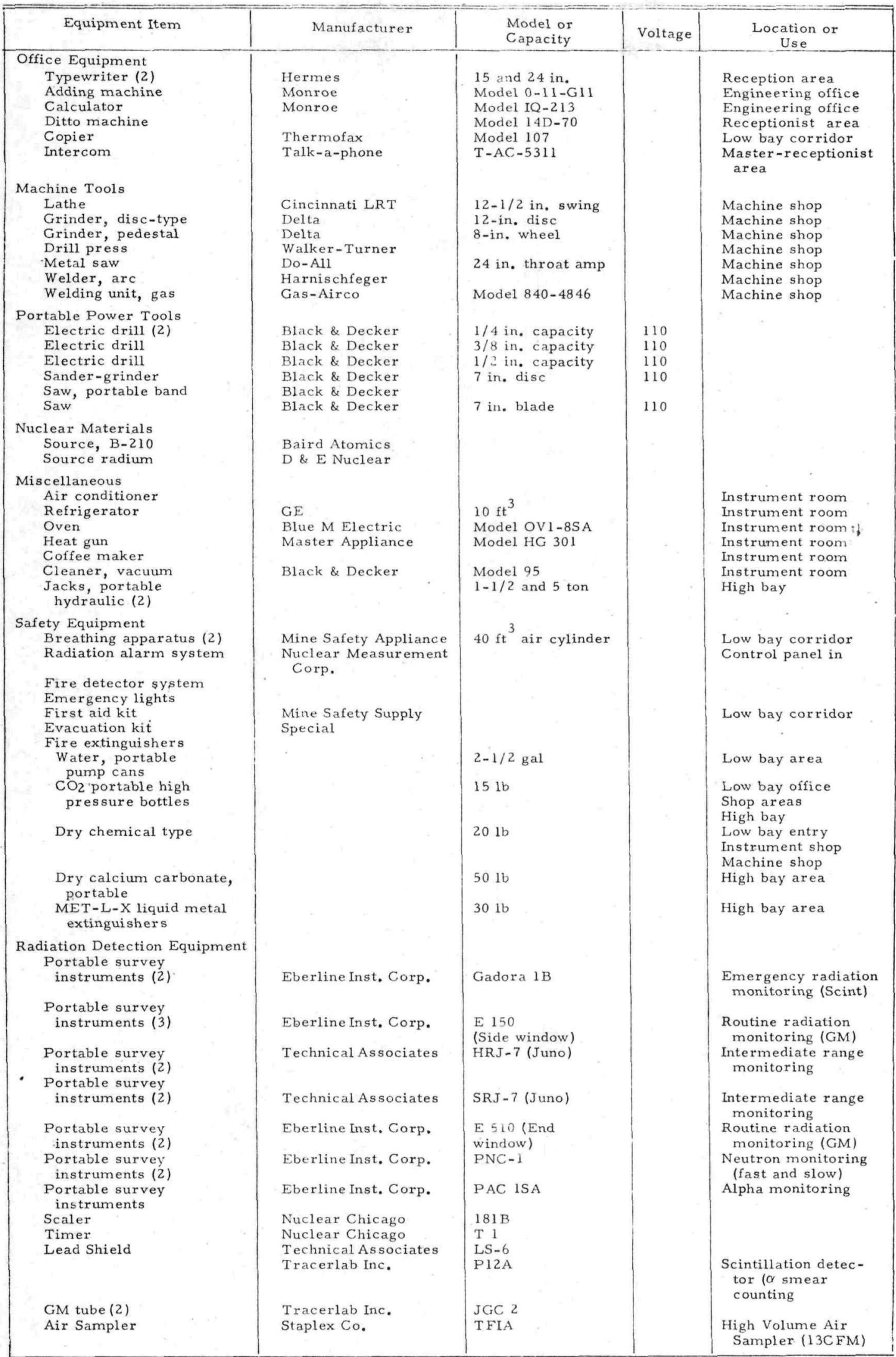

Staplex Co. Sampler (13CFM) 


\section{APPENDIX E \\ SPTF MAINTENANCE CHECKLIST}

This checklist is designed for use by SPTF personnel who perform routing or periodic maintenance operations. Use of the checklist provides a detailed reminder, as well as a record, of the maintenance operations performed. 
APPENDIX E

SPTF MAINTENANCE CHECKLIST

\begin{tabular}{|c|c|c|c|}
\hline Checklist Item & $\begin{array}{c}\text { Operator } \\
\text { Initial }\end{array}$ & Date & Remarks \\
\hline $\begin{array}{l}\text { Office Area } \\
\text { Lighting okay } \\
\text { Housekeeping okay } \\
\text { Safety hazards } \\
\text { Fire extinguishers }\end{array}$ & & & \\
\hline $\begin{array}{l}\text { Rest Rooms } \\
\text { Lighting okay } \\
\text { Ventilators } \\
\text { Plumbing and fixtures } \\
\text { Supplies } \\
\text { Hot water heater } \\
\text { Housekeeping } \\
\text { Fire extinguishers }\end{array}$ & & & 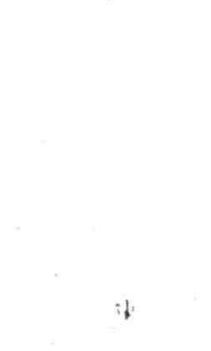 \\
\hline $\begin{array}{l}\text { Instrument Room } \\
\text { Lighting okay } \\
\text { Airconditioner } \\
\text { Appliances } \\
\text { Fire extinguishers } \\
\text { Safety hazards }\end{array}$ & & & \\
\hline $\begin{array}{l}\text { Machine Shop } \\
\text { Lighting okay } \\
\text { Tools and equipment } \\
\text { Fire extinguishers } \\
\text { Housekeeping } \\
\text { Safety hazards }\end{array}$ & & & \\
\hline $\begin{array}{l}\text { Boiler Room } \\
\text { Furnace } \\
\text { Pumps } \\
\text { Safety hazards }\end{array}$ & & & \\
\hline $\begin{array}{l}\text { Fan Room } \\
\text { Fans - condition and } \\
\text { lubrication } \\
\text { Filters } \\
\text { Fire extinguishers } \\
\text { Safety hazards } \\
\text { High Bay } \\
\text { Lighting okay } \\
\text { Floor condition } \\
\text { Housekeeping } \\
\text { Doors and locks } \\
\text { Ventilation }\end{array}$ & & & \\
\hline
\end{tabular}


APPENDIX E (Continued)

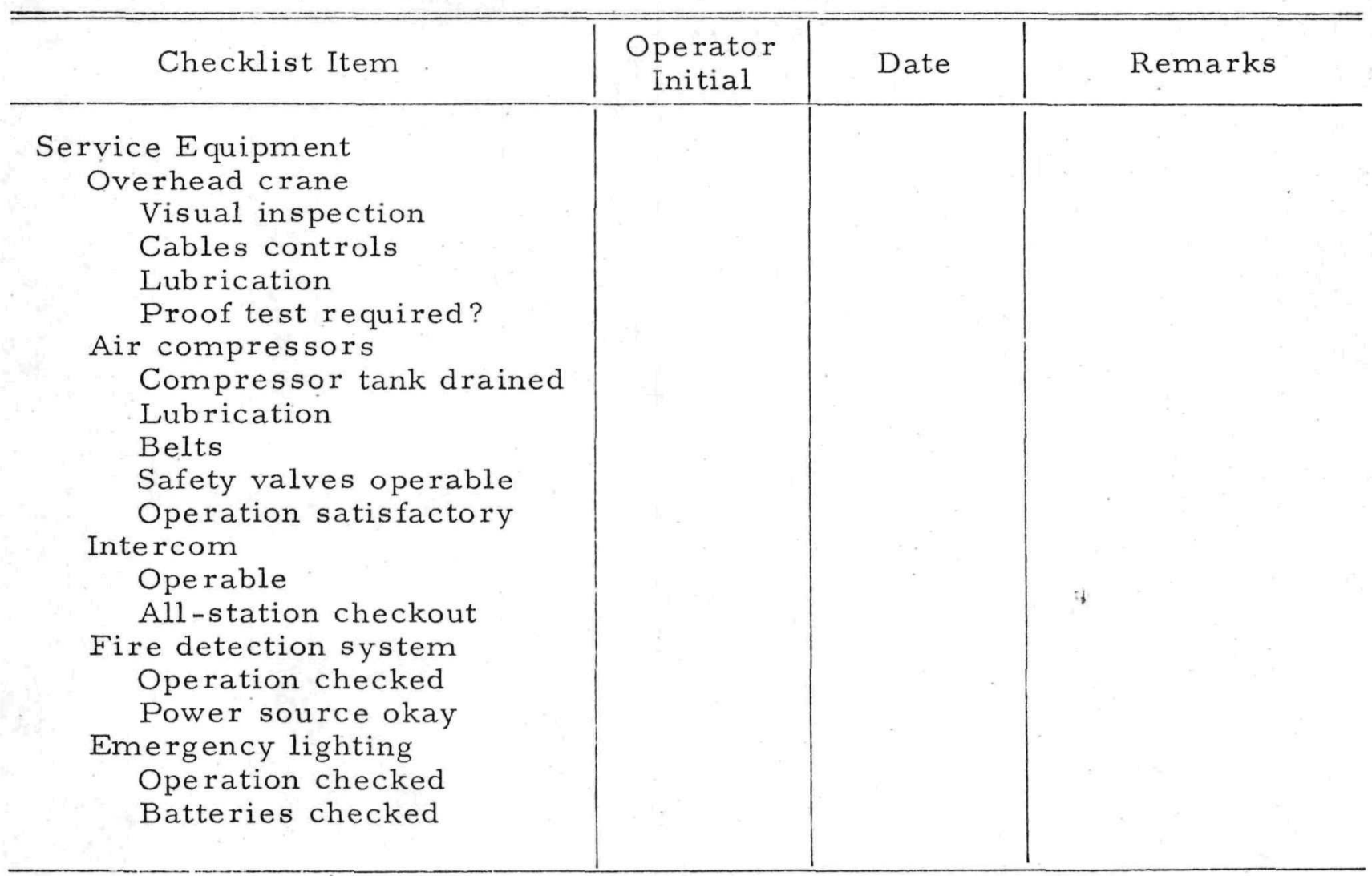


1. SNAP Prelaunch Test Facility Safeguards Report, NAA-SR-MEMO-8685, Atomics International (December 1963)

2. SNAPTRAN 2/10A-1 Reactor, NAA-SR-MEMO-7724, Atomics International (November 1963)

3. SNAP 10A Power System Shipment Safeguards Report, NAA-SR-MEMO-8147, Atomics International (December 1963)

4. Launch Operations Activities, NAA-SR-MEMO-10402, Atomics International (September 1964)

5. Shipping Procedures Manual, NAA-SR-MEMO-9357

6. NPU Prelaunch Operations - SPTF Manual, NAA-SR-MEMO-9352

7. NPU Prelaunch Operations - PACC-2 Manual, NAA-SR-MEMO-9561

8. AGE Operations and Maintenance Manual, NAA-SR-MEMO-9356. 